Supporting Information for:

\title{
Molecular Basis for Water-Promoted
}

\section{Supramolecular Chirality Inversion in Helical}

\section{Rosette Nanotubes}

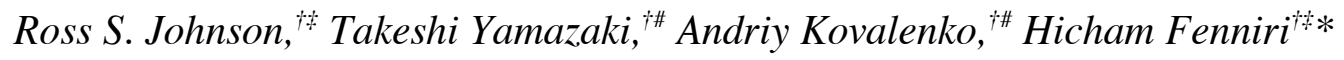

${ }^{\dagger}$ National Institute for Nanotechnology, ${ }^{~ D e p a r t m e n t ~ o f ~ C h e m i s t r y, ~ a n d ~}{ }^{\#}$ Department of Mechanical Engineering. University of Alberta, 11421 Saskatchewan Drive, Edmonton, Alberta, T6G 2M9, CANADA.

hicham.fenniri@ualberta.ca

RECEIVED DATE

TITLE RUNNING HEAD: "Chirality Inversion by Water Molecules".

CORRESPONDING AUTHOR FOOTNOTE: Professor Hicham Fenniri, National Institute for Nanotechnology, University of Alberta, 11421 Saskatchewan Drive, Edmonton, Alberta, T6G 2M9, CANADA. Tel: 780/641-1750, Fax: 780/641-1601, e-mail: hicham.fenniri@ualberta.ca 


\section{A. Synthesis of 1-3}

Abbreviations. AcOH (acetic acid); Bn (benzyl) Boc (tert-butyloxycarbonyl); br (broad); $n-$ $\mathrm{BuOH}$ (1-butanol); CBz (benzyloxycarbonyl); concd (concentrated); d (doublet); 1,2-DCE (1,2dichloroethane); DCM (dichloromethane); $\mathrm{dH}_{2} \mathrm{O}$ (deionized NanoPure water); DIEA (diisopropylethylamine); DMAP (4-N,N-dimethylaminopyridine); EA (ethylacetate); DMF (N,N-dimethylformamide); EI-MS (electron impact mass spectrometry); ESI-MS (electrospray ionization mass spectrometry); $\mathrm{EtOH}$ (ethanol); $\mathrm{Et}_{3} \mathrm{~N}$ (triethylamine); h (hour); m (multiplet); m.p. (melting point); $\mathrm{MeOH}$ (methanol), min (minute); NMMO (N-methylmorpholine $\mathrm{N}-$ oxide); NMR (nuclear magnetic resonance); $\mathrm{p}$ (pentuplet); $\mathrm{q}$ (quartet); $\mathrm{R}_{\mathrm{f}}$ (retention factor); $\mathrm{rt}$ (room temperature); s (singlet); sat (saturated); $t$-Bu (tert-butyl); TFA (trifluoroacetic acid); TFAA (trifluoroacetic anhydride); THF (tetrahydrofuran).

General. Melting points were recorded on a Büchi capillary melting point apparatus (model B545). ${ }^{1} \mathrm{H}$ and ${ }^{13} \mathrm{C}-\mathrm{NMR}$ spectra were recorded on Varian Inova NMR spectrometers (400, 500, or $800 \mathrm{MHz}$ ) with the solvent as internal reference. The NMR data is presented as follows: chemical shift, peak assignment, multiplicity, coupling constant, integration. The mass spectra were performed at the Mass Spectrometry Laboratory at the Department of Chemistry, University of Alberta, or in the Analytical Laboratory of The National Institute for Nanotechnology, University of Alberta. Compounds $\mathbf{1}, \mathbf{2}$, and $\mathbf{5}^{\text {1a-c }}$ were prepared according to previously reported procedures. Compound $\mathbf{3}$ was prepared in 13 steps according to Scheme 1. All the reagents and solvents are commercially available from Aldrich, Novabiochem, BaChem, Fluka, Fisher Scientific or Advanced ChemTech, and were used without further purification. Reagent grade $\mathrm{CH}_{2} \mathrm{Cl}_{2}$, THF, and $\mathrm{CH}_{3} \mathrm{OH}$ were purified on an MBraun solvent purification system. All the reactions were performed under $\mathrm{N}_{2}$ atmosphere. For column chromatography, 
commercial solvents were used without purification. Chromatographic supports were silica flash Merck $60(0.040-0.063 \mathrm{~mm})$ or silica gel Merck $60(0.063-0.2 \mathrm{~mm})$ for gravity chromatography. Silica-coated TLC plates (Merck F 60254) were used for monitoring reaction progress and visualizations were made under UV light or by chemical staining $\left(\mathrm{KMnO}_{4} / \mathrm{dH}_{2} \mathrm{O}\right.$, phosphomolybdic acid/EtOH, or ninhydrin/n-BuOH/AcOH).

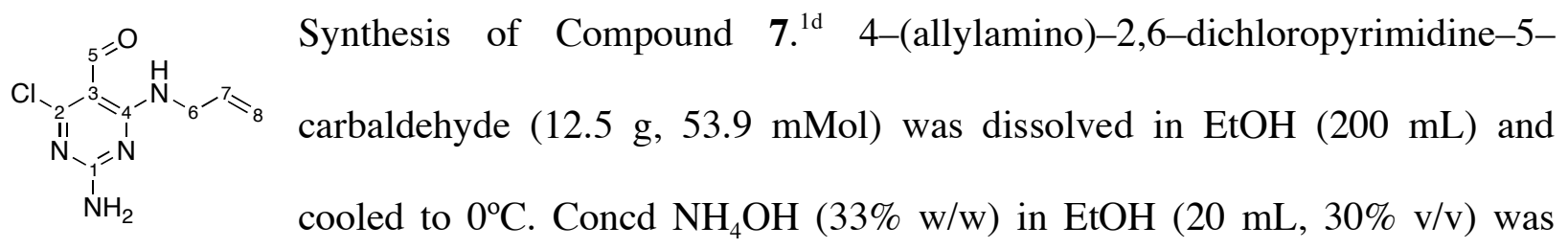
diluted with $\mathrm{EtOH}(70 \mathrm{~mL})$ and then added to the reaction mixture. The reaction was stirred overnight then evaporated to dryness (rotavap). The residue was dissolved in EA (300 mL), washed with $\mathrm{dH}_{2} \mathrm{O}(100 \mathrm{~mL})$ and brine $(100 \mathrm{~mL})$, dried over $\mathrm{Na}_{2} \mathrm{SO}_{4}$, filtered, then evaporated to dryness (rotavap). The desired compound $\left(7, \mathrm{C}_{8} \mathrm{H}_{9} \mathrm{ClN}_{4} \mathrm{O}, 65 \%\right)$ was obtained as a white solid after flash chromatography $\left(\mathrm{SiO}_{2}, 5-20 \%\right.$ EA/hexane $) . \mathrm{R}_{\mathrm{f}}=0.18(20 \%$ EA/hexane $) . \mathrm{m} . \mathrm{p} .=134-$ $136^{\circ} \mathrm{C}$.

${ }^{1} \mathrm{H}-\mathrm{NMR}\left(400 \mathrm{MHz}, \mathrm{CDCl}_{3}\right) \delta(\mathrm{ppm}): 10.09$ (C5H, s, 1H), 9.31 (C6NH, br s, 1H), 5.91 $(\mathrm{C} 7 \mathrm{H}$, dddd, $\mathrm{J}=17,17,11,5 \mathrm{~Hz}, 1 \mathrm{H}), 5.44\left({\mathrm{C} 1 \mathrm{NH}_{2}}_{2}\right.$ br s, $\left.2 \mathrm{H}\right), 5.25-5.15(\mathrm{C} 8 \mathrm{H}, \mathrm{m}, 2 \mathrm{H}), 4.12$ $(\mathrm{C} 6 \mathrm{H}, \mathrm{tt}, \mathrm{J}=5.6,1.6 \mathrm{~Hz})$.

${ }^{13} \mathrm{C}-\mathrm{NMR}\left(100 \mathrm{MHz}, \mathrm{CDCl}_{3}\right) \delta$ (ppm): 188.9 (C5), 166.7 (C1), 162.5 (C4), 162.2 (C2), 133.4 (C7), 116.5 (C8), 102.7 (C3), 42.8 (C6).

Positive ESI-MS: Expected mass for $\left(\mathrm{M}+\mathrm{H}^{+}\right) / \mathrm{z}, 212.6$. Observed, $213.6\left(\left(\mathrm{M}+\mathrm{H}^{+}\right) / \mathrm{z}\right.$, $100 \%)$. 


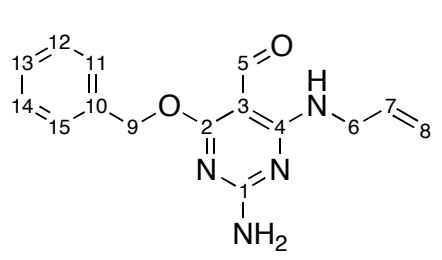

Synthesis of Compound 8. BnOH $(0.10 \mathrm{~mL} 0.93 \mathrm{mMol})$ was added to a solution of $\mathrm{NaH}(0.07 \mathrm{~g}, 3.09 \mathrm{mMol})$ in dry THF $(2 \mathrm{~mL})$ and stirred for $10 \mathrm{~min}$. Compound $7(0.22 \mathrm{~g}, 1.03 \mathrm{mMol})$ dissolved in dry THF ( $5 \mathrm{~mL}$ ) was then added. The reaction was refluxed under $\mathrm{N}_{2}$ and stirred for $4 \mathrm{~h}$. After cooling saturated $\mathrm{NH}_{4} \mathrm{Cl}(5 \mathrm{~mL})$ was added at $0^{\circ} \mathrm{C}$. The THF was removed under reduced pressure (rotavap) and the residue was dissolved in EA $(250 \mathrm{~mL})$, washed with $\mathrm{dH}_{2} \mathrm{O}(100 \mathrm{~mL})$ and brine $(100 \mathrm{~mL})$, dried over $\mathrm{Na}_{2} \mathrm{SO}_{4}$, filtered, and evaporated to dryness to yield an orange oil. The desired compound $\left(8, \mathrm{C}_{15} \mathrm{H}_{16} \mathrm{~N}_{4} \mathrm{O}_{2}, 76 \%\right)$ was obtained as a yellow oil after flash chromatography $\left(\mathrm{SiO}_{2}, 5-15 \% \mathrm{EA} /\right.$ hexane $) . \mathrm{R}_{\mathrm{f}}=0.16$ (20\% EA/hexane).

${ }^{1} \mathrm{H}-\mathrm{NMR}\left(500 \mathrm{MHz}, \mathrm{CDCl}_{3}\right) \delta(\mathrm{ppm}): 10.04(\mathrm{C} 5 \mathrm{H}, \mathrm{s}, 1 \mathrm{H}), 9.35(\mathrm{C} 6 \mathrm{NH}, \mathrm{t}, \mathrm{J}=5.5 \mathrm{~Hz}, 1 \mathrm{H})$, 7.39-7.30 (C11H-C15H, m, 5H), $5.91(\mathrm{C} 7 \mathrm{H}, \mathrm{dddd}, \mathrm{J}=17,17,11,5 \mathrm{~Hz}, 1 \mathrm{H}), 5.65\left(\mathrm{C}_{1 \mathrm{NH}_{2}}\right.$, br s, $2 \mathrm{H}), 5.38,(\mathrm{C} 9 \mathrm{H}, \mathrm{s}, 2 \mathrm{H}), 5.24-5.12(\mathrm{C} 8 \mathrm{H}, \mathrm{m}, 2 \mathrm{H}), 4.10(\mathrm{C} 6 \mathrm{H}, \mathrm{tt}, \mathrm{J}=5.5,2 \mathrm{~Hz}, 2 \mathrm{H})$.

${ }^{13} \mathrm{C}-\mathrm{NMR}\left(125 \mathrm{MHz}, \mathrm{CDCl}_{3}\right.$ ) $\delta$ (ppm): 186.1 (C5), 172.1 (C2), 163.7 (C4), 163.5 (C1), 136.2 (C10), 134.0 (C7), 128.3, 127.9, 127.6 (C11-C15), 115.7 (C8), 92.9 (C3), 67.6 (C9), 42.5 (C6).

Positive ESI-MS: Expected mass for $\left(\mathrm{M}+\mathrm{H}^{+}\right) / \mathrm{z}, 284.3$. Observed, $285.6\left(\left(\mathrm{M}+\mathrm{H}^{+}\right) / \mathrm{z}\right.$, $100 \%)$.

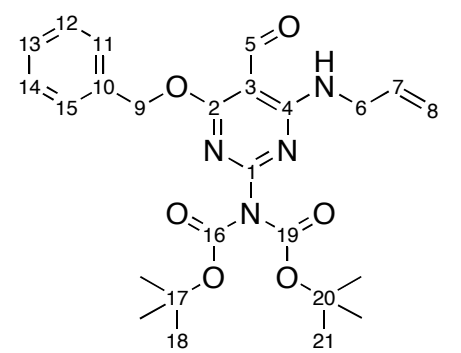

Synthesis of Compound 9. Compound $8(6.4 \mathrm{~g}, 22.52 \mathrm{mMol})$ was dissolved in dry THF $(75 \mathrm{~mL})$, then $\mathrm{Et}_{3} \mathrm{~N}(13.8 \mathrm{~mL}, 99.13 \mathrm{mMol})$, $\operatorname{DMAP}(0.27 \mathrm{~g}, 2.25 \mathrm{mMol})$ and $\mathrm{Boc}_{2} \mathrm{O}(10.81 \mathrm{~g}, 49.57 \mathrm{mMol})$ were added sequentially. The reaction was stirred under argon atmosphere for $24 \mathrm{~h}$. The solvent was then removed (rotavap), and the residue was dissolved in EA and washed with $10 \%$ citric acid $(100 \mathrm{~mL}), 5 \% \mathrm{NaHCO}_{3}(250 \mathrm{~mL})$, and brine $(100 \mathrm{~mL})$. The organic layer was then dried over $\mathrm{Na}_{2} \mathrm{SO}_{4}$, and evaporated to dryness (rotavap). The desired 
compound $\left(9, \mathrm{C}_{25} \mathrm{H}_{32} \mathrm{~N}_{4} \mathrm{O}_{6}, 72 \%\right)$ was obtained as a white solid after flash chromatography $\left(\mathrm{SiO}_{2}\right.$, $0-2 \%$ EA/hexane). $R_{\mathrm{f}}=0.64(20 \% \mathrm{EA} /$ hexane $)$.

${ }^{1} \mathrm{H}-\mathrm{NMR}\left(500 \mathrm{MHz}, \mathrm{CDCl}_{3}\right) \delta(\mathrm{ppm}): 10.22(\mathrm{C} 5 \mathrm{H}, \mathrm{s}, 1 \mathrm{H}), 9.30(\mathrm{C} 6 \mathrm{NH}, \mathrm{t}, \mathrm{J}=5.5 \mathrm{~Hz}, 1 \mathrm{H})$, 7.47-7.37 (C11H-C15H, m, 5H), $5.95(\mathrm{C} 7 \mathrm{H}, \mathrm{dddd}, \mathrm{J}=17,17,11,5 \mathrm{~Hz}, 1 \mathrm{H}), 5.51(\mathrm{C} 9, \mathrm{~s}, 2 \mathrm{H})$, 5.28-5.18 (C8H, m, 2H), $4.20(\mathrm{C} 6 \mathrm{H}, \mathrm{tt}, \mathrm{J}=5.5,1.5 \mathrm{~Hz}, 2 \mathrm{H}), 1.50(\mathrm{C} 18 \mathrm{H}$ and $\mathrm{C} 21 \mathrm{H}, \mathrm{s}, 18 \mathrm{H})$.

${ }^{13} \mathrm{C}-\mathrm{NMR}\left(125 \mathrm{MHz}, \mathrm{CDCl}_{3}\right) \delta(\mathrm{ppm}): 188.2$ (C5), 172.0 (C2), 162.9 (C4), 159.4 (C1), 150.2 (C16 and C19), 135.8 (C10), 133.7 (C7), 128.5, 128.3, 128.2, (C11-C15), 116.4 (C8), 95.3 (C3), 83.5 (C17 and C20), 68.7 (C9), 43.0 (C6), 27.7 (C18 and C21).

Positive ESI-MS: Expected mass, 484.5. Observed, $485.6\left(\left(\mathrm{M}+\mathrm{H}^{+}\right) / \mathrm{z}, 100 \%\right), 385.6((\mathrm{M}+$ $\left.\mathrm{H}^{+}\right) / \mathrm{z}-$ Boc, $\left.7 \%\right)$.

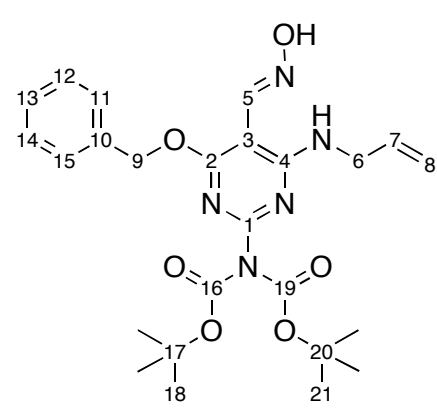

Synthesis of compound 10. Compound 9 (7.65 g, $15.79 \mathrm{mMol})$ was dissolved in pyridine $(150 \mathrm{~mL})$, then hydroxylamine hydrochloride (2.2 $\mathrm{g}, 31.58 \mathrm{mMol})$ was added, and the mixture was stirred under argon atmosphere for $5 \mathrm{~h} . \mathrm{dH}_{2} \mathrm{O}(5 \mathrm{~mL})$ was then added and the pyridine was removed (rotavap). The residual solid was dissolved in EA $(250 \mathrm{~mL})$, washed with $\mathrm{dH}_{2} \mathrm{O}(100 \mathrm{~mL})$ and brine $(100 \mathrm{~mL})$, dried over $\mathrm{Na}_{2} \mathrm{SO}_{4}$, and evaporated to dryness. The desired compound (10, $\mathrm{C}_{25} \mathrm{H}_{33} \mathrm{~N}_{5} \mathrm{O}_{6}$, quantitative) was obtained as a yellow oil and was used in the next step without further purification. $R_{\mathrm{f}}=0.30(20 \%$ EA/hexane).

${ }^{1} \mathrm{H}-\mathrm{NMR}\left(500 \mathrm{MHz}, \mathrm{CDCl}_{3}\right) \delta(\mathrm{ppm}): 8.59(\mathrm{C} 5 \mathrm{H}, \mathrm{s}, 1 \mathrm{H}), 8.34(\mathrm{C} 6 \mathrm{NH}, \mathrm{t}, \mathrm{J}=5.5 \mathrm{~Hz}, 1 \mathrm{H})$, 7.43-7.32 (C11H-C15H, m, 5H), 5.92 (C7H, dddd, J = 17, 17, 11, 5 Hz, 1H), 5.43 (C9H, s, 2H), 5.20-5.07 (C8H, m, 2H), 4.18-4.13 (C6H, m, 2H), $1.49(\mathrm{C} 18 \mathrm{H}$ and $\mathrm{C} 21 \mathrm{H}, \mathrm{s}, 18 \mathrm{H})$. 
${ }^{13} \mathrm{C}-\mathrm{NMR}\left(125 \mathrm{MHz}, \mathrm{CDCl}_{3}\right) \delta(\mathrm{ppm}): 167.4(\mathrm{C} 2), 161.0(\mathrm{C} 4), 155.9$ (C1), 150.7 (C16 and C19), 145.1 (C5), 136.3 (C10), 134.3 (C7), 128.3, 127.8, 127.7 (C11-C15), 115.4 (C8), 89.9 (C3), 82.9 (C17 and C20), 68.1 (C9), 43.1 (C6), 27.7 (C18 and C21).

Positive ESI-MS: Expected mass, 499.5. Observed, $500.6\left(\left(\mathrm{M}+\mathrm{H}^{+}\right) / \mathrm{z}, 100 \%\right), 400.6((\mathrm{M}+$ $\left.\mathrm{H}^{+}\right) / \mathrm{z},-$ Boc $\left.5 \%\right)$.

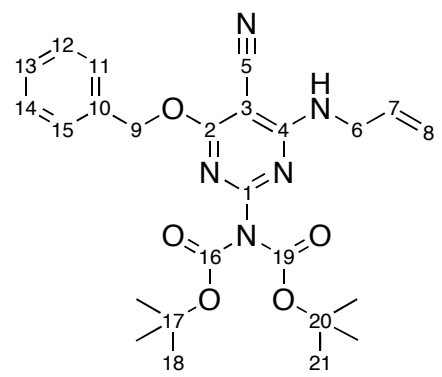

Synthesis of compound 11. Compound $\mathbf{1 0}(0.28 \mathrm{~g}, 0.56 \mathrm{mMol})$ was dissolved in THF $(15 \mathrm{~mL})$ and $\mathrm{Et}_{3} \mathrm{~N}(0.23 \mathrm{~mL}, 1.68 \mathrm{mMol})$ was added. The solution was cooled to $0^{\circ} \mathrm{C}$ and TFAA $(0.11 \mathrm{~mL}, 0.84$ mMol) was added slowly while stirring. The mixture was allowed to warm to rt, heated to reflux for $4 \mathrm{~h}$, then cooled back to $0^{\circ} \mathrm{C} \cdot \mathrm{dH}_{2} \mathrm{O}$ $(1 \mathrm{~mL})$ was added and the solvent was removed under vacuum (rotavap). The residual solid was dissolved in EA $(50 \mathrm{~mL})$, washed with $\mathrm{dH}_{2} \mathrm{O}(25 \mathrm{~mL}), 10 \%$ citric acid $(25 \mathrm{~mL}), 5 \% \mathrm{NaHCO}_{3}(25$ $\mathrm{mL}$ ), and brine ( $25 \mathrm{~mL})$, then dried over $\mathrm{Na}_{2} \mathrm{SO}_{4}$, filtered, and evaporated to dryness (rotavap). The desired compound (11, $\left.\mathrm{C}_{25} \mathrm{H}_{31} \mathrm{~N}_{5} \mathrm{O}_{5}, 89 \%\right)$ was obtained as a white crystalline solid after flash chromatography $\left(\mathrm{SiO}_{2}, 0-6 \% \mathrm{EA} /\right.$ hexane $) . \mathrm{R}_{\mathrm{f}}=0.45$ (20\% EA/hexane).

${ }^{1} \mathrm{H}-\mathrm{NMR}\left(500 \mathrm{MHz}, \mathrm{CDCl}_{3}\right) \delta(\mathrm{ppm}): 7.46-7.34(\mathrm{C} 11 \mathrm{H}-\mathrm{C} 15 \mathrm{H}, \mathrm{m}, 5 \mathrm{H}), 5.90(\mathrm{C} 7 \mathrm{H}, \mathrm{J}=17$, 17, 11, $5 \mathrm{~Hz}, 1 \mathrm{H}), 5.58(\mathrm{C} 6 \mathrm{NH}$, br s, 1H), $5.47(\mathrm{C} 9 \mathrm{H}, \mathrm{s}, 2 \mathrm{H}), 5.27-5.19(\mathrm{C} 8 \mathrm{H}, \mathrm{m}, 2 \mathrm{H}), 4.15$ $(\mathrm{C} 6 \mathrm{H}, \mathrm{tt}, \mathrm{J}=5.5,1.5 \mathrm{~Hz}, 2 \mathrm{H}), 1.52(\mathrm{C} 18 \mathrm{H}$ and $\mathrm{C} 21 \mathrm{H}, \mathrm{s}, 18 \mathrm{H})$.

${ }^{13} \mathrm{C}-\mathrm{NMR}\left(125 \mathrm{MHz}, \mathrm{CDCl}_{3}\right) \delta(\mathrm{ppm}): 171.0$ (C2), $164.4(\mathrm{C} 1), 158.4(\mathrm{C} 4), 150.0$ (C16 and C19), 135.4 (C10), 133.3 (C7), 128.5, 128.3, 128.1 (C11-C15), 117.4 (C8), 113.9 (C5), 83.6 (C17 and C20), 71.5 (C3), 69.0 (C9), 43.7 (C6), 27.7 (C18 and C21).

Positive ESI-MS: Expected mass, 481.5. Observed, $482.6\left(\left(\mathrm{M}+\mathrm{H}^{+}\right) / \mathrm{z}, 100 \%\right), 382.6((\mathrm{M}+$ $\left.\mathrm{H}^{+}\right) / \mathrm{z},-$ Boc $18 \%$ ). 


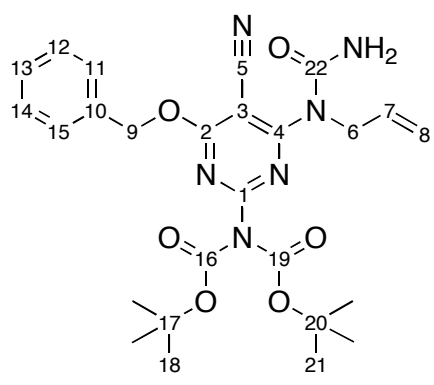

Synthesis of compound 12. Compound $11(0.24 \mathrm{~g}, 0.50 \mathrm{mMol})$ was dissolved in dry DCM $(10 \mathrm{~mL})$ then $\mathrm{Et}_{3} \mathrm{~N}(0.28 \mathrm{~mL}, 2.0 \mathrm{mMol})$ was added. The reaction was cooled to $0^{\circ} \mathrm{C}$ and $\mathrm{N}$-chlorocarbonyl isocyanate $(0.08 \mathrm{~mL}, 1.0 \mathrm{mMol})$ was added slowly. The reaction was stirred at $0^{\circ} \mathrm{C}$ for $30 \mathrm{~min}, 2 \mathrm{~h}$ at $\mathrm{rt}$, cooled down to $0^{\circ} \mathrm{C}$ and

quenched with $\mathrm{dH}_{2} \mathrm{O}(1 \mathrm{~mL})$. The reaction mixture was diluted with $\mathrm{DCM}(40 \mathrm{~mL})$ and then poured over $\mathrm{dH}_{2} \mathrm{O}(25 \mathrm{~mL})$. The organic layer was washed with $\mathrm{dH}_{2} \mathrm{O}(25 \mathrm{~mL})$, dried over $\mathrm{Na}_{2} \mathrm{SO}_{4}$, filtered, and evaporated to dryness (rotavap). The desired compound (12, $\mathrm{C}_{26} \mathrm{~N}_{32} \mathrm{~N}_{6} \mathrm{O}_{6}$, $62 \%)$ was obtained as a white solid and was used in the next step without further purifications. A small sample was purified by flash chromatography $\left(\mathrm{SiO}_{2}, 20-25 \% \mathrm{EA} / \mathrm{hexane}\right)$ for spectroscopic characterization. $\mathrm{R}_{\mathrm{f}}=0.52(50 \% \mathrm{EA} /$ hexane $)$.

${ }^{1} \mathrm{H}-\mathrm{NMR}\left(500 \mathrm{MHz}, \mathrm{CDCl}_{3}\right) \delta(\mathrm{ppm}):$ 7.46-7.38 (C11H-C15H, m, 5H), 5.93-5.85 (C7H, m, 2H), $5.49(\mathrm{C} 9 \mathrm{H}, \mathrm{s}, 2 \mathrm{H}), 5.30-5.21(\mathrm{C} 8 \mathrm{H}, \mathrm{m}, 2 \mathrm{H}), 4.92(\mathrm{C} 6 \mathrm{H}, \mathrm{d}, \mathrm{J}=5 \mathrm{~Hz}, 2 \mathrm{H}), 1.59(\mathrm{C} 18$ and $\mathrm{C} 21, \mathrm{~s}, 18 \mathrm{H})$.

${ }^{13} \mathrm{C}-\mathrm{NMR}\left(125 \mathrm{MHz}, \mathrm{CDCl}_{3}\right.$ ) $\delta(\mathrm{ppm}): 172.2$ (C2), 163.5 (C1), 155.9 (C4), 155.0 (C22), 149.2 (C16 and C19), 134.5 (C10), 132.9 (C7), 128.6, 128.5, 128.0 (C11-C15), 117.0 (C8), 84.9 (C17 and C20), 80.0 (C5), 69.9 (C3), 48.1 (C6), 27.6 (C18 and C21).

Positive ESI-MS: Expected mass, 524.5. Observed, $525.6\left(\left(\mathrm{M}+\mathrm{H}^{+}\right) / \mathrm{z}, 100 \%\right), 425.6((\mathrm{M}+$ $\left.\left.\mathrm{H}^{+}\right) / \mathrm{z}-\mathrm{Boc}, 11 \%\right)$

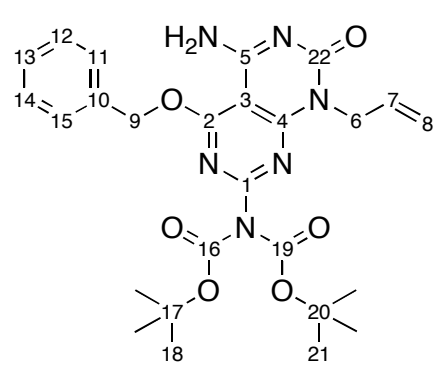

Synthesis of compound 13. Compound $12(0.54 \mathrm{~g}, 1.04 \mathrm{mMol})$ from the previous step was stirred in a methanolic solution of $\mathrm{NH}_{3}(7 \mathrm{M}$, $25 \mathrm{~mL}$ ) under an argon atmosphere for $1 \mathrm{~h}$. The solvent was then removed and the residual solid was dissolved in DCM $(200 \mathrm{~mL})$, 
washed with $\mathrm{dH}_{2} \mathrm{O}(100 \mathrm{~mL})$, dried over $\mathrm{Na}_{2} \mathrm{SO}_{4}$, and evaporated to dryness (rotavap). The desired compound (13, $\mathrm{C}_{26} \mathrm{~N}_{32} \mathrm{~N}_{6} \mathrm{O}_{6}, 48 \%$ over 2 steps) was obtained as a white foam after flash chromatography $\left(\mathrm{SiO}_{2}, 60-100 \% \mathrm{EA} /\right.$ hexane $) . \mathrm{R}_{\mathrm{f}}=0.30(5 \% \mathrm{MeOH} / \mathrm{DCM})$.

${ }^{1} \mathrm{H}-\mathrm{NMR}\left(500 \mathrm{MHz}, \mathrm{CDCl}_{3}\right) \delta(\mathrm{ppm}):$ 7.44-7.34 $(\mathrm{C} 11 \mathrm{H}-\mathrm{C} 15 \mathrm{H}, \mathrm{m}, 5 \mathrm{H}), 7.19\left(\mathrm{C}^{2} \mathrm{NH}_{2}\right.$, br s, 1H), 5.94-5.86 (C7H, m, 1H), 5.61 (C9H, s, 2H), 5.22-5.11 (C8H, m, 2H), $4.77(\mathrm{C} 6 \mathrm{H}, \mathrm{d}, \mathrm{J}=6$ $\mathrm{Hz}, 2 \mathrm{H}), 1.51(\mathrm{C} 18 \mathrm{H}$ and $\mathrm{C} 21 \mathrm{H}, \mathrm{s}, 18 \mathrm{H})$.

${ }^{13} \mathrm{C}-\mathrm{NMR}\left(125 \mathrm{MHz}, \mathrm{CDCl}_{3}\right.$ ) $\delta(\mathrm{ppm}): 167.3$ (C2), $161.0(\mathrm{C} 1), 160.8$ (C4), 158.2 (C5), 155.4 (C22), 149.8 (C16 and C19), 134.6 (C10), 132.1 (C7), 129.0, 128.9, 128.8 (C11-C15), 117.7 (C8), 87.9 (C3), 84.1 (C17 and C20), 70.3 (C9), 44.5 (C6), 27.8 (C18 and C21).

Positive ESI-MS: Expected mass, 524.5. Observed, $525.6\left(\left(\mathrm{M}+\mathrm{H}^{+}\right) / \mathrm{z}, 100 \%\right), 1049.8(2(\mathrm{M}$ $\left.+\mathrm{H}^{+}\right) / \mathrm{z}, 35 \%$.

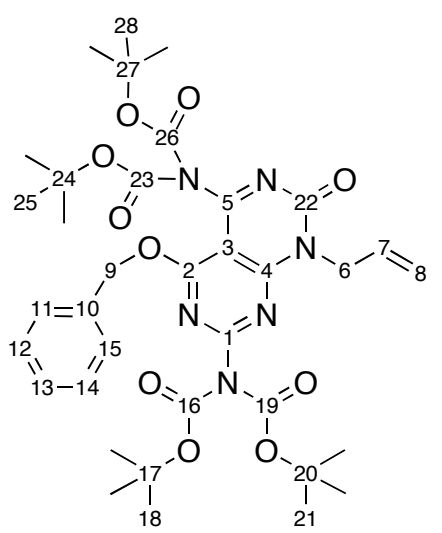

Synthesis of compound 14. Compound $13(0.26 \mathrm{~g}, 0.49 \mathrm{mMol})$ was dissolved in $\mathrm{THF}(20 \mathrm{~mL})$, then $\mathrm{Et}_{3} \mathrm{~N}(0.41 \mathrm{~mL}, 2.97 \mathrm{mMol})$, DMAP $(0.06 \mathrm{~g}, 0.49 \mathrm{mMol})$, and $\mathrm{Boc}_{2} \mathrm{O}(0.32 \mathrm{~g}, 1.48 \mathrm{mMol})$ were sequentially added. The mixture was stirred under an argon atmosphere at $\mathrm{rt}$ for $24 \mathrm{~h}$. The solvent was then removed (rotavap) and the residue was dissolved in EA $(150 \mathrm{~mL})$, washed with $10 \%$

citric acid $(75 \mathrm{~mL}), 5 \% \mathrm{NaHCO}_{3}(75 \mathrm{~mL})$, and brine $(75 \mathrm{~mL})$, dried over $\mathrm{Na}_{2} \mathrm{SO}_{4}$, and evaporated to dryness. The desired compound $\left(\mathbf{1 4}, \mathrm{C}_{36} \mathrm{H}_{48} \mathrm{~N}_{6} \mathrm{O}_{10}, 74 \%\right)$ was obtained as a white foam after flash chromatography $\left(\mathrm{SiO}_{2}, 10-20 \% \mathrm{EA} /\right.$ hexane $) . \mathrm{R}_{\mathrm{f}}=0.74$ (50\% EA/hexane).

${ }^{1} \mathrm{H}-\mathrm{NMR}\left(500 \mathrm{MHz}, \mathrm{CDCl}_{3}\right) \delta(\mathrm{ppm}):$ 7.42-7.30 (C11H-C15H, m, 5H), 5.95-5.87 (C7H, m, 1H), $5.52(\mathrm{C} 9 \mathrm{H}, \mathrm{s}, 2 \mathrm{H}), 5.25-5.14(\mathrm{C} 8 \mathrm{H}, \mathrm{m}, 2 \mathrm{H}), 4.86(\mathrm{C} 6 \mathrm{H}, \mathrm{d}, \mathrm{J}=5.5 \mathrm{~Hz}, 2 \mathrm{H}), 1.52(\mathrm{C} 18 \mathrm{H}$ and $\mathrm{C} 21 \mathrm{H}, \mathrm{s}, 18 \mathrm{H}), 1.25(\mathrm{C} 25 \mathrm{H}$ and $\mathrm{C} 28 \mathrm{H}, \mathrm{s}, 18 \mathrm{H})$ 
${ }^{13} \mathrm{C}-\mathrm{NMR}\left(125 \mathrm{MHz}, \mathrm{CDCl}_{3}\right) \delta(\mathrm{ppm}): 166.4$ (C2), 160.9 (C1), 160.4 (C22), 158.7 (C5), 154.9 (C22), 149.4 (C16, and C19), 148.8 (C23 and C26), 134.3 (C10), 130.8 (C7), 128.7, 128.6, (C11-C15), 118.5 (C8), 94.2 (C3), 84.5 (C17 and C20), 83.8 (C24 and C27), 70.5 (C9), 45.2 (C6), 27.7 (C18 and C21), 27.6 (C25 and C28).

Positive ESI-MS: Expected mass, 724.8. Observed, $725.6\left(\left(\mathrm{M}+\mathrm{H}^{+}\right) / \mathrm{z}, 100 \%\right), 625.6((\mathrm{M}+$ $\left.\left.\mathrm{H}^{+}\right) / \mathrm{z}-\mathrm{Boc}, 14 \%\right)$.

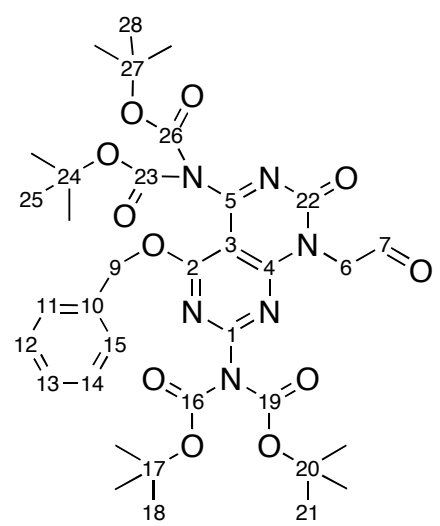

Synthesis of compound 15. Compound $\mathbf{1 4}(0.26 \mathrm{~g}, 0.36 \mathrm{mMol})$ was dissolved in THF $(2 \mathrm{~mL}), t-\mathrm{BuOH}(8 \mathrm{~mL})$, and $\mathrm{dH}_{2} \mathrm{O}(1 \mathrm{~mL})$. Aqueous NMMO (50\% w/w, $0.14 \mathrm{~mL}, 0.72 \mathrm{mMol})$ was then added followed by a $t-\mathrm{BuOH}$ solution of $\mathrm{OsO}_{4}(0.098 \mathrm{M}, 0.18 \mathrm{~mL})$. The reaction was stirred at $\mathrm{rt}$ for $6 \mathrm{~h}$ then the solvent was removed (rotavap). The residual solid was dissolved in EA $(150 \mathrm{~mL})$, washed with $\mathrm{dH}_{2} \mathrm{O}(75 \mathrm{~mL})$, and brine $(75 \mathrm{~mL})$, dried over $\mathrm{Na}_{2} \mathrm{SO}_{4}$, filtered, and evaporated to dryness. The residue was then dissolved in DCM $(4 \mathrm{~mL})$, and added to a solution of $\mathrm{NaIO}_{4}(0.15$ g, $0.72 \mathrm{mMol})$ in $\mathrm{dH}_{2} \mathrm{O}(2 \mathrm{~mL})$. The biphasic reaction mixture was stirred vigorously overnight. An additional portion of $\mathrm{NaIO}_{4}\left(0.15 \mathrm{~g}, 0.718 \mathrm{mMol}\right.$ in $\left.2 \mathrm{~mL} \mathrm{dH}_{2} \mathrm{O}\right)$ was added, and the reaction mixture was stirred for 2 additional days. The reaction mixture was then diluted in DCM (100 $\mathrm{mL})$, poured over $\mathrm{dH}_{2} \mathrm{O}(50 \mathrm{~mL})$, and the organic layer was separated, washed with $\mathrm{dH}_{2} \mathrm{O}(50$ $\mathrm{mL}$ ), and brine $(50 \mathrm{~mL})$, dried over $\mathrm{Na}_{2} \mathrm{SO}_{4}$, filtered, and evaporated to dryness. The desired compound (15, $\mathrm{C}_{35} \mathrm{H}_{46} \mathrm{~N}_{6} \mathrm{O}_{11}, 54 \%$ over 2 steps) was obtained as a white foam after flash chromatography $\left(\mathrm{SiO}_{2}, 15-30 \% \mathrm{EA} / \mathrm{h}\right.$ exane). $\mathrm{Rf}=0.37(5 \% \mathrm{MeOH} / \mathrm{DCM}) . \mathrm{m} . \mathrm{p} .=74-76^{\circ} \mathrm{C}$. 
${ }^{1} \mathrm{H}-\mathrm{NMR}\left(500 \mathrm{MHz}, \mathrm{CDCl}_{3}\right) \delta(\mathrm{ppm}): 9.66(\mathrm{C} 7 \mathrm{H}, \mathrm{s}, 1 \mathrm{H}), 7.47-7.37(\mathrm{C} 11 \mathrm{H}-\mathrm{C} 15 \mathrm{H}, \mathrm{m}, 5 \mathrm{H})$, $5.58(\mathrm{C} 9 \mathrm{H}, \mathrm{s}, 2 \mathrm{H}), 5.16(\mathrm{C} 6 \mathrm{H}, \mathrm{s}, 2 \mathrm{H}), 1.55(\mathrm{C} 18 \mathrm{H}$ and $\mathrm{C} 21 \mathrm{H}, \mathrm{s}, 18 \mathrm{H}), 1.32(\mathrm{C} 25 \mathrm{H}$ and $\mathrm{C} 28 \mathrm{H}, \mathrm{s}$, $18 \mathrm{H})$.

${ }^{13} \mathrm{C}-\mathrm{NMR}\left(125 \mathrm{MHz}, \mathrm{CDCl}_{3}\right.$ ) $\delta$ (ppm): 192.7 (C7), 166.3 (C2) 160.0 (C1), 160.8 (C4), 158.5 (C5), 154.9 (C22), 149.1 (C16 and C19), 148.6 (C23 and C26), 134.1 (C10), 128.7, 128.6, 128.5 (C11-C15), 94.1 (C3), 84.6 (C17 and C20), 84.0 (C24 and C27), 70.6 (C9), 51.9 (C6), 27.6 (C18 and $\mathrm{C} 21), 27.6$ (C25 and $\mathrm{C} 28)$.

Positive ESI-MS: Expected mass, 726.7. Observed, $727.6\left(\left(\mathrm{M}+\mathrm{H}^{+}\right) / \mathrm{z}, 40 \%\right), 749.6((\mathrm{M}+$ $\left.\left.\mathrm{Na}^{+}\right) / \mathrm{z}, 30 \%\right), 627.6\left(\left(\mathrm{M}+\mathrm{H}^{+}\right) / \mathrm{z}-\mathrm{Boc}, 100 \%\right), 527.6\left(\left(\mathrm{M}+\mathrm{H}^{+}\right) / \mathrm{z}-2 \mathrm{Boc}, 10 \%\right)$.

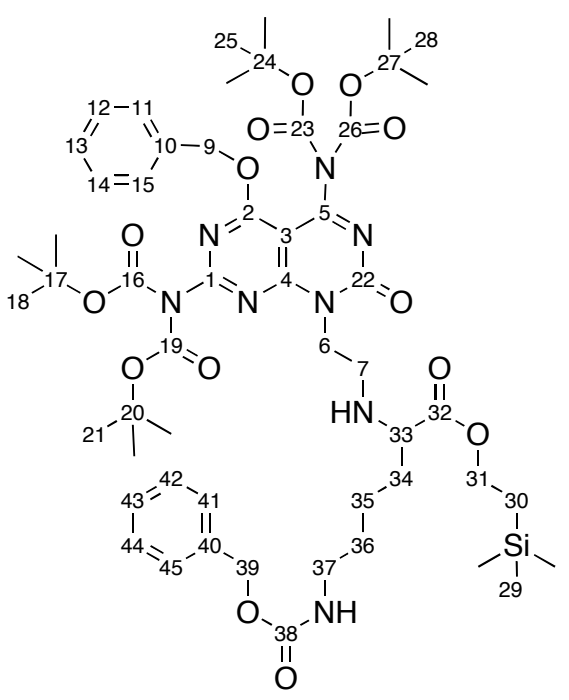
Synthesis of compound 17. Protected lysine $16(0.14 \mathrm{~g}, 0.28$ mMol) was dissolved in DCM (2 mL) and DIEA (0.08 mL, $0.46 \mathrm{mMol})$ was added slowly. Compound $15(0.135 \mathrm{~g}, 0.185$ $\mathrm{mMol})$ dissolved in DCM (3 $\mathrm{mL})$ was then added and the reaction mixture was stirred for $15 \mathrm{~min}$ before addition of $\mathrm{Na}(\mathrm{OAc})_{3} \mathrm{BH}(0.05 \mathrm{~g}, 0.278 \mathrm{mMol})$. The reaction was stirred under an argon atmosphere at rt overnight. The solvent was then removed (rotavap) and the residual solid was dissolved in

EA $(100 \mathrm{~mL})$, washed with $\mathrm{dH}_{2} \mathrm{O}(50 \mathrm{~mL}), 10 \%$ citric acid $(50 \mathrm{~mL}), 5 \% \mathrm{NaHCO}_{3}(50 \mathrm{~mL})$, and brine $(50 \mathrm{~mL})$, dried over $\mathrm{Na}_{2} \mathrm{SO}_{4}$, filtered, and evaporated to dryness. The desired compound $\left(17, \mathrm{C}_{54} \mathrm{H}_{78} \mathrm{~N}_{8} \mathrm{O}_{14} \mathrm{Si}, 65 \%\right)$ was isolated as a white foam after flash chromatography $\left(\mathrm{SiO}_{2}, 15-\right.$ $30 \% \mathrm{EA} /$ hexane $) . \mathrm{R}_{\mathrm{f}}=0.46(20 \% \mathrm{EA} / \mathrm{hexane})$.

${ }^{1} \mathrm{H}-\mathrm{NMR}\left(500 \mathrm{MHz}, \mathrm{CDCl}_{3}\right) \delta(\mathrm{ppm}): 7.44-7.28(\mathrm{C} 11 \mathrm{H}-\mathrm{C} 15 \mathrm{H}$ and $\mathrm{C} 41 \mathrm{H}-\mathrm{C} 45 \mathrm{H}, \mathrm{m}, 10 \mathrm{H})$, $5.53(\mathrm{C} 9 \mathrm{H}, \mathrm{s}, 2 \mathrm{H}), 5.07(\mathrm{C} 39 \mathrm{H}, \mathrm{s}, 2 \mathrm{H}), 5.01(\mathrm{C} 37 \mathrm{NH}, 1 \mathrm{H}), 4.39(\mathrm{C} 31 \mathrm{H}, \mathrm{t}, \mathrm{J}=6 \mathrm{~Hz}, 2 \mathrm{H}), 4.19-$ 
$4.15(\mathrm{C} 6 \mathrm{H}, \mathrm{m}, 2 \mathrm{H}), 3.19(\mathrm{C} 33 \mathrm{H}, \mathrm{t}, \mathrm{J}=7 \mathrm{~Hz}, 1 \mathrm{H}), 3.13-3.01(\mathrm{C} 37 \mathrm{H}$ and $\mathrm{C} 7 \mathrm{H}, \mathrm{m}, 3 \mathrm{H}), 2.81-2.76$ $(\mathrm{C} 7 \mathrm{H}, \mathrm{m}, 1 \mathrm{H}), 1.57(\mathrm{C} 18 \mathrm{H}$ and $\mathrm{C} 21 \mathrm{H}, \mathrm{s}, 18 \mathrm{H}), 1.54-1.24(\mathrm{C} 34 \mathrm{H}-\mathrm{C} 36 \mathrm{H}, \mathrm{m}, 6 \mathrm{H}), 1.29(\mathrm{C} 25 \mathrm{H}$ and $\mathrm{C} 28 \mathrm{H}, \mathrm{s}, 18 \mathrm{H}), 1.00-0.96(\mathrm{C} 30 \mathrm{H}, \mathrm{m}, 2 \mathrm{H}), 0.04(\mathrm{C} 29 \mathrm{H}, \mathrm{s}, 9 \mathrm{H})$.

${ }^{13} \mathrm{C}-\mathrm{NMR}\left(125 \mathrm{MHz}, \mathrm{CDCl}_{3}\right) \delta(\mathrm{ppm}): 175.4$ (C32), 166.3 (C2), 161.4 (C1), 160.2 (C4), 158.3 (C5), 156.3 (C38), 155.4 (C22), 149.5 (C16 and C19), 149.0 (C23 and C26), 136.7 (C40), 134.4 (C10), 128.6, 128.6, 128.5, 128.3, 128.0, 127.9 (C11-C15 and C41-C45), 94.0 (C3), 84.5 (C17 and C20), 83.7 (C24 and C27), 70.4 (C9), 66.3 (C39), 62.7 (C33), 60.9 (C31), 45.1 (C6), 42.8 (C7), 40.8 (C37), 32.8 (C34), 29.5 (C36), 27.7 (C18, C21, C25 and C28), 22.9 (C35), 17.4 (C30), -1.60 (C29).

Positive ESI-MS: Expected mass, 1091.3. Observed, $1091.7\left(\left(\mathrm{M}+\mathrm{H}^{+}\right) / \mathrm{z}, 100 \%\right), 991.7((\mathrm{M}$ $\left.\left.+\mathrm{H}^{+}\right) / \mathrm{z}-\mathrm{Boc}, 17 \%\right)$.

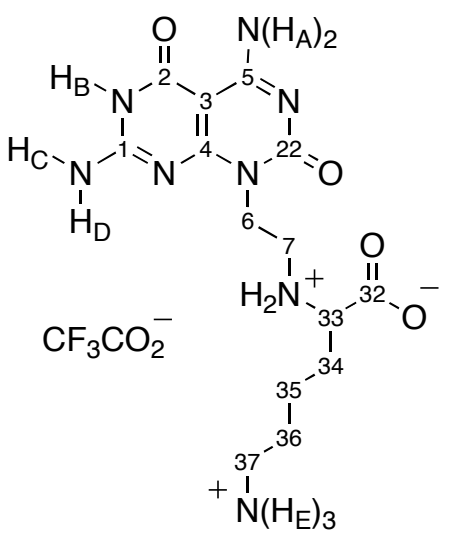

Synthesis of compound 3. Compound $17(0.132 \mathrm{~g}, 0.12 \mathrm{mMol})$ was stirred in a 95:5 TFA:thioanisole $(10 \mathrm{~mL})$ for $72 \mathrm{~h}$. TFA was then removed under reduced pressure (rotavap) and the residual solid was suspended in diethylether, sonicated, then centrifuged down. The pellet was isolated and resuspended in diethylether, sonicated and centrifuged down. This operation was repeated two more times before the solid was dried under vacuum for $72 \mathrm{~h}$ to yield the desired compound $\left(\mathrm{C}_{14} \mathrm{H}_{22} \mathrm{~N}_{8} \mathrm{O}_{4}\left(\mathrm{CF}_{3} \mathrm{CO}_{2} \mathrm{H}\right)_{3.5}\left(\mathrm{H}_{2} \mathrm{O}\right)_{1.5}, 78 \%\right)$ as a white powder. m.p. $=187-191^{\circ} \mathrm{C}$. The following ${ }^{1} \mathrm{H}$ and ${ }^{13} \mathrm{C}-\mathrm{NMR}$ assignments were made based on COSY, HMBC, HMQC, and NOESY NMR experiments.

${ }^{1} \mathrm{H}-\mathrm{NMR}\left(800 \mathrm{MHz}, \mathrm{H}_{2} \mathrm{O} / \mathrm{D}_{2} \mathrm{O} 90 \%\right) \delta(\mathrm{ppm}): 9.15\left(\mathrm{H}_{\mathrm{A}}, \mathrm{s}, 2 \mathrm{H}\right), 8.34\left(\mathrm{H}_{\mathrm{B}}, \mathrm{s}, 1 \mathrm{H}\right), 7.96\left(\mathrm{H}_{\mathrm{C}}, \mathrm{s}\right.$, 1H), $7.42\left(\mathrm{H}_{\mathrm{E}}\right.$, br s, 3H), $7.34\left(\mathrm{H}_{\mathrm{D}}, \mathrm{s}, 1 \mathrm{H}\right), 4.32-4.25(\mathrm{C} 6 \mathrm{H}, \mathrm{m}, 2 \mathrm{H}), 3.69(\mathrm{C} 33 \mathrm{H}, \mathrm{dd} \mathrm{J}=4.8,2.4$ 
$\mathrm{Hz}, 1 \mathrm{H}), 3.26-3.22(\mathrm{C} 7 \mathrm{H}, \mathrm{m}, 2 \mathrm{H}), 2.81-2.77(\mathrm{C} 37 \mathrm{H}, \mathrm{m}, 2 \mathrm{H}), 1.80-1.67(\mathrm{C} 34 \mathrm{H}, \mathrm{m}, 2 \mathrm{H}), 1.54-$ 1.46 (C36, m, 2H), 1.32-1.18 (C35, m, 2H).

${ }^{1} \mathrm{H}-\mathrm{NMR}\left(800 \mathrm{MHz}, \mathrm{CD}_{3} \mathrm{OH}\right) \delta(\mathrm{ppm}): 9.27\left(\mathrm{H}_{\mathrm{A}}, \mathrm{s}, 2 \mathrm{H}\right), 8.72\left(\mathrm{H}_{\mathrm{B}}, \mathrm{s}, 1 \mathrm{H}\right), 8.35\left(\mathrm{H}_{\mathrm{C}}, \mathrm{s}, 1 \mathrm{H}\right)$, $7.67\left(\mathrm{H}_{\mathrm{E}}\right.$, br s, 3H), $7.55\left(\mathrm{H}_{\mathrm{D}}, \mathrm{s}, 1 \mathrm{H}\right), 4.35-4.24(\mathrm{C} 6 \mathrm{H}, \mathrm{m}, 2 \mathrm{H}), 3.94(\mathrm{C} 33 \mathrm{H}, \mathrm{dd} \mathrm{J}=4,3.2 \mathrm{~Hz}$, 1H), 3.34-3.27 (C7H, m, 2H), 2.74-2.70 (C37H, m, 2H), 1.85-1.73 (C34H, m, 2H), 1.46-1.54 (C36H, m, 2H), 1.44-1.25 (C35H, m, 2H).

${ }^{13} \mathrm{C}-\mathrm{NMR}\left(200 \mathrm{MHz}, \mathrm{H}_{2} \mathrm{O} / \mathrm{D}_{2} \mathrm{O}\right.$ 90\%) $\delta(\mathrm{ppm}): 175.5$ (C32), 165.4 (C2), 163.6 (C4), 160.1 (C1), 158.8 (C5), 152.4 (C22), 86.0 (C3), 64.5 (C33), 47.4 (C7) 42.0 (C37), 41.6 (C6), 31.5 (C34), 29.3 (C36), 24.2 (C35).

Positive ESI-MS: Expected mass, 366.38. Observed, $367.6\left(\left(\mathrm{M}+\mathrm{H}^{+}\right) / \mathrm{z}, 100 \%\right)$.

High-resolution EI-MS: Expected mass for $\left(\mathrm{M}+\mathrm{H}^{+}\right) / \mathrm{z}, 367.18368$. Observed, 367.18359.

Elemental analysis: calculated for $\mathrm{C}_{14} \mathrm{H}_{22} \mathrm{~N}_{8} \mathrm{O}_{4}\left(\mathrm{CF}_{3} \mathrm{CO}_{2} \mathrm{H}\right)_{3.5}\left(\mathrm{H}_{2} \mathrm{O}\right)_{1.5}, \mathrm{MW}=792.48$ : C 31.83, H 3.62, N 14.14. Found: C 31.76, H 3.47, N 14.00. 


\section{B. CD spectroscopy}

All circular dichroism spectra were recorded on a JASCO J-810 spectropolarimeter. Samples were scanned from 350-200 $\mathrm{nm}$ at a rate of $100 \mathrm{~nm} / \mathrm{min}$. Stock solutions $(1 \mathrm{mg} / \mathrm{mL})$ of $\mathbf{1}$ and 2 were prepared and aged for $672 \mathrm{~h}$, then their CD spectra were recorded by taking aliquots of the stock solutions and diluting them to $\left(6.8 \times 10^{-5} \mathrm{M}\right)$ at $20^{\circ} \mathrm{C}$ in $\mathrm{dH}_{2} \mathrm{O}$ or $\mathrm{MeOH}$ as indicated in Figure 1 (main text). Solutions of $3\left(1.3 \times 10^{-3} \mathrm{M}\right)$ in $\mathrm{dH}_{2} \mathrm{O}$ and $\mathrm{MeOH}$ were prepared and allowed to equilibrate at $20^{\circ} \mathrm{C}$. CD spectra were monitored by taking aliquots of the stock solutions and diluting them to $\left(4.0 \times 10^{-5} \mathrm{M}\right)$ at $20^{\circ} \mathrm{C}$ in $\mathrm{dH}_{2} \mathrm{O}$ and $\mathrm{MeOH}$ as indicated in the figure captions. The $\mathrm{CD}$ spectra of module 3 in $\mathrm{dH}_{2} \mathrm{O}$ were always mirror image of the spectra in $\mathrm{MeOH}$, thus establishing that the supramolecular chirality recorded is not a random event. As shown by the following CD spectra, the growth rate and amplitude of the CD profile was significantly larger in $\mathrm{MeOH}$, as a result of the formation of longer nanotubes in this medium (see main text and SEM data).

At $20^{\circ} \mathrm{C}$, the VT-CD spectrum in $\mathrm{dH}_{2} \mathrm{O}$ (Figure $\mathrm{S} 2$, left) shows two maxima (53.6 mdeg at $290 \mathrm{~nm}, 46.9 \mathrm{mdeg}$ at $245 \mathrm{~nm})$ and one minimum $(-43.5 \mathrm{mdeg}$ at $228 \mathrm{~nm})$. At $20^{\circ} \mathrm{C}$, the CD spectrum in $\mathrm{MeOH}$ (Figure S2, right) shows two minima (-59.7 mdeg at $289 \mathrm{~nm},-54.0 \mathrm{mdeg}$ at $243 \mathrm{~nm}$ ) and one maximum (35.6 mdeg at $229 \mathrm{~nm}$ ). The attenuation of the CD profile upon heating demonstrates that the recorded cotton effect is the result of supramolecular chirality rather than intrinsic molecular chirality of $\mathbf{3}$. In addition, in the presence of a strong acid (5\% TFA) 3 is CD-silent, in agreement with the supramolecular nature of the observed chirality (data not shown). 

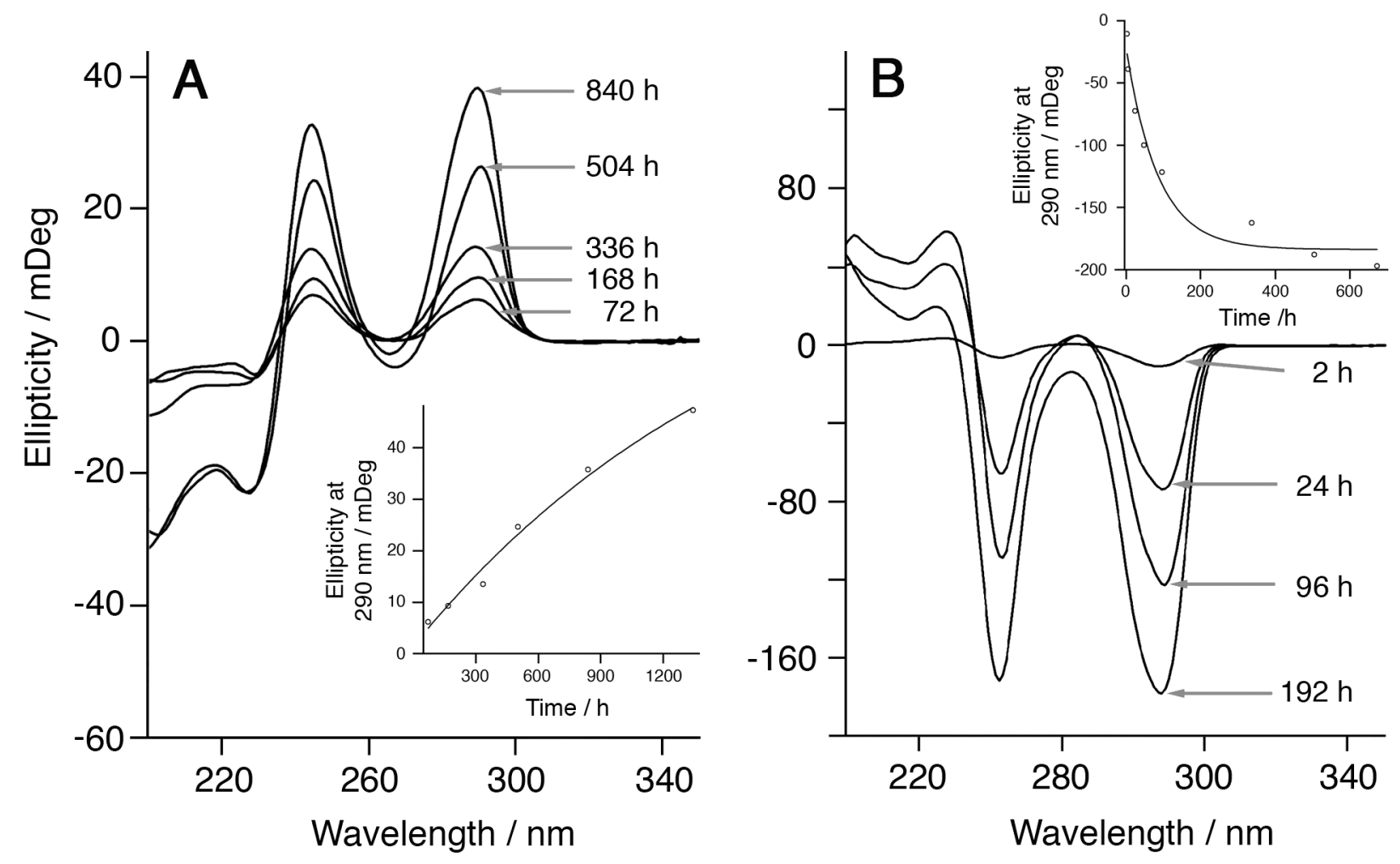

Figure S1. Time-dependent CD spectra of $3\left(4.0 \times 10^{-5} \mathrm{M}\right)$ in $\mathrm{dH}_{2} \mathrm{O}(\mathrm{A})$ and $\mathrm{MeOH}(\mathrm{B})$ at $20^{\circ} \mathrm{C}$. Solutions of $3\left(1.3 \times 10^{-3} \mathrm{M}\right)$ in $\mathrm{dH}_{2} \mathrm{O}$ and $\mathrm{MeOH}$ were prepared and allowed to age at $20^{\circ} \mathrm{C}$. Aliquots of these stock solutions were diluted $\left(4.0 \times 10^{-5} \mathrm{M}\right)$ and their CD spectra recorded over a period of 1 month. Insets show the evolution of ellipticity $(290 \mathrm{~nm})$ versus time. 

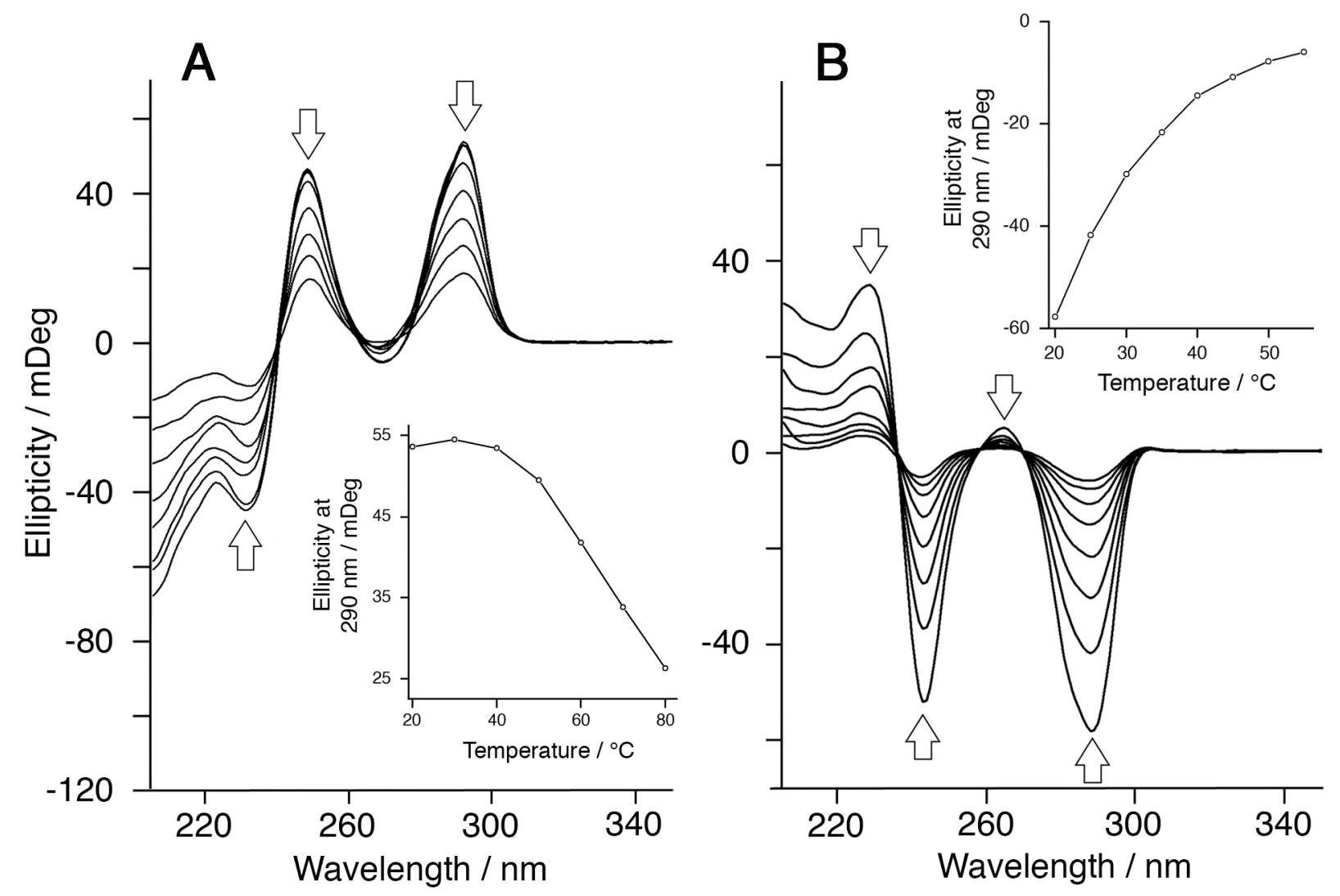

Figure S2. Variable temperature $\mathrm{CD}$ spectra of $\mathbf{3}\left(4.0 \times 10^{-5} \mathrm{M}\right)$ in $\mathrm{dH}_{2} \mathrm{O}\left(\mathrm{A}, \mathrm{T}_{\text {initial }}=20^{\circ} \mathrm{C}, \mathrm{T}_{\text {final }}\right.$ $\left.=90^{\circ} \mathrm{C}, \mathrm{T}_{\text {ramp }}=1^{\circ} \mathrm{C} / \mathrm{min}\right)$ and $\mathrm{MeOH}\left(\mathrm{B}, \mathrm{T}_{\text {initial }}=20^{\circ} \mathrm{C}, \mathrm{T}_{\text {final }}=55^{\circ} \mathrm{C}, \mathrm{T}_{\text {ramp }}=1^{\circ} \mathrm{C} / \mathrm{min}\right)$. Compound $3\left(1.3 \times 10^{-3} \mathrm{M}\right)$ was dissolved in $\mathrm{dH}_{2} \mathrm{O}$ and $\mathrm{MeOH}$ and allowed to age for 6 weeks and 1 day, respectively, before it was diluted to $4.0 \times 10^{-5} \mathrm{M}$ for $\mathrm{CD}$ measurements. 


\section{NMR Studies}

NMR samples were prepared by dissolving 3 in $0.75 \mathrm{~mL}$ of $\mathrm{H}_{2} \mathrm{O} / \mathrm{D}_{2} \mathrm{O}(90: 10)$, and $\mathrm{CD}_{3} \mathrm{OH}$ (99.8\%) to a final concentration of $15.89 \mathrm{mM}$ and $18.7 \mathrm{mM}$, respectively. As shown in Figure S3, the 1D and 2D NMR spectra for 3 in water and methanol were essentially the same. 2D NMR experiments were conducted at $5^{\circ} \mathrm{C}$ on a Varian Inova-800 spectrometer equipped with either a $5 \mathrm{~mm}$ triple axis gradient $\mathrm{HCN}$ probe or a $5 \mathrm{~mm} \mathrm{HCN}$-Zaxis-gradient cold probe. One dimensional single $90^{\circ}$ pulse ${ }^{1} \mathrm{H}$ spectra were collected with a water presaturation period of $2 \mathrm{~s}$ ( $\gamma \mathrm{B} 1$ of $\sim 150 \mathrm{~Hz}$ ), sweep widths of $12 \mathrm{kHz}$, and acquisition times of $2 \mathrm{~s}$. Standard Varian 2D ${ }^{1} \mathrm{H},{ }^{1} \mathrm{H}-\mathrm{NOESY}$ spectroscopy (BioPack, Varian Inc.) was employed with a solvent presaturation and/or a 3-9-19-WATERGATE² solvent suppression scheme and sweep widths of 12 (2048 complex points) and $8 \mathrm{kHz}$ (256 complex points) for the directly and indirectly detected dimensions, respectively. Gradient absolute value hetero-nuclear multiple bond correlation spectra (gHMBC, BioPack, Varian Inc.) were collected with optimization for either 4 or $8 \mathrm{~Hz}$ couplings and with sweep widths of 12 (2048 complex points) and $32 \mathrm{kHz}$ (512 complex points) for the ${ }^{1} \mathrm{H}$ and ${ }^{13} \mathrm{C}$ dimensions, respectively. The standard sequence was modified in-house to include a $\mathrm{z}$-gradient $-90^{\circ}-\mathrm{z}-$ gradient $\mathrm{T}_{1}$ artifact suppression sequence before the saturation period. $1 \mathrm{D}{ }^{13} \mathrm{C}$ spectra were collected with a sweep width of $40 \mathrm{kHz}$. Total acquisition time for the $2 \mathrm{D}$ experiments were approximately $8-24 \mathrm{~h}$ each, depending on sample concentration and signal to noise ratio. All directly and indirectly detected data sets were zero filled to twice the number of acquired points. Both spectral dimensions were typically apodized using either a $\pi / 2$ or $\pi / 3$ shifted sinebell weighting function, depending on desired resolution in the region of interest. Spectra were acquired, processed and analyzed using the VNMRJ 1.1C (Varian Inc.) software package as described previously. ${ }^{3}$ 


\section{AFM imaging}

AFM measurements were performed in tapping mode (TM-AFM) at a scan rate of $2 \mathrm{~Hz}$ per line using a Digital Instruments/Veeco Instruments MultiMode Nanoscope IV equipped with an E scanner. Silicon cantilevers (MikroMasch USA, Inc.) with spring constants of $40 \mathrm{~N} / \mathrm{m}$ were used. Solutions of $3\left(1 \mathrm{mg} / \mathrm{mL}, 1.3 \times 10^{-3} \mathrm{M}\right)$ were aged for 1 month in water and methanol. A small sample of each solution was then diluted to $4.0 \times 10^{-5} \mathrm{M}$ prior to imaging. AFM samples were prepared by depositing $50 \mu \mathrm{L}$ of the diluted solutions on freshly cleaved highly ordered pyrolytic graphite (HOPG) and rapidly blowing the surface with compressed nitrogen to remove excess solution and to dry the surface. 
A
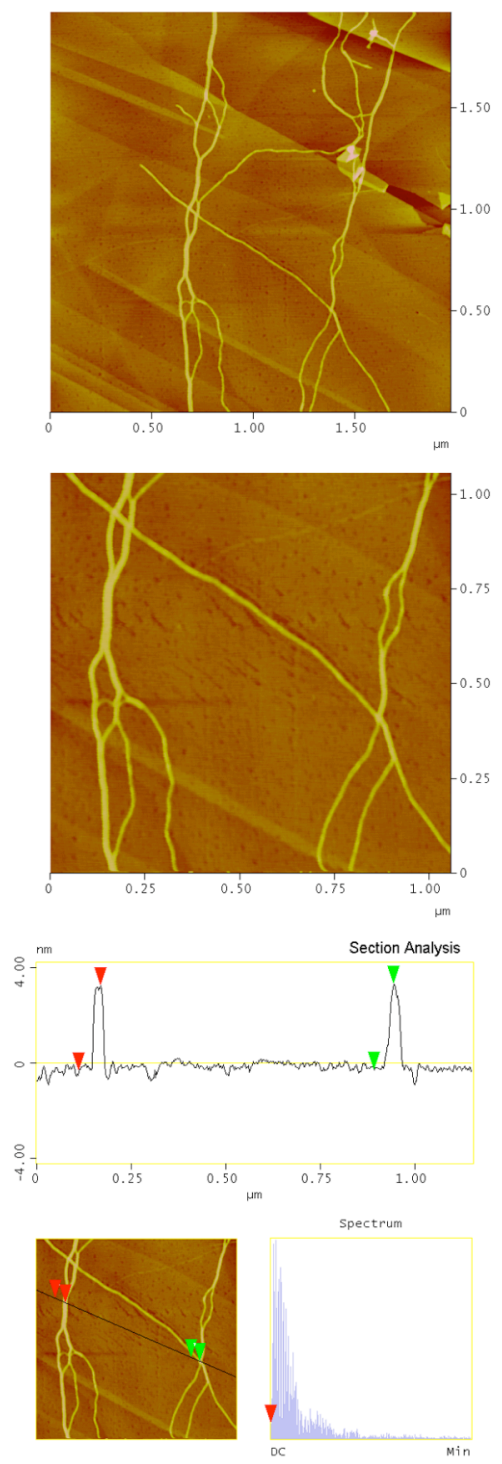

B
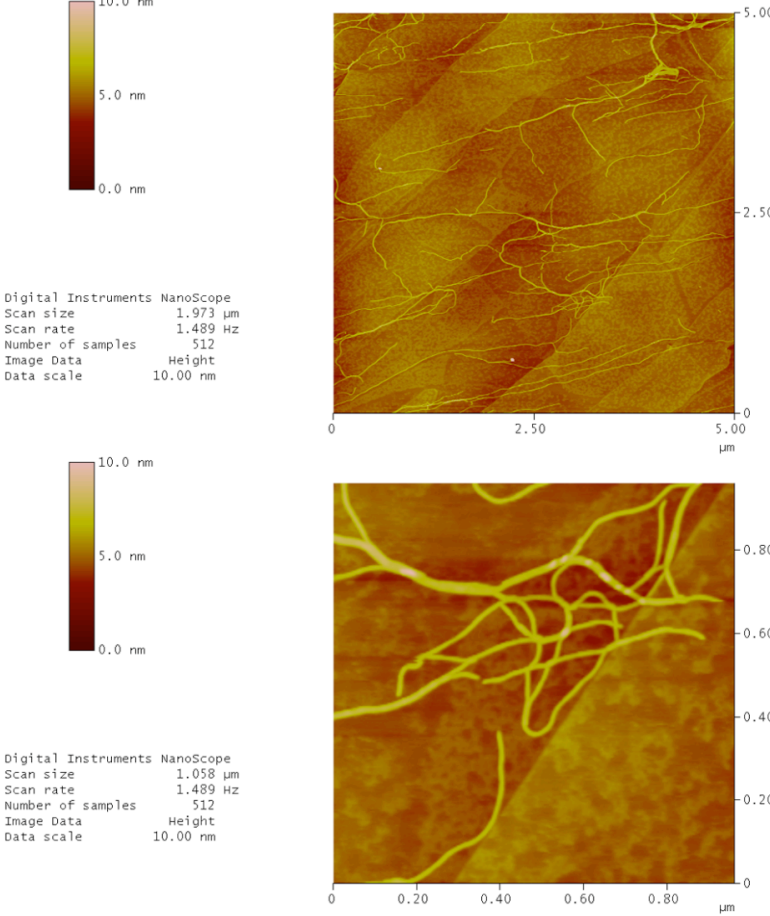

Section Analysis

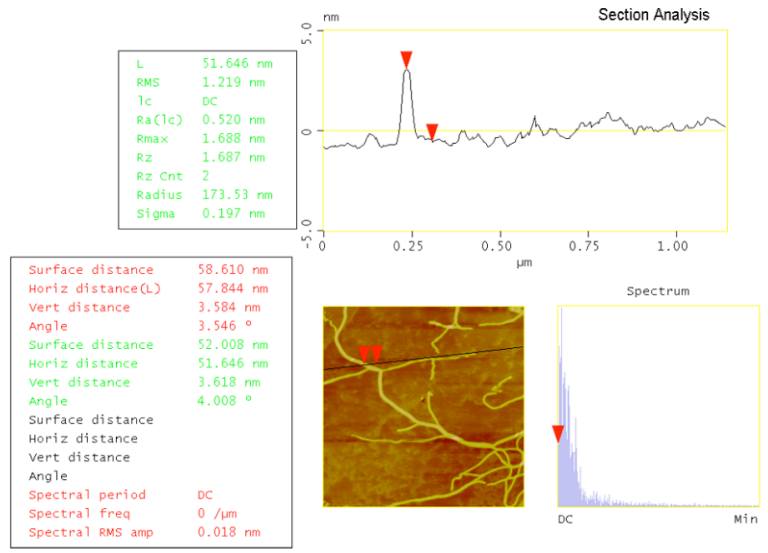

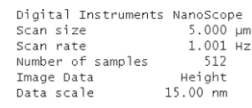
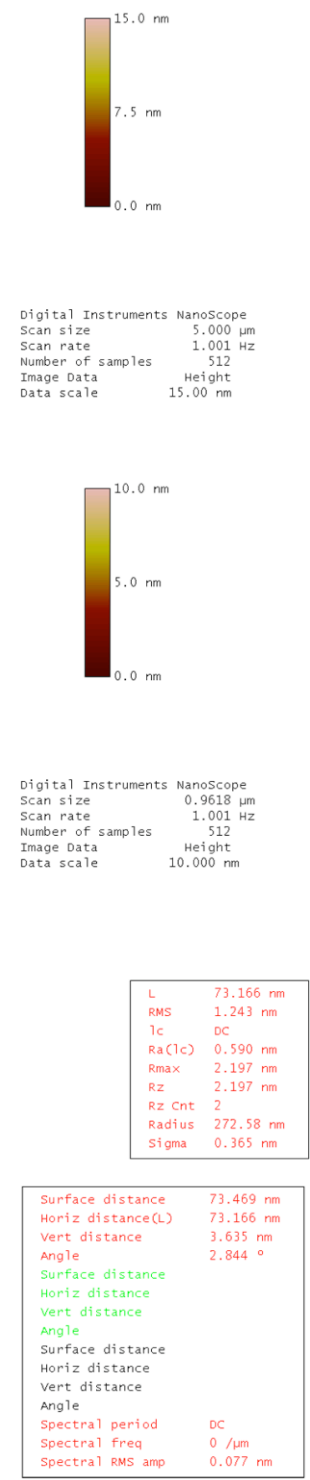

Figure S3. Tapping mode atomic force microscopy images and cross section analyses featuring a height of $3.58 \mathrm{~nm}$ for the $\mathrm{W}$-chiromer (A) and $3.63 \mathrm{~nm}$ for the M-chiromer (B) on HOPG. 


\section{E. TEM imaging}

TEM imaging was performed on a JEOL 2010 microscope operating at $200 \mathrm{kV}$. Compound 3 $\left(1.3 \times 10^{-3} \mathrm{M}, 1 \mathrm{mg} / \mathrm{mL}\right)$ was dissolved in $\mathrm{dH}_{2} \mathrm{O}$ and $\mathrm{MeOH}$ and aged for 2 weeks. An aliquot $(0.02 \mathrm{~mL})$ of each of the solutions was deposited on a 400-mesh carbon coated grid (Electron Microscopy Sciences), then blotted after $10 \mathrm{~s}$. The samples were negatively stained with either $1 \%$ uranyl acetate or Nano-W (Methylamine Tungstate, Nanoprobes Inc.). Uranyl acetate was dissolved in $\mathrm{MeOH}$ for the $\mathrm{M}$-chiromer, and in $\mathrm{dH}_{2} \mathrm{O}$ for the $\mathrm{W}-$ chiromer. Nano-W was found to stain the M-chiromer more effectively. All samples were air-dried before imaging.

The average diameters of the chiromers were determined by randomly measuring individual assemblies using Adobe Photoshop version 8.0. The $\mathrm{W}$-chiromer was found to have a diameter of $3.8 \pm 0.4 \mathrm{~nm}$ and the $\mathrm{M}-$ chiromer had a diameter of $3.8 \pm 0.3 \mathrm{~nm}$. This study established that the chiromers were visually identical and had identical outer diameters.

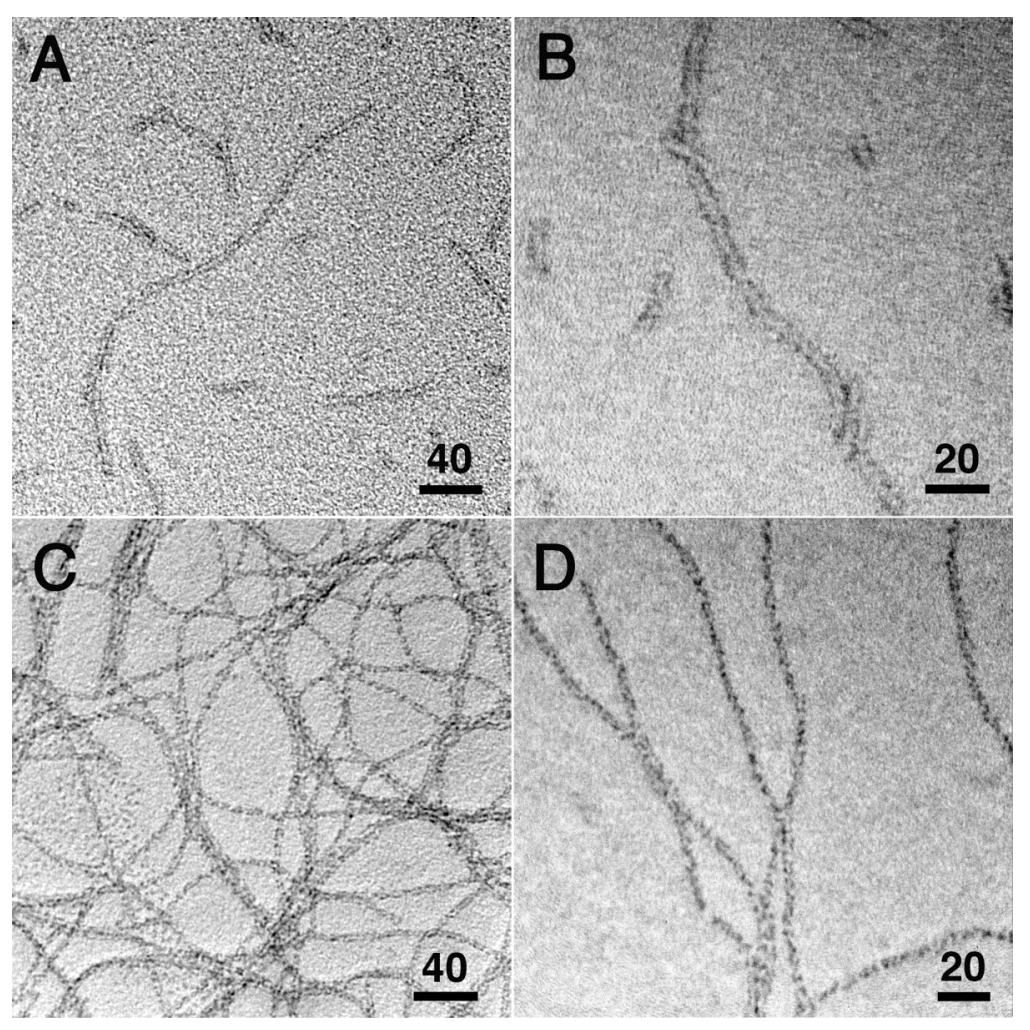

Figure S4. TEM images of the W-chiromer of $3\left(1.3 \times 10^{-3} \mathrm{M}, 1\right.$ $\mathrm{mg} / \mathrm{mL}$ ) negatively stained with Nano-W (A, B) and uranyl acetate (C, D). Scale bars in $\mathrm{nm}$. 


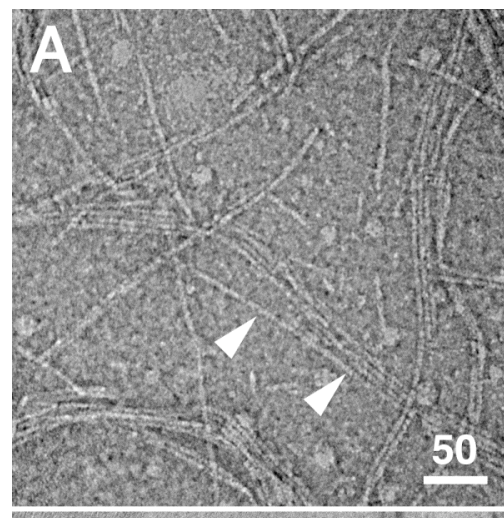

B

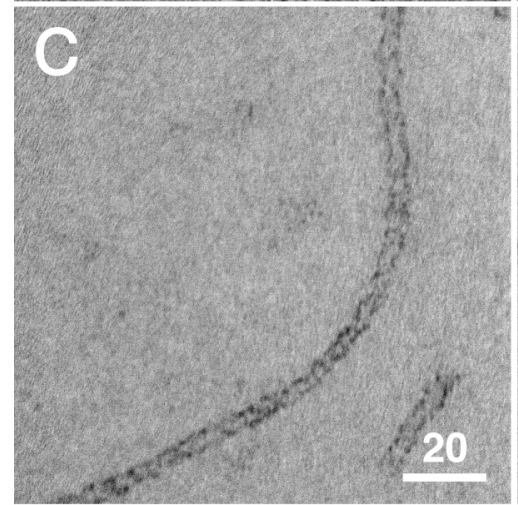

D

20
Figure S5. TEM images of the Mchiromer of $3\left(1.3 \times 10^{-3} \mathrm{M}, 1\right.$ $\mathrm{mg} / \mathrm{mL}$ ) negatively stained with uranyl acetate (A) and Nano-W (B-D). Arrowheads point at individual nanotubes. Scale bars in nm. 


\section{F. SEM imaging}

W-chiromer and M-chiromer were imaged at both stock solution concentration $\left(0.65-1.3 \times 10^{-5}\right.$ $\mathrm{M}, 0.5-1 \mathrm{mg} / \mathrm{mL})$ and $\mathrm{CD}$ concentration $\left(4.0 \times 10^{-5} \mathrm{M}\right)$ at time intervals ranging from $24-672 \mathrm{~h}$ after sample preparation. Samples were prepared by depositing $0.02 \mathrm{~mL}$ of the chiromers on ultra-thin carbon coated 400 mesh copper grids (Electron Microscopy Sciences) and blotting after $10 \mathrm{~s}$. All samples were air-dried and heated on a hotplate for $10 \mathrm{~min}$ prior to imaging to remove any residual solvents. All SEM images were obtained without negative staining, at $5 \mathrm{kV}$ accelerating voltage and a working distance of $3.0 \mathrm{~mm}$ on a high resolution Hitachi S-4800 cold field emission SEM. Other than the length and density of nanotubes, the SEM images showed no visible structural differences between the $\mathrm{W}$-chiromer and $\mathrm{M}$-chiromer.
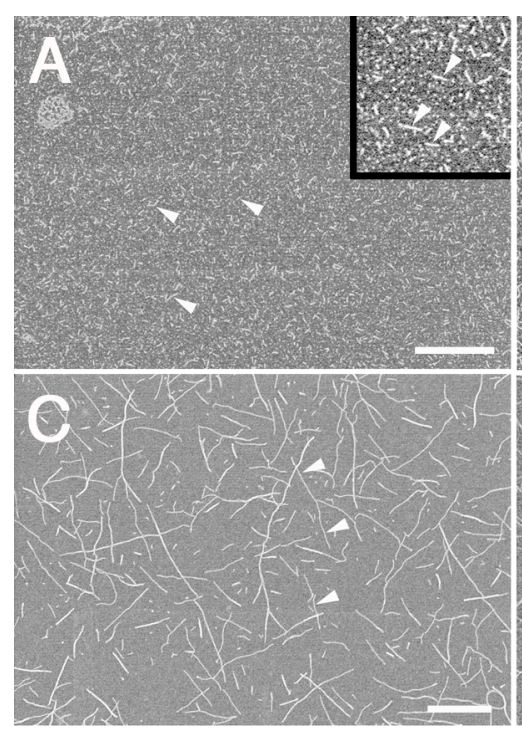

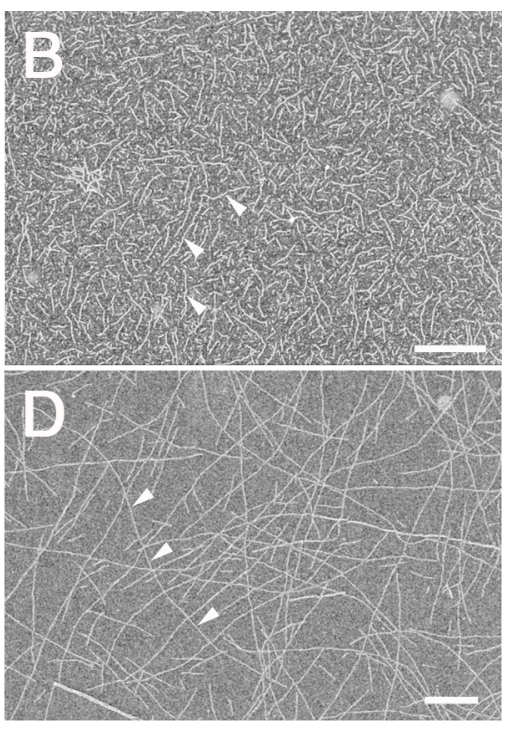

Figure S6. SEM images of $\mathbf{3}(4.0 \times$ $\left.10^{-5} \mathrm{M}\right)$ prepared from an aqueous stock solution of $\mathbf{3}\left(1.3 \times 10^{-3} \mathrm{M}\right)$ that was aged for $24 \mathrm{~h}(\mathrm{~A})$ and 672 h (B) at $20^{\circ} \mathrm{C}$ prior to dilution and imaging (scale bars $=200 \mathrm{~nm}$, inset $\left.=200 \times 200 \mathrm{~nm}^{2}\right)$. SEM images of

$3\left(4.0 \times 10^{-5} \mathrm{M}\right)$ prepared from a

stock solution of $3\left(1.3 \times 10^{-3} \mathrm{M}\right)$ in methanol that was aged for $24 \mathrm{~h}(\mathrm{C})$ and $672 \mathrm{~h}(\mathrm{D})$ at $20^{\circ} \mathrm{C}$ prior to dilution and imaging Scale bars $=400 \mathrm{~nm}$. 


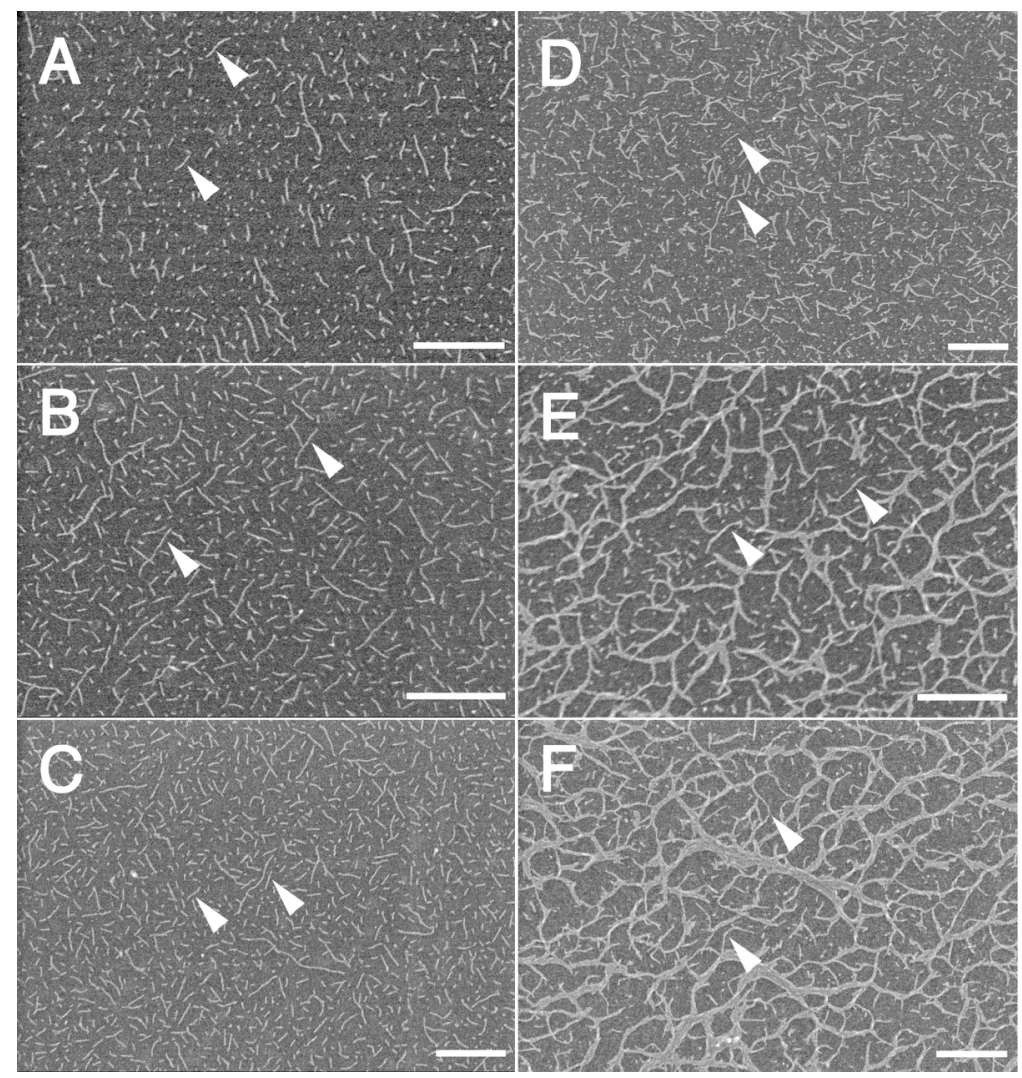

Figure S7. Time-dependent SEM images of the $\mathrm{W}$-chiromer $(\mathrm{A}-\mathrm{C})$ and M-chiromer (D-F). Compound $3\left(0.65 \times 10^{-3} \mathrm{M}, 0.5 \mathrm{mg} / \mathrm{mL}\right)$ was dissolved in $\mathrm{dH}_{2} \mathrm{O}$ and $\mathrm{MeOH}$ at $20^{\circ} \mathrm{C}$, and aliquots were viewed after $1 \mathrm{~h}(\mathrm{~A}, \mathrm{D}), 1$ day $(\mathrm{B}, \mathrm{E})$, and 3 days $(\mathrm{C}, \mathrm{F})$. Arrowheads point at individual rosette nanotubes. Scale bars $=250 \mathrm{~nm}$.

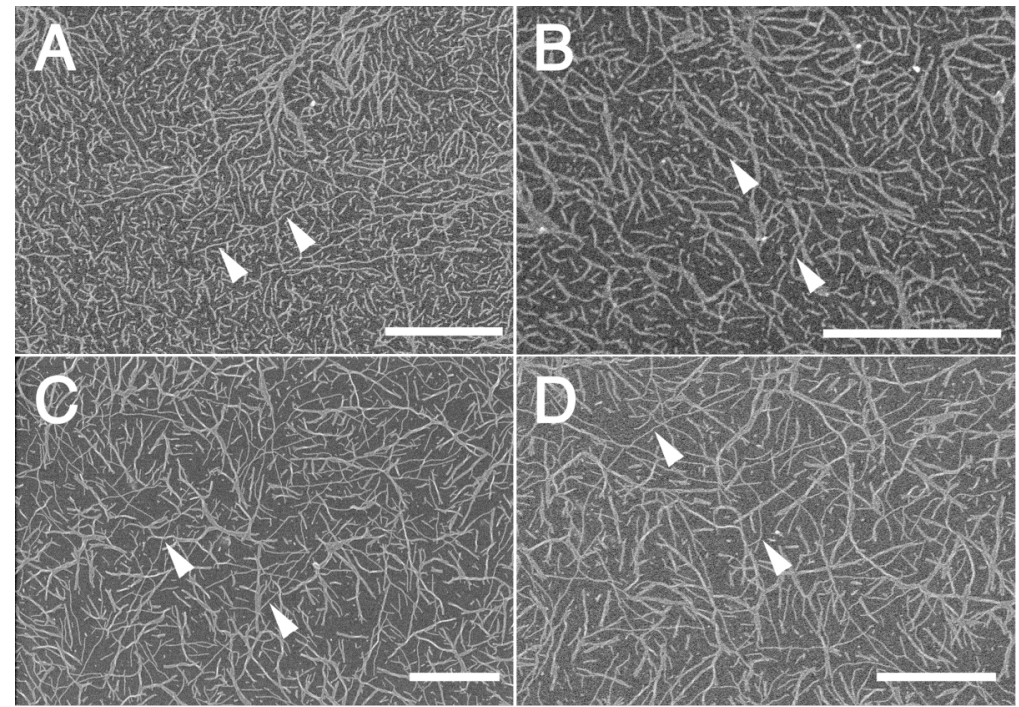

Figure S8. Time-dependent SEM images of the $\mathrm{W}$-chiromer $(\mathrm{A}, \mathrm{B})$ and $\mathrm{M}$-chiromer (C, D). Compound $3\left(1.3 \times 10^{-3} \mathrm{M}, 1 \mathrm{mg} / \mathrm{mL}\right)$ was dissolved in $\mathrm{dH}_{2} \mathrm{O}$ and $\mathrm{MeOH}$ at $20^{\circ} \mathrm{C}$, and aliquots were viewed after 28 days. Scale bars $=500 \mathrm{~nm}$. 

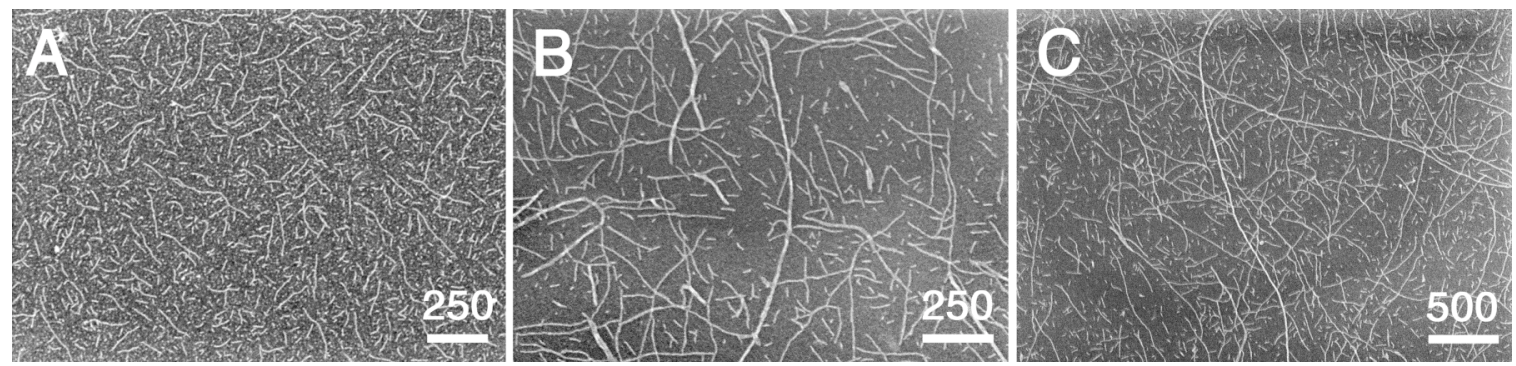

Figure S9. SEM images showing that $\mathrm{MeOH}$ induces elongation of the rosette nanotubes. Compound $3\left(1.3 \times 10^{-3} \mathrm{M}, 1 \mathrm{mg} / \mathrm{mL}\right)$ was dissolved in water at $20^{\circ} \mathrm{C}$ and aged for 28 days. An aliquot $(62.5 \mu \mathrm{L})$ was then diluted in $\mathrm{dH}_{2} \mathrm{O}(1937.5 \mu \mathrm{L})$ to a final concentration of $4.0 \times 10^{-5} \mathrm{M}$ before viewing by SEM (A). Another aliquot $(62.5 \mu \mathrm{L})$ of the same solution was diluted in $\mathrm{MeOH}(1937.5 \mu \mathrm{L})$ and viewed by $\operatorname{SEM}(\mathrm{B}, \mathrm{C})$. Scale bars in $\mathrm{nm}$. 


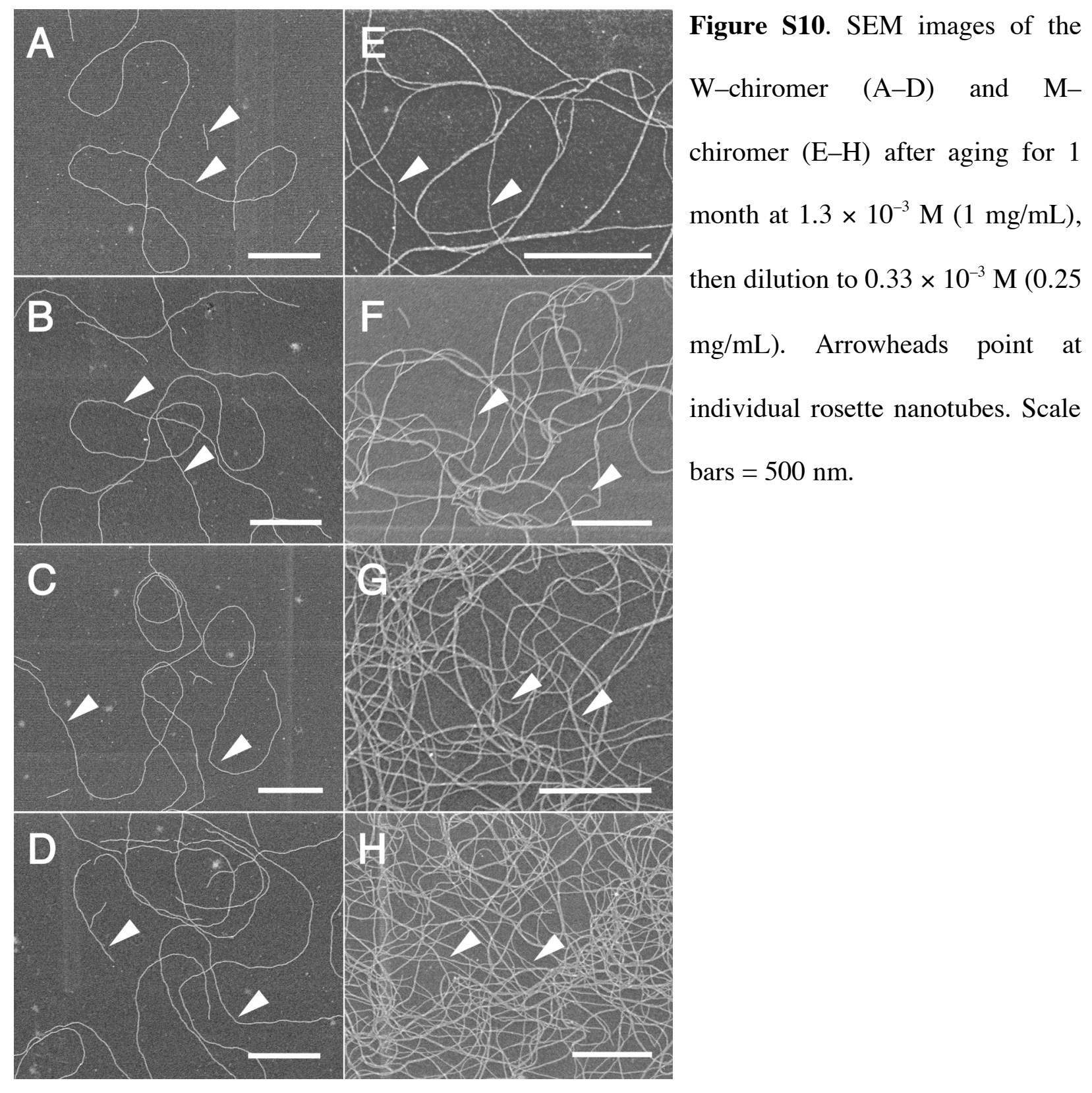



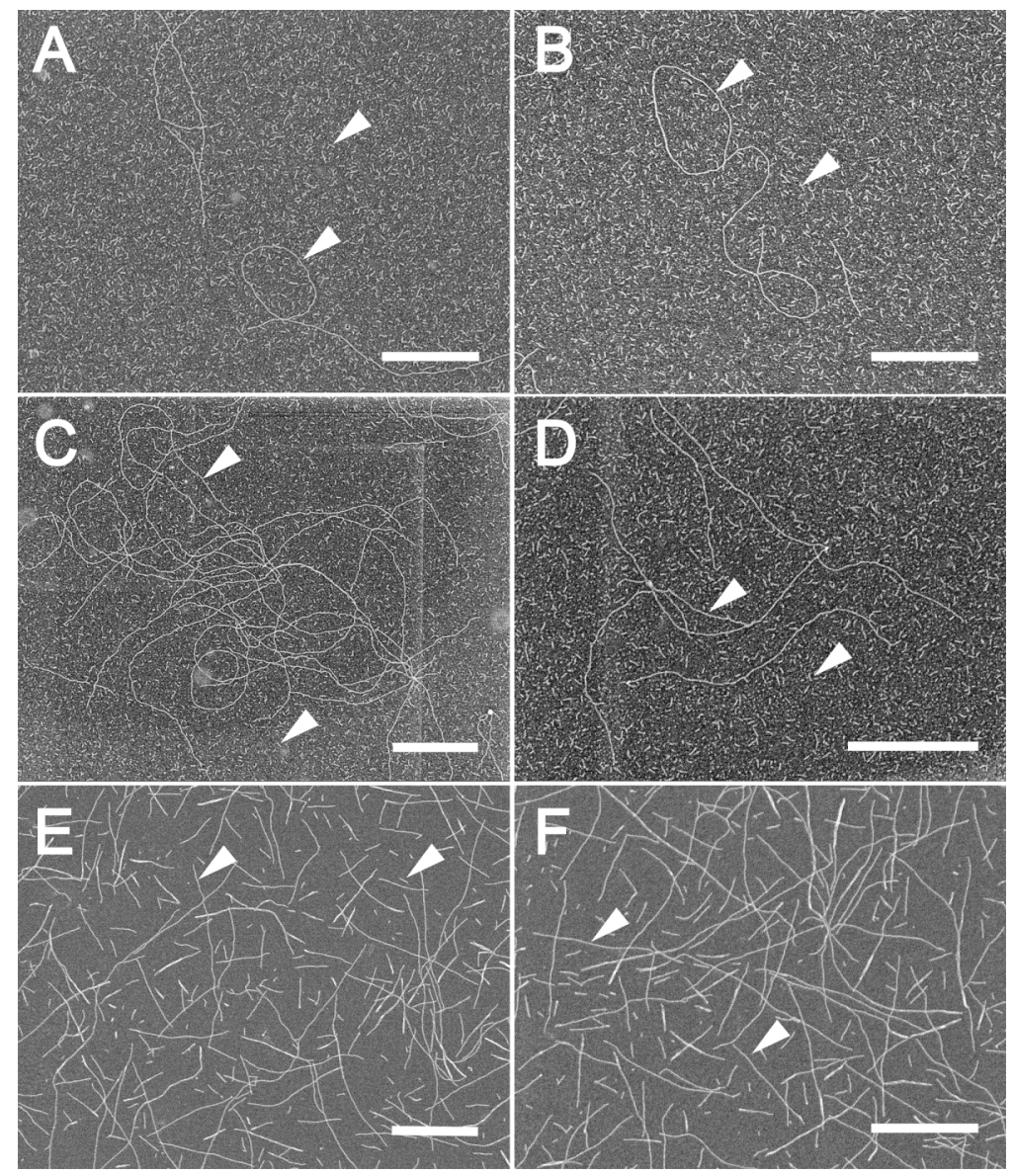

Figure S11. Effect of heating on the growth of the W-chiromer (AD) and M-chiromer (E, F). Compound $3\left(1 \mathrm{mg} / \mathrm{mL}, 1.3 \times 10^{-3}\right.$ M) was dissolved in $\mathrm{dH}_{2} \mathrm{O}$ and $\mathrm{MeOH}$. The water samples were aged for $24(\mathrm{~A}, \mathrm{~B})$ and $672 \mathrm{~h}(\mathrm{C}, \mathrm{D})$ at $20^{\circ} \mathrm{C}$ before they were refluxed for $3 \mathrm{~s}$, diluted to $\mathrm{CD}$ concentration $\left(4.0 \times 10^{-5} \mathrm{M}\right)$ and imaged by SEM. The methanol samples were aged at $20^{\circ} \mathrm{C}$ for $24 \mathrm{~h}$ before they were refluxed for $3 \mathrm{~s}$, diluted to $\mathrm{CD}$ concentration $\left(4.0 \times 10^{-5} \mathrm{M}\right)$ and imaged by $\operatorname{SEM}(\mathrm{E}, \mathrm{F})$. Comparison of these images with those in Figure S8 show that heating promotes end-to-end fusion and elongation of the nanotubes. Scale bar $=500 \mathrm{~nm}$. 


\section{G. UV-Vis spectroscopy}

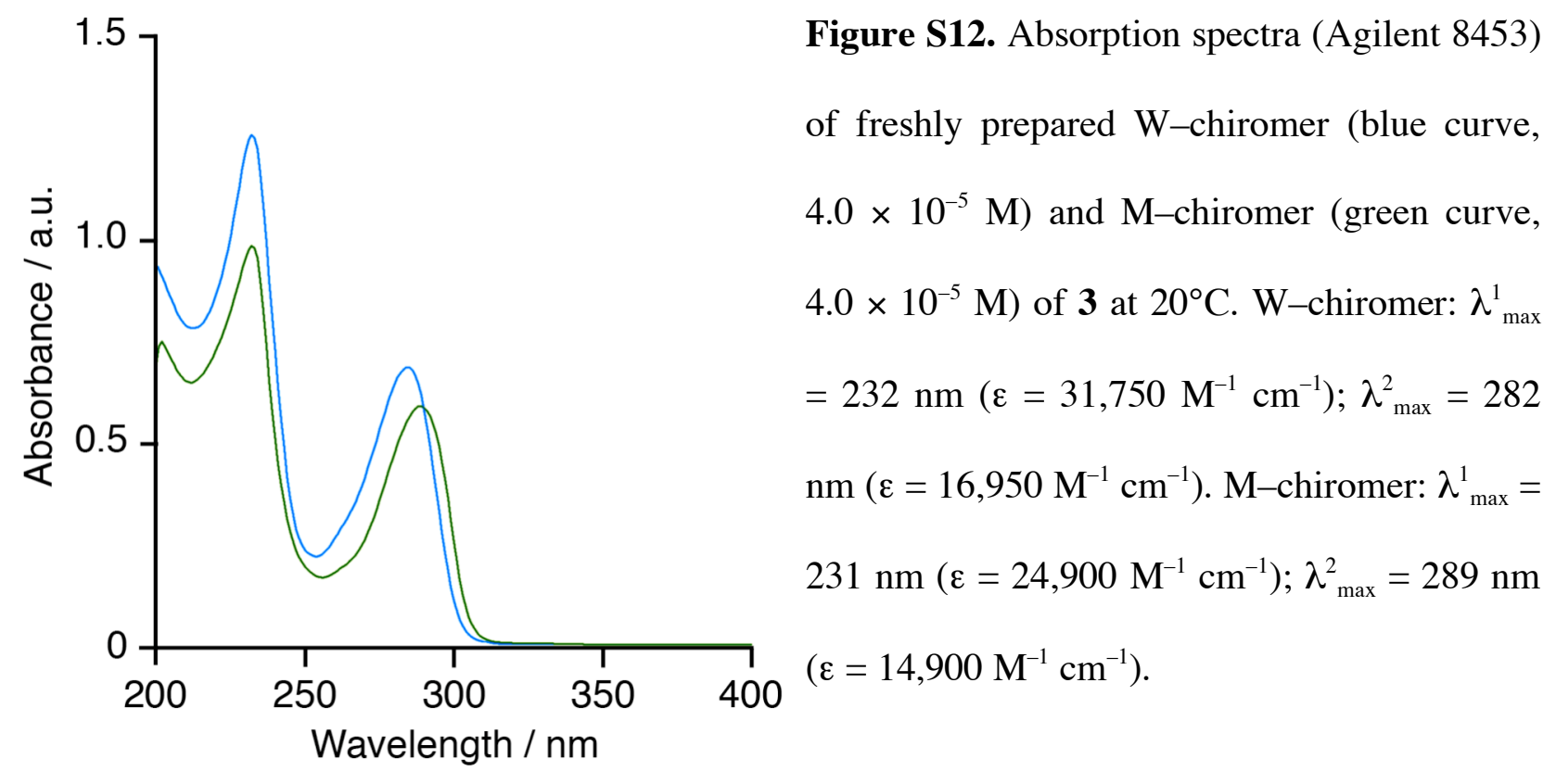




\section{H. Binary solvent studies}
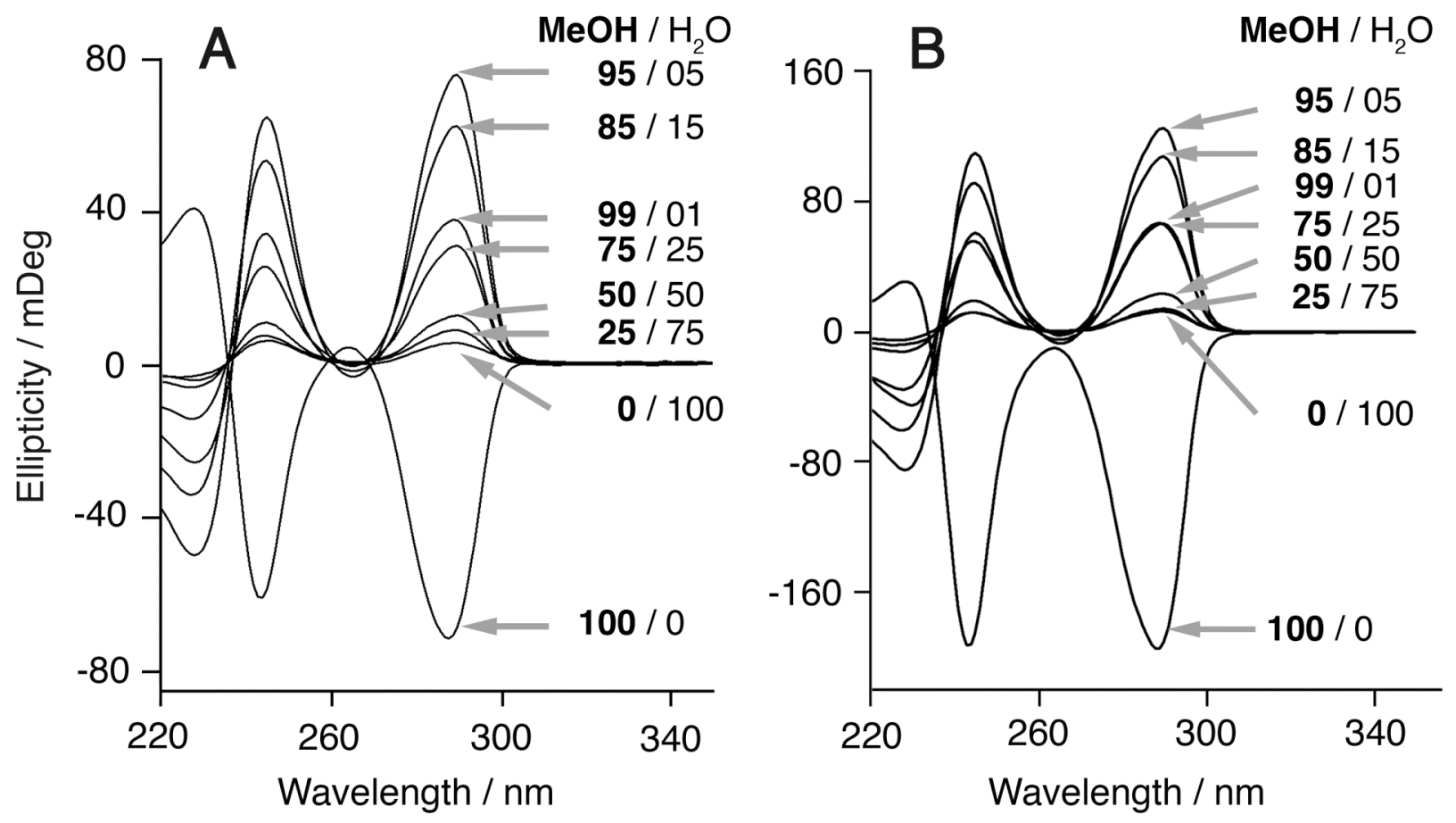

Figure S13. Binary solvent study showing that the W-chiromer is the dominant species. Nine samples of $3\left(1.3 \times 10^{-3} \mathrm{M}, 1 \mathrm{mg} / \mathrm{mL}\right)$ dissolved in $\mathrm{MeOH} / \mathrm{dH}_{2} \mathrm{O}(\mathrm{v} / \mathrm{v}: 0 / 100,25 / 75,50 / 50$, 75/25. 85/15, 95/5, 99/1, 100/0). Their CD spectra were recorded after 24 (A), 48, 168, 336, 504, and $672 \mathrm{~h}(\mathrm{~B})$ at $20^{\circ} \mathrm{C}$ by diluting aliquots from the stock solutions to a final concentration of 4.0 $\times 10^{-5} \mathrm{M}$ in the same binary solvent mixtures. The CD spectra for $48,168,336$ and $504 \mathrm{~h}$ are not shown, but are summarized in Figure S14. 


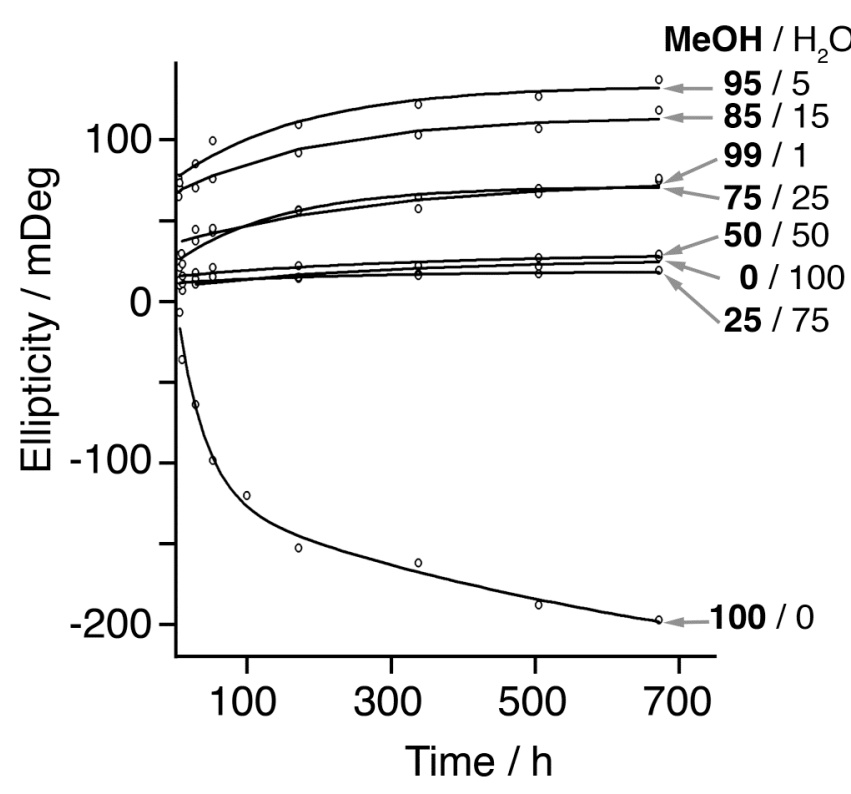

Figure S14. Binary solvent study showing that methanol accelerates chiromer growth regardless of the composition of the solvent mixture. CD spectra were recorded in various $\mathrm{MeOH} / \mathrm{dH}_{2} \mathrm{O}$ solvent mixtures $24,48,168$, 336,504 , and $672 \mathrm{~h}$ after the stock solutions were prepared. Note that the rate of $\mathrm{CD}$ growth is faster and more pronounced in the presence of methanol. 


\section{DLS measurements}

Compound $3\left(1.3 \times 10^{-3} \mathrm{M}, 1 \mathrm{mg} / \mathrm{mL}\right)$ was dissolved in $\mathrm{MeOH}$ and $\mathrm{dH}_{2} \mathrm{O}$, and filtered through a $0.2 \mu \mathrm{m}$ pore diameter nonsterile PVFD membrane filter (Whatman). Dynamic Light Scattering (DLS) experiments were performed after 3, 24, 48, 72, 168, and $336 \mathrm{~h}$ using a Malvern Zetasizer Nano $\mathrm{S}$ working at a $90^{\circ}$ scattering angle at $25^{\circ} \mathrm{C}$. The instrument is equipped with a $40 \mathrm{~mW}$ He-Ne laser $(\lambda=633 \mathrm{~nm})$ and an avalanche photodiode detector. Size distributions were calculated using an inverse Laplace transform algorithm, and the hydrodynamic radii were calculated using the Stokes-Einstein equation. Over the two-week period, the average hydrodynamic radius for the $\mathrm{W}$-chiromer was observed to grow from 16.4 to $20.4 \mathrm{~nm}$ while the M-chiromer grew from $21.7 \mathrm{~nm}$ to $49.3 \mathrm{~nm}$ (Figure 5). These results indicate that the nanotubes grow in both solvents overtime, but that methanol promotes the formation of longer nanotubes, in agreement with the SEM (Figures S6-S11) and CD (Figures S1, S2, S13, S14) data.

The effect of heating on the chiromers was also monitored by DLS (Figure S15). Compound $3\left(1.3 \times 10^{-3} \mathrm{M}, 1 \mathrm{mg} / \mathrm{mL}\right)$ was dissolved in $\mathrm{MeOH}$ and $\mathrm{dH}_{2} \mathrm{O}$, filtered through a 0.2 $\mu \mathrm{m}$ pore diameter nonsterile PVFD membrane filter (Whatman), then each solution was split into two equal-volume samples. One was kept at $20^{\circ} \mathrm{C}$ while the other was refluxed for $3 \mathrm{~s}$. The solutions were then allowed to equilibrate for $3 \mathrm{~h}$ before recording their DLS spectra (Figure S15). The results show that the mean hydrodynamic diameter of the W-chiromer increased dramatically from 45 ( $97 \%$ in the $36-52 \mathrm{~nm}$ range) to $369 \mathrm{~nm}$ (91\% in the $233-526 \mathrm{~nm}$ range). The mean hydrodynamic diameter of the M-chiromer increased from $66 \mathrm{~nm}$ (92\% in the 36-103 $\mathrm{nm}$ range) to $429 \mathrm{~nm}$ ( $88 \%$ in the $165-837 \mathrm{~nm}$ range). These results are in agreement with the SEM studies (Figure S11). 

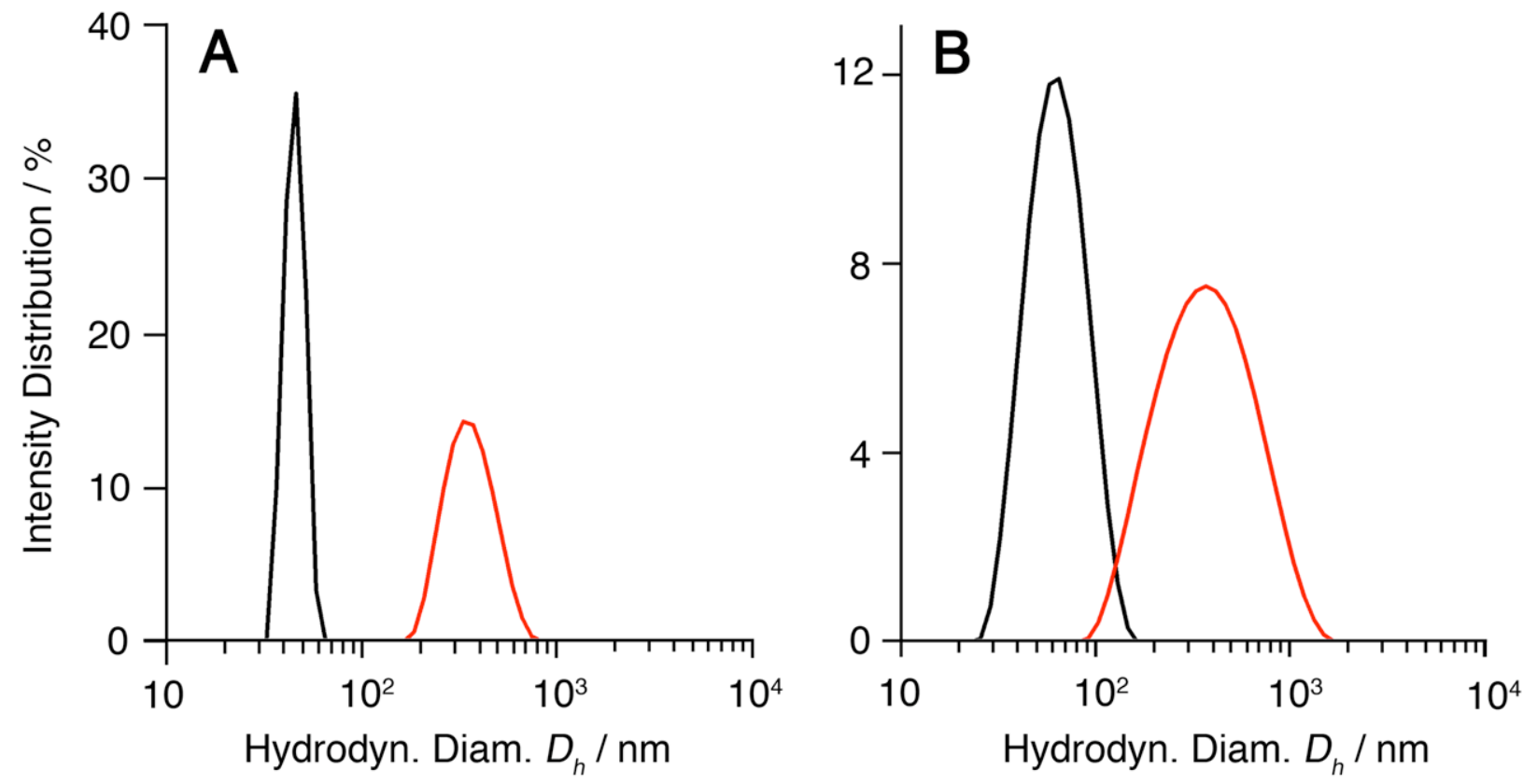

Figure S15. Dynamic light scattering (DLS) regularization diagram showing the hydrodynamic diameter $\left(D_{h}\right)$ versus scattering intensity of the $\mathrm{W}$-chiromer (A) and M-chiromer (B), without heating (black plots) and after refluxing for $3 \mathrm{~s}$ (red plots). 


\section{J. Chiral memory experiments}
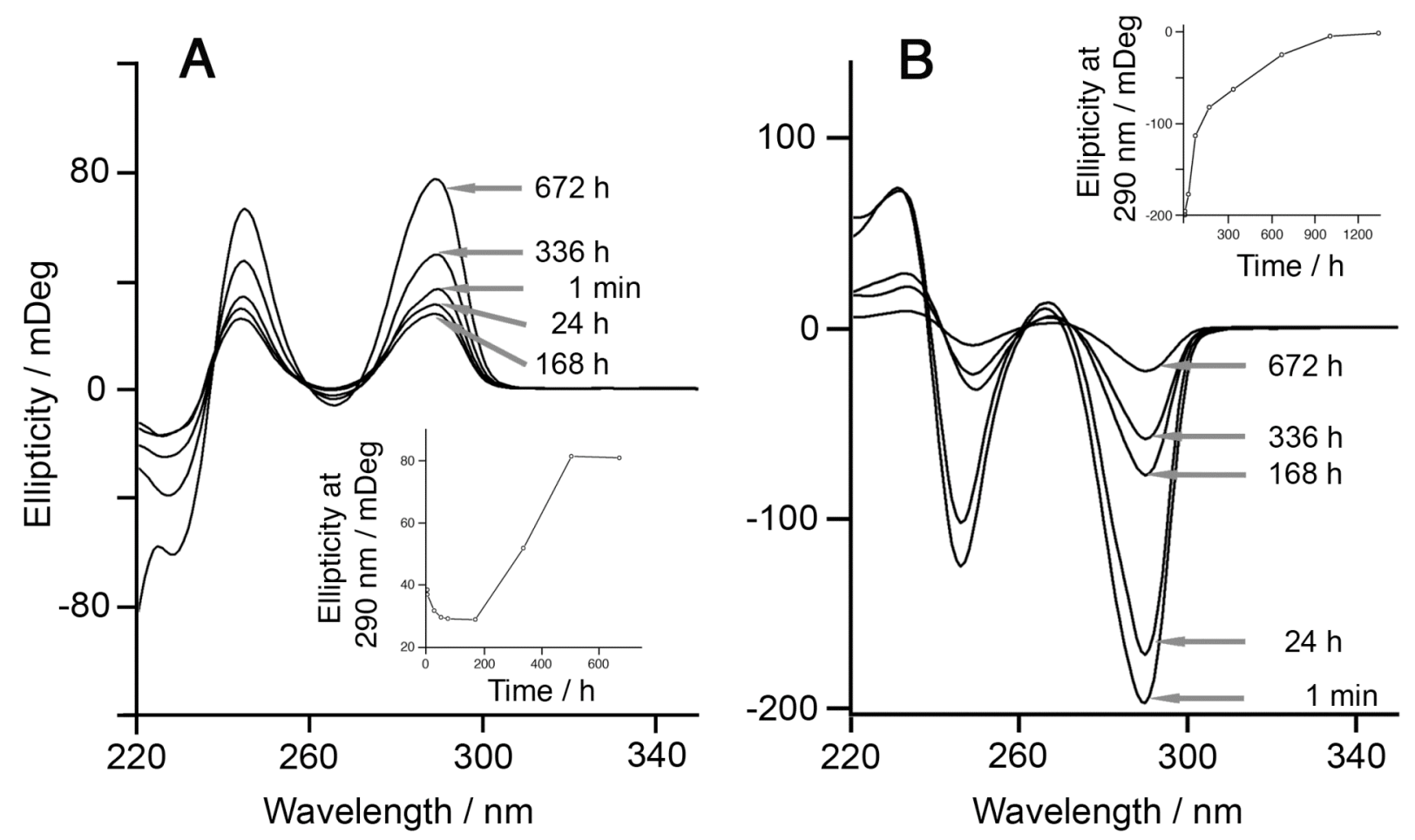

Figure S16. CD studies showing the ability of the $\mathrm{W}$-chiromer (A) and $\mathrm{M}$-chiromer (B) to memorize their SC. Compound $3\left(1.3 \times 10^{-3} \mathrm{M}, 1 \mathrm{mg} / \mathrm{mL}\right)$ was dissolved in water and methanol and aged for $672 \mathrm{~h}$ at $20^{\circ} \mathrm{C}$. The CD profile was monitored by diluting aliquots $(62.5 \mu \mathrm{L})$ of each solution in the solvent that induces the opposite chirality $\left(1937.5 \mu \mathrm{L}, 97 \% \mathrm{v} / \mathrm{v},[3]_{\text {final }}=4.0 \times 10^{-5}\right.$ M) after 1 minute, 24, 168, 336, and $672 \mathrm{~h}$. Insets in both graphs show the evolution of the ellipticity at $290 \mathrm{~nm}$ as a function of time. 


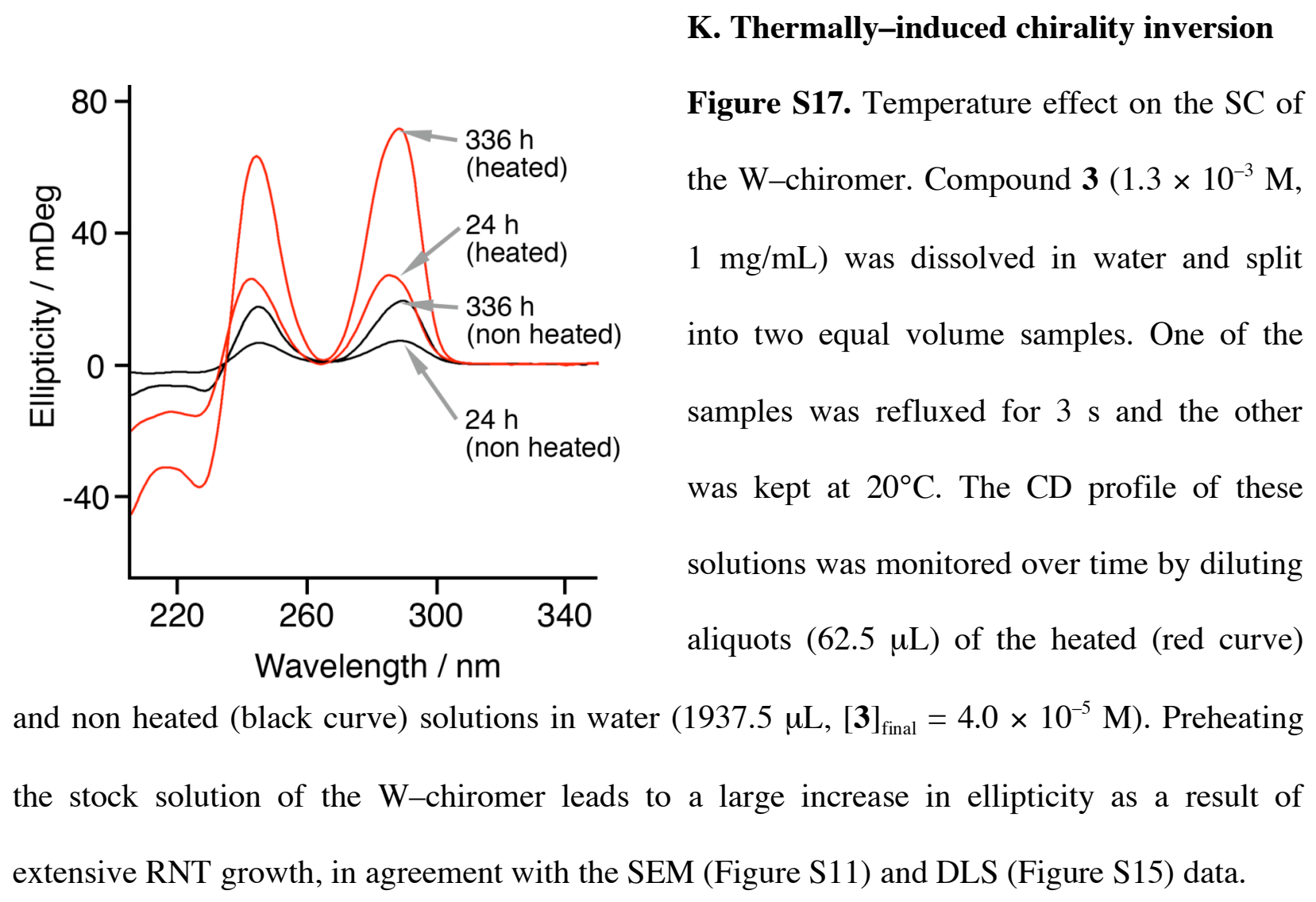



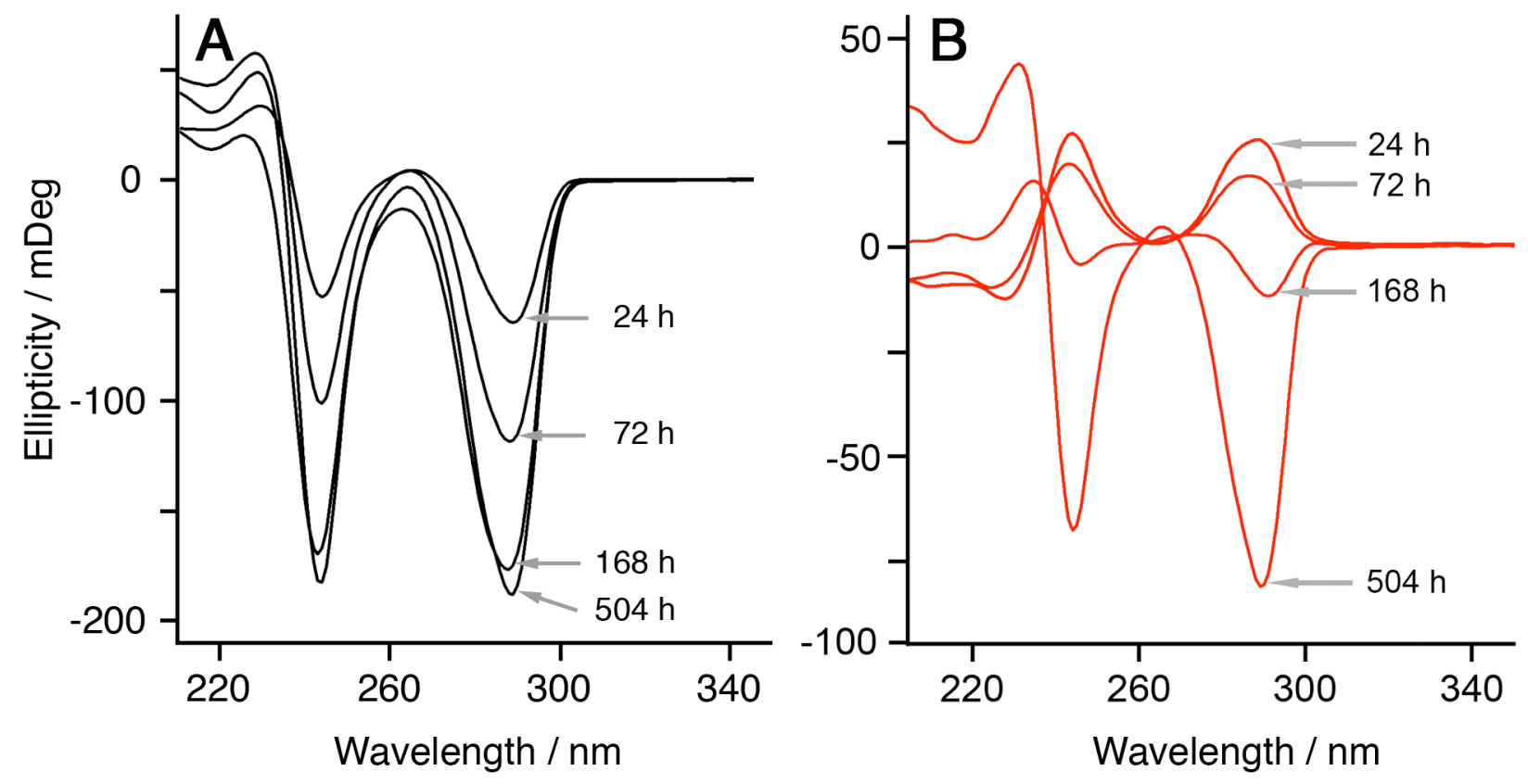

Figure S18. Thermally-induced SC inversion of the M-chiromer. Compound $3\left(1.3 \times 10^{-3} \mathrm{M}, 1\right.$ $\mathrm{mg} / \mathrm{mL}$ ) was dissolved in methanol and split into five equal-volume samples. The first was kept at $20^{\circ} \mathrm{C}(\mathrm{A})$ while the others were refluxed for $3 \mathrm{~s}$ after $24,72,168$, and $504 \mathrm{~h}(\mathrm{~B})$, respectively. The solutions were allowed to cool down to $20^{\circ} \mathrm{C}$ before dilution for $\mathrm{CD}$ measurements $(4.0 \times$ $\left.10^{-5} \mathrm{M}\right)$. Preheating the stock solution of the M-chiromer within $72 \mathrm{~h}$ leads to complete inversion of SC. Beyond $72 \mathrm{~h}$, the M-chiromer becomes kinetically locked. 


\section{Catalytic transfer of supramolecular conformational chirality}

The ability of the W-chiromer to catalyze the SC inversion of the M-chiromer was tested by adding catalytic amounts of $\mathrm{W}$-chiromer $(10 \mathrm{~mol} \%)$ to the M-chiromer and following the evolution of the CD profile over 14 days. As shown in Figures S19 and 5 (main text), The 10/90 mixture of W/M chiromer underwent a complete inversion of the $\mathrm{CD}$ profile, whereas the control experiment underwent an attenuation of the CD profile, in agreement with the chiral memory experiments (Figure S16B). The rate of inversion was further accelerated upon increasing the concentration of W-chiromer (Figure S20).
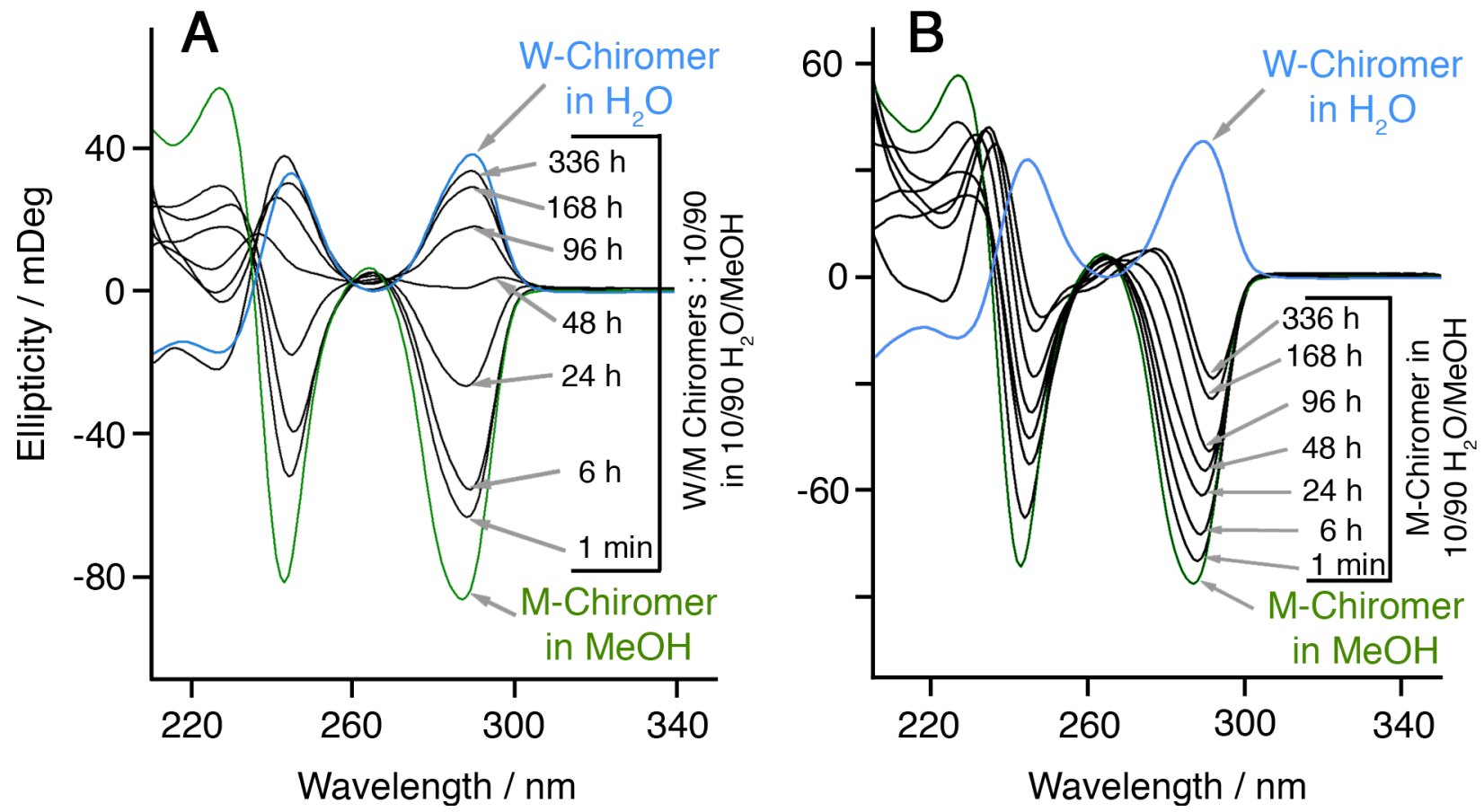

Figure S19. Chirality inversion of M-chiromer catalyzed by W-chiromer. Compound 3 (1.3 $\times$ $10^{-3} \mathrm{M}, 1 \mathrm{mg} / \mathrm{mL}$ ) was dissolved in $\mathrm{dH}_{2} \mathrm{O}$, and $\mathrm{MeOH}$ and aged for 672 and $168 \mathrm{~h}$, respectively. The W/M chiromers were then mixed in a 10/90 v/v ratio and their CD spectra were recorded over a period of $336 \mathrm{~h}$. The samples were diluted to $4.0 \times 10^{-5} \mathrm{M}$ immediately before CD measurement (A). The W-chiromer was replaced by water in the control experiment (B). 


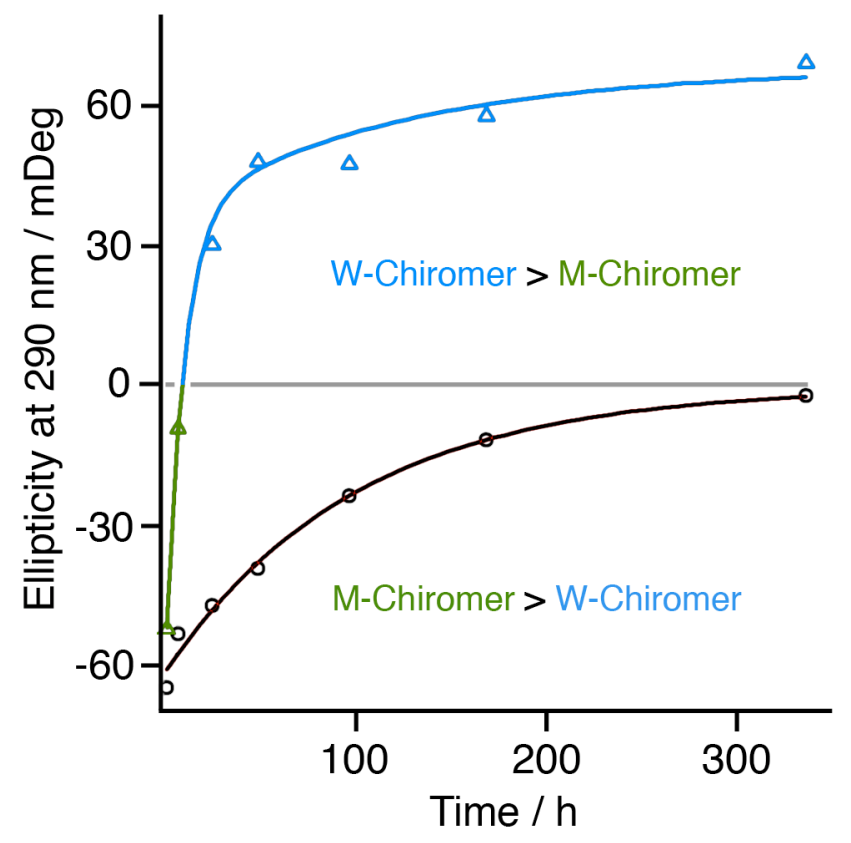

Figure S20. Chirality inversion of $\mathrm{M}-$ chiromer catalyzed by W-chiromer. Compound $3\left(1.3 \times 10^{-3} \mathrm{M}, 1 \mathrm{mg} / \mathrm{mL}\right)$ was dissolved in $\mathrm{dH}_{2} \mathrm{O}$ and $\mathrm{MeOH}$ and aged for 672 and $168 \mathrm{~h}$, respectively, to ensure full maturity of the RNTs and maximum CD intensity. The $\mathrm{W} / \mathrm{M}$ chiromers were then mixed in a $25 / 75 \mathrm{v} / \mathrm{v}$ ratio and their $\mathrm{CD}$ spectra were recorded over a period of $336 \mathrm{~h}$ (green/blue curve). The W-chiromer was replaced with water in the control experiment (black curve). The conversion is much faster with $25 \% \mathrm{~W}$-chiromer, then it is with $10 \%$ (Figure 5, main text). 


\section{Theory and modeling}

Based on the experimental results (sections B-L), it is clear that the chiromers self-assemble into mirror image RNTs. It is also clear that the water and methanol chiromers correspond to the thermodynamic and kinetic products, respectively. To learn more about the conformational states responsible for this behavior, we performed a conformational search in both water and methanol as follows:

Step 1. Conformational search. The pendant (L-lysine) of compound 3 was assigned +1 net charge through protonation of the amino groups and deprotonation of carboxylic acid group. The motif was minimized, then 648 conformations were generated by varying dihedral angles around 6 bonds as shown in Figure S21. The lysine aminobutyl side chain was assumed to be all-trans at this stage, but was optimized in Step 3.

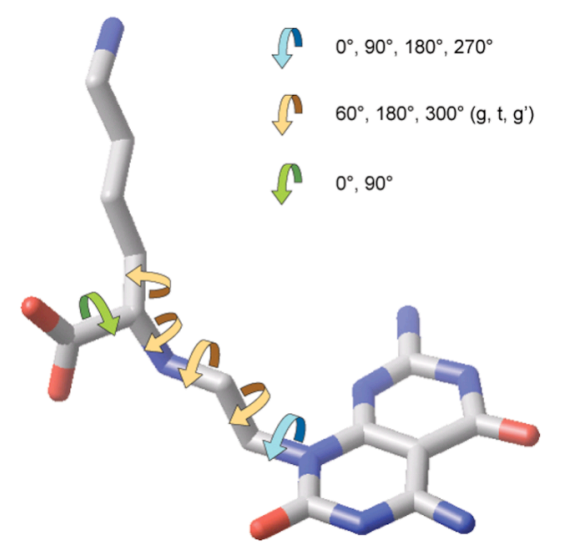

Figure S21. Conformers of compound 3 generated by varying the dihedral angles around 6 bonds as indicated by the curved arrows.

Step 2. Formation of the RNTs. Each of the 648 non-optimized conformers of $\mathbf{3}$ was multiplied and arranged to form a six-fold symmetry rosette maintained by $18 \mathrm{H}$-bonds. The rosettes were then stacked in a tubular fashion with an inter-planar separation of $4.5 \AA$ and a rotation angle of $30^{\circ}$ per rosette along the main axis. This arrangement was based on previous work done on similar systems. ${ }^{1,4}$ Due to severe steric constraints, only 153 of the 648 conformers could be assembled into RNTs. 
Step 3. Energy minimization of the RNTs. Molecular models for the RNTs were generated using Macromodel 8.5. The RNT interaction models employed the OPLS-AA force field. ${ }^{5}$ The PRCG energy minimization in implicit GB/SA water was then applied to the 153 RNTs consisting each of 11 rosettes, with the top and bottom 2 rosettes as well as all the $\mathrm{G} \wedge \mathrm{C}$ bases fixed to reduce end effects. The central rosette in each of the 153 RNTs was taken to finally construct RNTs composed of $N=1-10$ rosettes.

Step 4. Solvation free energy. To obtain the structure and thermodynamics of solvation in water and methanol, we employed the three-dimensional reference interaction site model (3D-RISM) integral equation complemented with the Kovalenko-Hirata $(\mathrm{KH})$ closure approximation. ${ }^{6}$ The 3D-RISM-KH integral equation theory of molecular solvation explicitly and properly accounts for the effect of chemical specificities of the RNTs, water and methanol solvents, and counter ions, in particular the association effects on the solvation structure and thermodynamics. This theoretical method based on first principles of statistical mechanics provides a detailed microscopic insight into the organization of solution molecules both outside and inside the nanotube, and their role in nanotube formation. ${ }^{7}$

The solvation structure is given by the probability density of finding site $\alpha$ of solvent molecules at position $\mathbf{r}$ around the solute molecule, $\rho_{a} g_{\alpha}(\mathbf{r})$, which is determined by the average number density $\rho_{\alpha}$ of solvent site $\alpha$ in the solution bulk and the 3D distribution function $g_{\alpha}(\mathbf{r})$ of solvent site $\alpha$, or normalized probability density, showing site density enhancement $\left(g_{\alpha}>1\right)$ or depletion $\left(g_{\alpha}<1\right)$ relative to the average density at a distance from the solute (where $\left.g_{\alpha}=1\right)$.

The 3D-RISM integral equation is written as

$$
h_{\gamma}(\mathbf{r})=\sum_{\alpha} \int d \mathbf{r}^{\prime} c_{\alpha}\left(\mathbf{r}-\mathbf{r}^{\prime}\right) \chi_{\alpha \gamma}\left(r^{\prime}\right)
$$


where $h_{\gamma}(\mathbf{r})$ is the $3 \mathrm{D}$ total correlation function of site $\gamma$ related to the 3D distribution function by $g_{\gamma}(\mathbf{r})=h_{\gamma}(\mathbf{r})+1$, and $c_{\gamma}(\mathbf{r})$ is the $3 \mathrm{D}$ direct correlation function which has the asymptotics of the solute-solvent site interaction potential: $c_{\gamma}(\mathbf{r}) \sim-u_{\gamma}(\mathbf{r}) /\left(k_{B} T\right) ; \chi_{\alpha \gamma}(r)$ is the site-site susceptibility of pure solvent; the site indices $\alpha$ and $\gamma$ enumerate all sites on all sorts of solvent molecules. The other relation between the $3 \mathrm{D}$ total and direct correlation functions we employed to complement the 3D-RISM integral equation (1) is the 3D-KH closure

$$
\begin{aligned}
& g_{\gamma}(\mathbf{r})=\left\{\begin{array}{lll}
\exp \left(d_{\gamma}(\mathbf{r})\right) & \text { for } & d_{\gamma}(\mathbf{r}) \leq 0 \\
1+d_{\gamma}(\mathbf{r}) & \text { for } & d_{\gamma}(\mathbf{r})>0
\end{array}\right. \\
& d_{\gamma}(\mathbf{r})=-\frac{u_{\gamma}(\mathbf{r})}{k_{B} T}+h_{\gamma}(\mathbf{r})-c_{\gamma}(\mathbf{r}),
\end{aligned}
$$

where $u_{\gamma}(\mathbf{r})$ is the $3 \mathrm{D}$ intermolecular interaction potential between the whole solute and solvent site $\gamma$ specified by the molecular force field, and $k_{B} T$ is the Boltzmann constant times the temperature of the solution.

The site-site susceptibility of solvent breaks up into the intra- and intermolecular terms,

$$
\chi_{\alpha \gamma}(r)=\omega_{\alpha \gamma}(r)+\rho_{\alpha} h_{\alpha \gamma}(r)
$$

where the intramolecular correlation function, or intramolecular matrix $\omega_{\alpha \gamma}(r)=\delta_{\alpha \gamma}+\left(1-\delta_{\alpha \gamma}\right) \delta(r-$ $\left.l_{\alpha \gamma}\right) /\left(4 \pi l_{\alpha \gamma}{ }^{2}\right)$ represents the geometry of solvent molecules with the site-site separations $l_{\alpha \gamma}$ specified by the molecular force field, and $h_{\alpha \gamma}(r)$ is the radial total correlation function between sites $\alpha$ and $\gamma$ in pure solvent. In advance of the 3D-RISM-KH calculation, the site-site correlation functions $h_{\alpha \gamma}(r)$ of pure solvent are obtained from the dielectrically consistent RISM theory $^{8}$ coupled with the KH closure (DRISM-KH), applied to the bulk solution with counter ions at infinite dilution. The bulk solvent susceptibility (3) is then input into the 3D-RISM 
integral equation (1) and the convolution is calculated by the 3D fast Fourier transform technique. The long range electrostatic asymptotics of all the correlation functions in equations (1)-(3) is separated out and treated analytically. ${ }^{6}$

The solvation free energy of the solute supramolecule in multicomponent solvent obtained from the 3D-RISM-KH integral equations (1) and (2) is given by the closed analytical expression

$$
\mu_{\mathrm{solv}}=k_{B} T \sum_{\gamma} \rho_{\gamma} \int d \mathbf{r}\left[\frac{1}{2} h_{\gamma}^{2}(\mathbf{r}) \Theta\left(-h_{\gamma}(\mathbf{r})\right)-c_{\gamma}(\mathbf{r})-\frac{1}{2} h_{\gamma}(\mathbf{r}) c_{\gamma}(\mathbf{r})\right]
$$

where the site index $\gamma$ enumerates all sites on all sorts of solvent species, and $\Theta(x)$ is the Heaviside step function,

$$
\Theta(x)=\left\{\begin{array}{lll}
1 & \text { for } & x \geq 0 \\
0 & \text { for } & x<0
\end{array}\right.
$$

The 3D-RISM-KH equations (1) and (2) are solved for solvent with counter ions at infinite dilution, which in particular gives the potential of mean force between the supramolecule and counter ions with account of both the dielectric screening by solvent and the short-range features of the solvation structure. The density of counter ions $\rho_{-}$to be inserted in Equation (3) is determined from the electroneutrality condition for counter ions with charge $q_{-}$surrounding the nanotube with total charge $Q_{T}$,

$$
Q_{T}+q_{-} \rho_{-} \int_{\text {cell }} d \mathbf{r} g_{-}(\mathbf{r})=0
$$

The 3D-RISM-KH theory was applied to the 153 RNTs composed of $N$ rosettes $(N=1-$ 10) in water or methanol, and in the presence of $\mathrm{Cl}^{-}$counter ions. The free energy of a given 
RNT conformer was obtained as a sum of the internal energy and the solvation free energy $\mu_{\text {solv }}$ given by Equation (3). Figures S22-S29 present the free energy trajectories, relative to the most stable RNT at $N=1$ (RNT\#163). Three stable W-chiromers (\#2, \#163, \#515) and 4 stable Mchiromers (\#1, \#2,\#163, \#515) were identified (Table S1 and Figure 5).

Table S1. Most stable chiromers identified

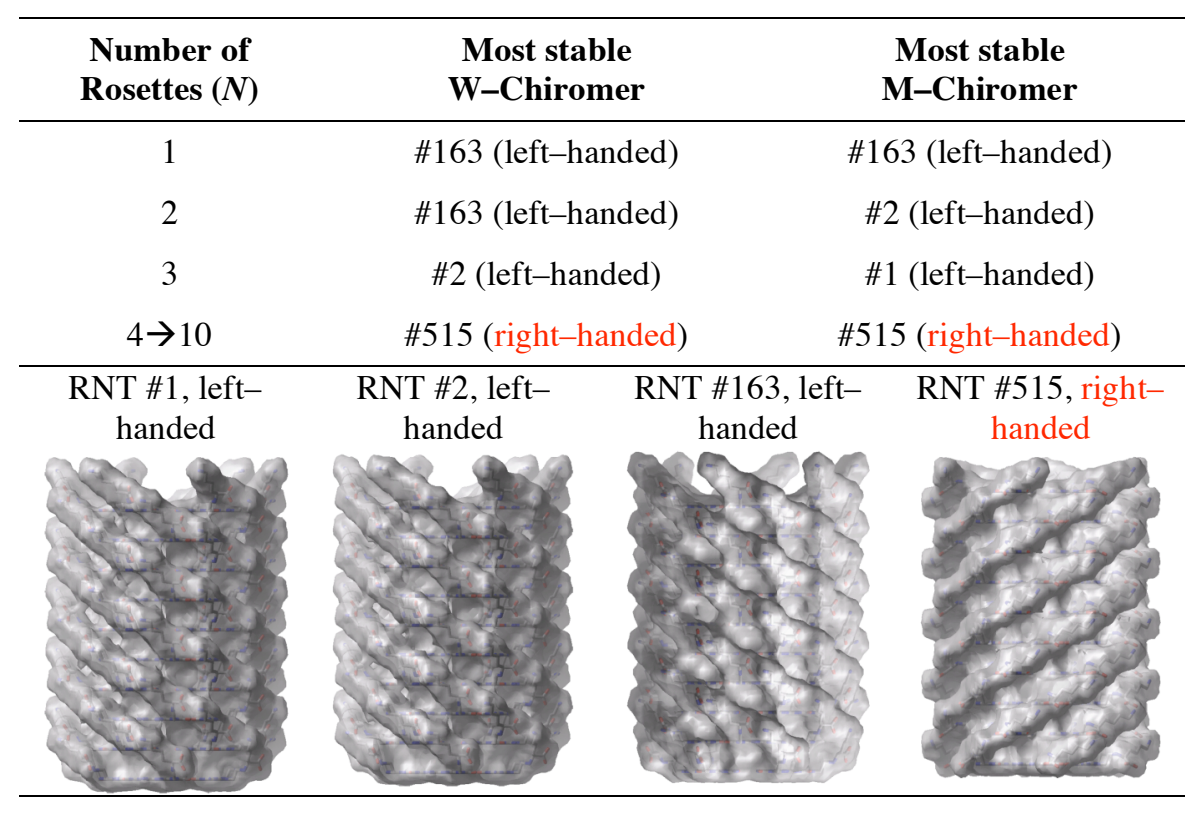
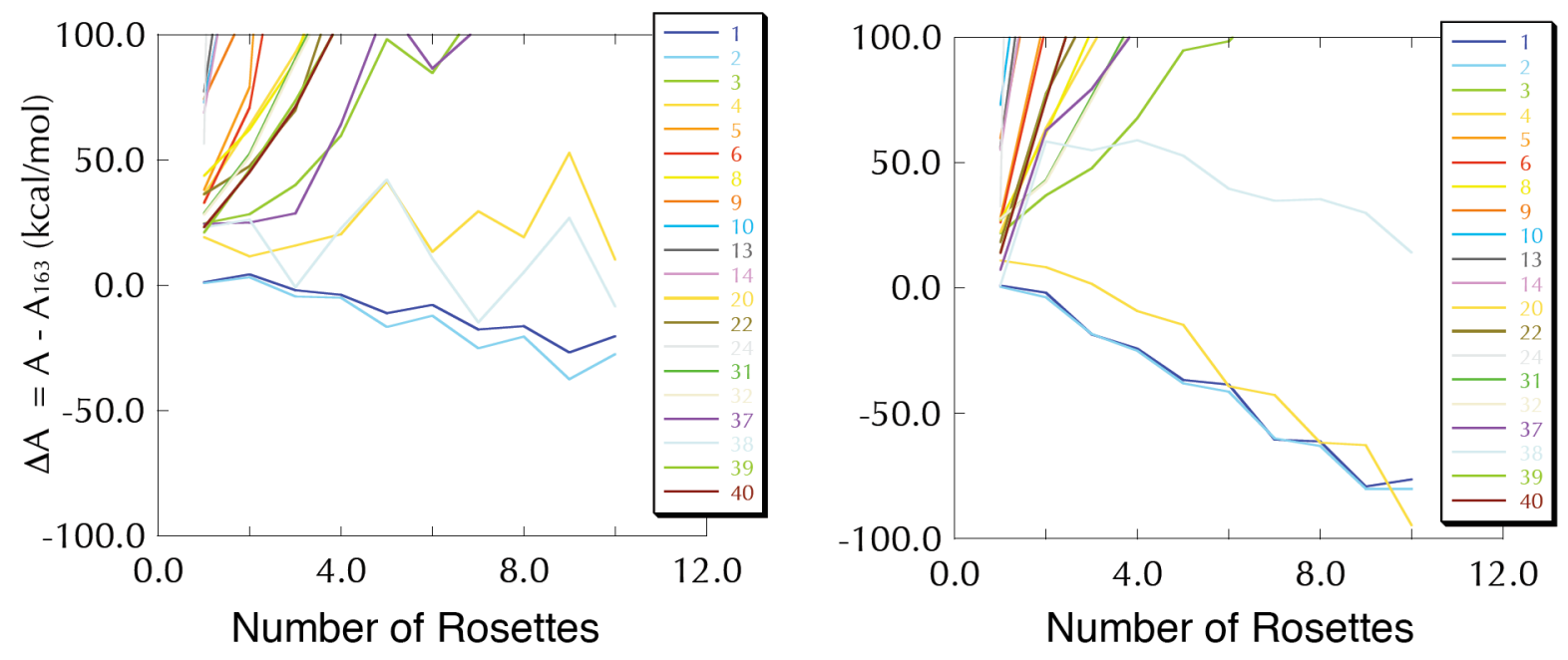

Figure S22. Free energy trajectories of RNTs 1-40 relative to RNT \#163 in water (left) and methanol (right). 

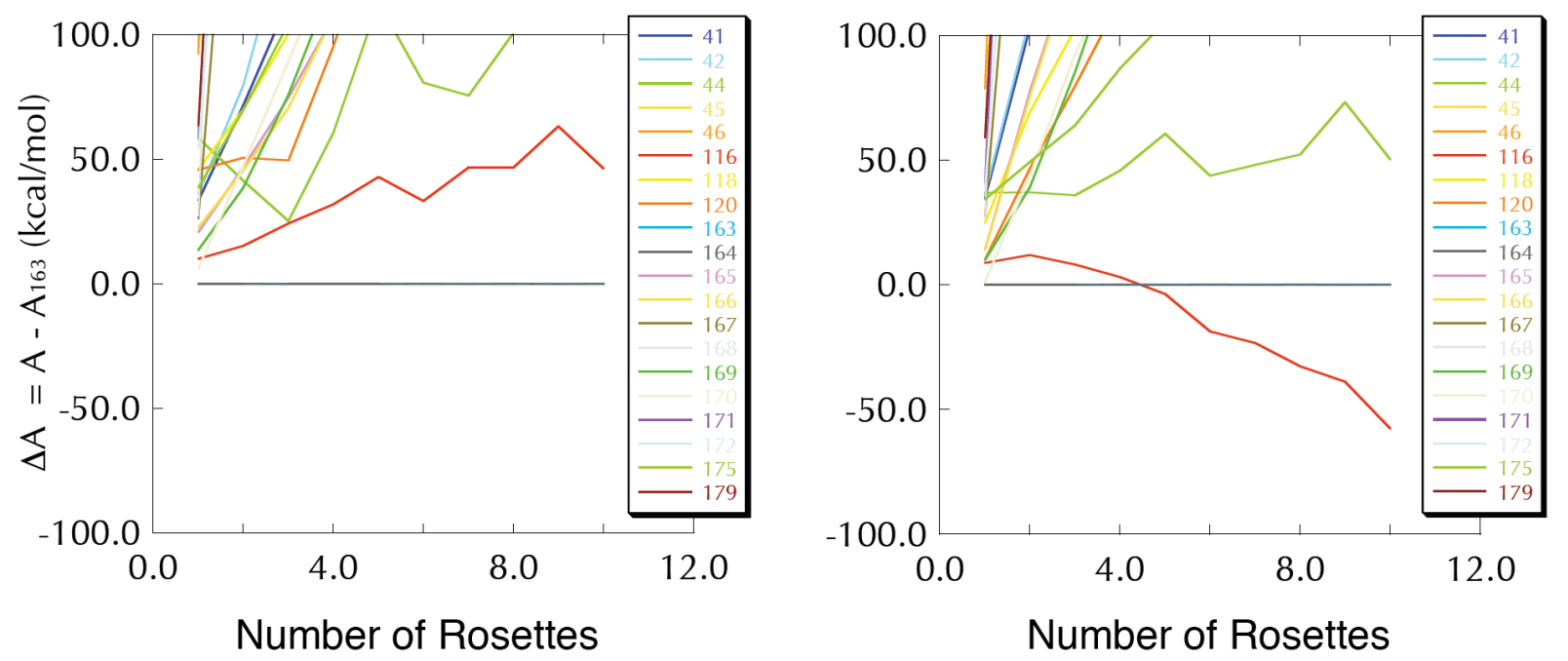

Figure S23. Free energy trajectories of RNTs 41-179 relative to RNT \#163 in water (left) and methanol (right).
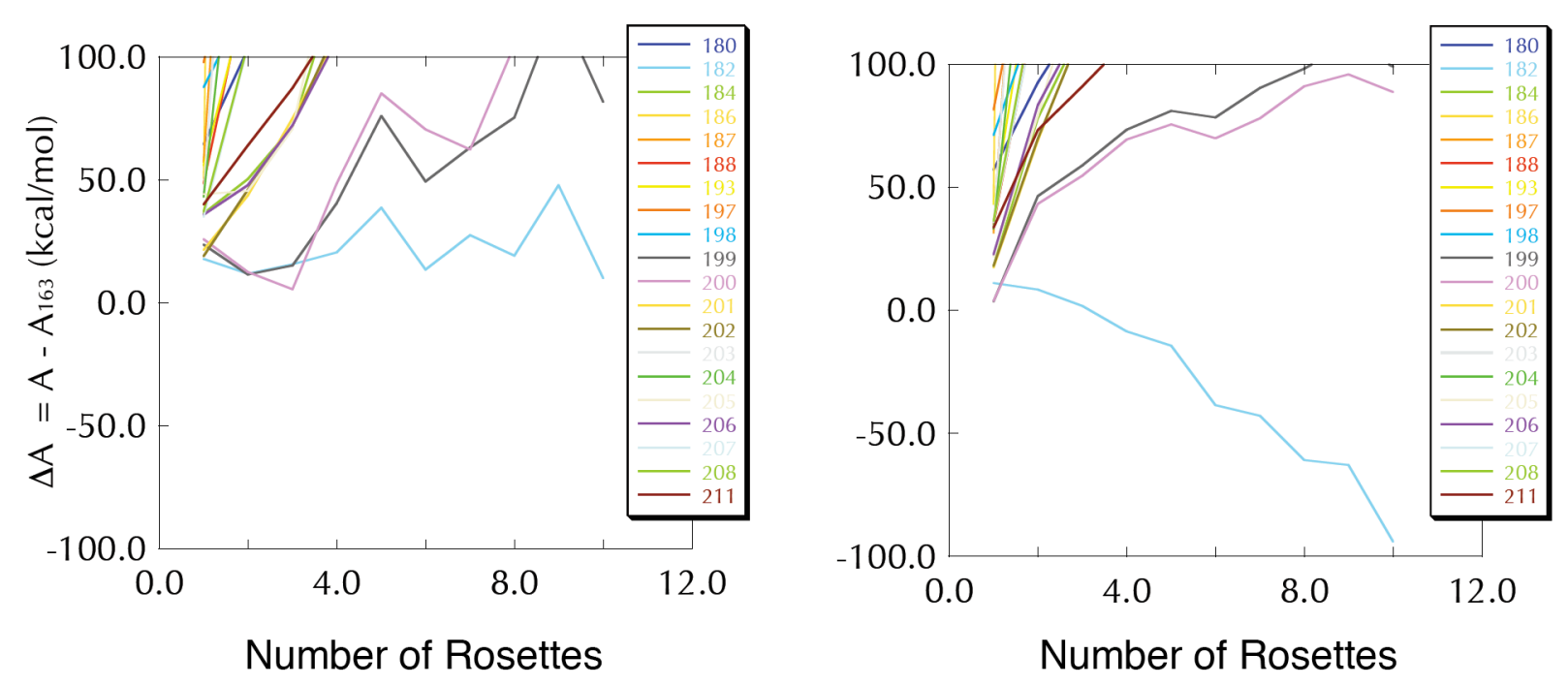

Figure S24. Free energy trajectories of RNTs 180-211 relative to RNT \#163 in water (left) and methanol (right). 

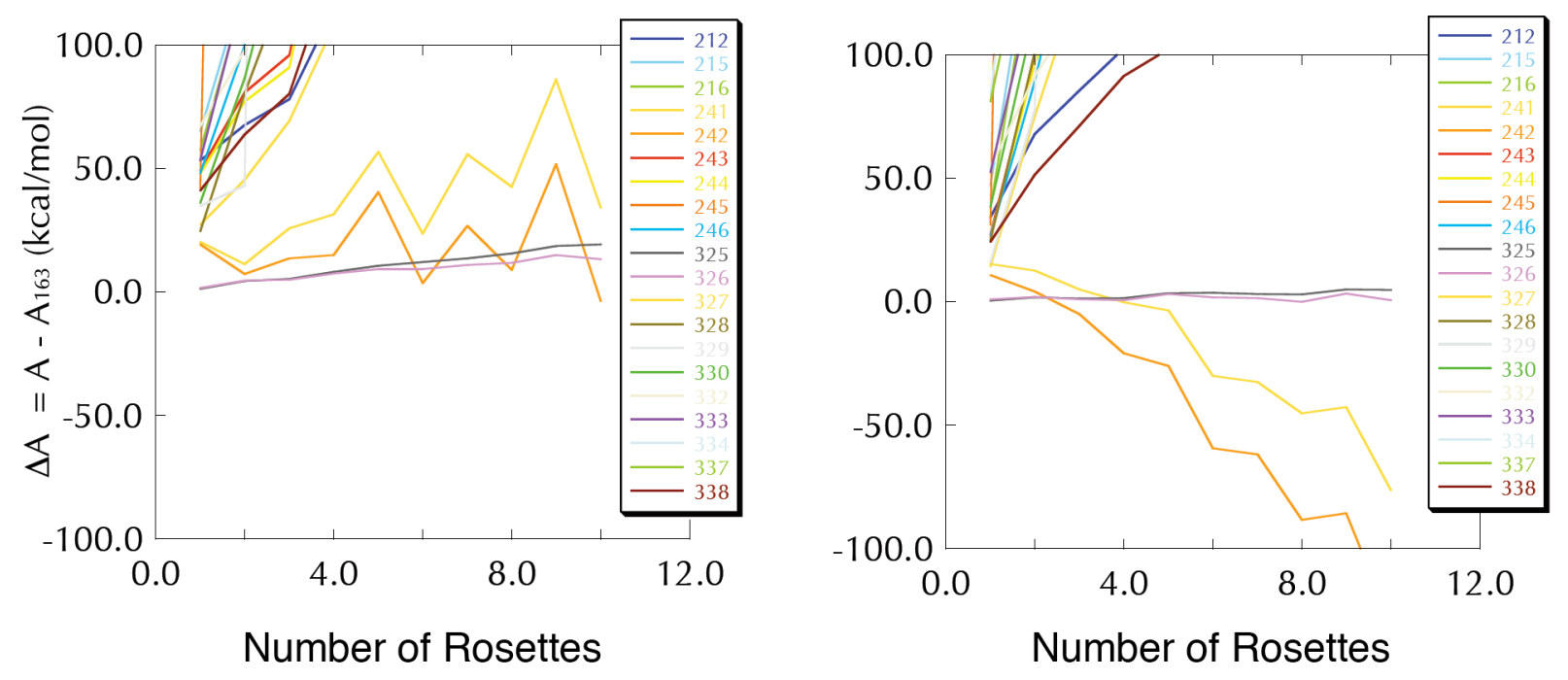

Figure S25. Free energy trajectories of RNTs 212-338 relative to RNT \#163 in water (left) and methanol (right).
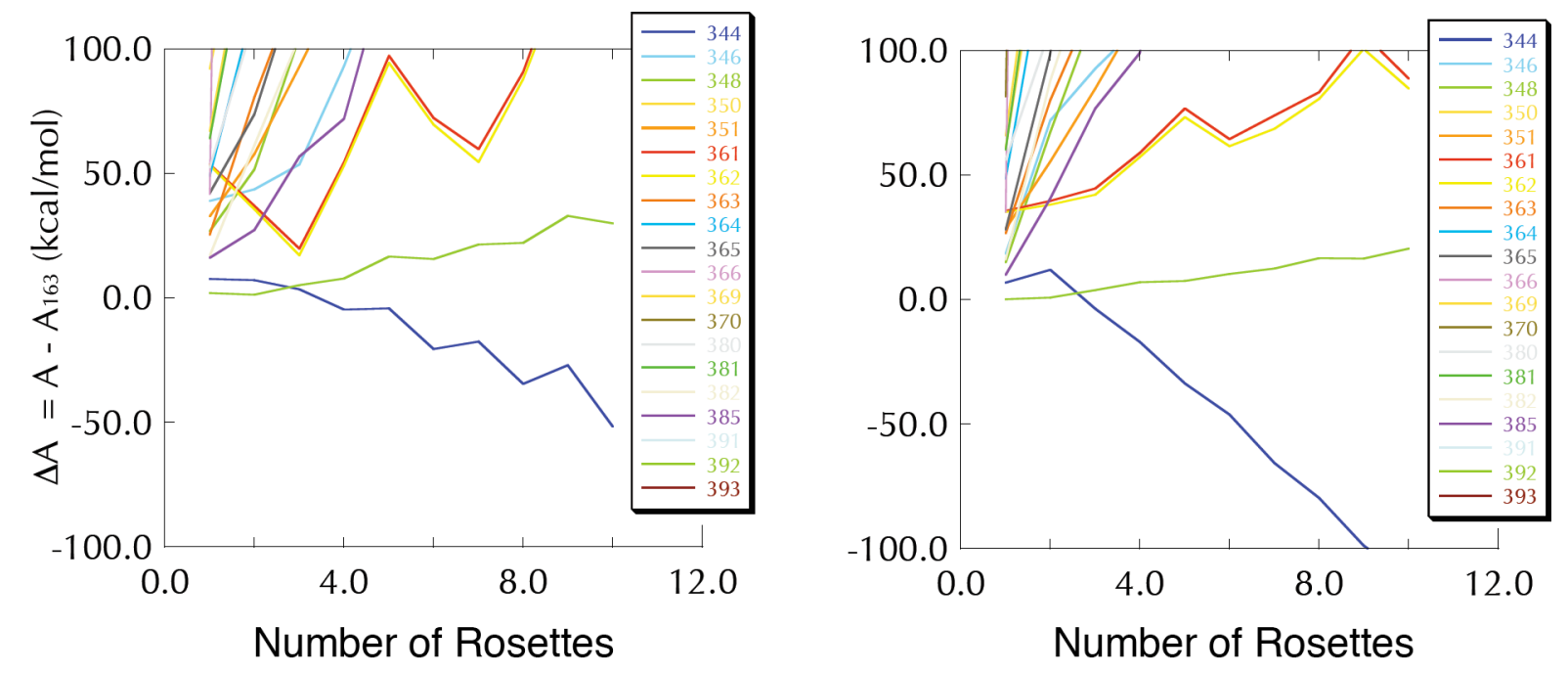

Figure S26. Free energy trajectories of RNTs 344-393 relative to RNT \#163 in water (left) and methanol (right). 

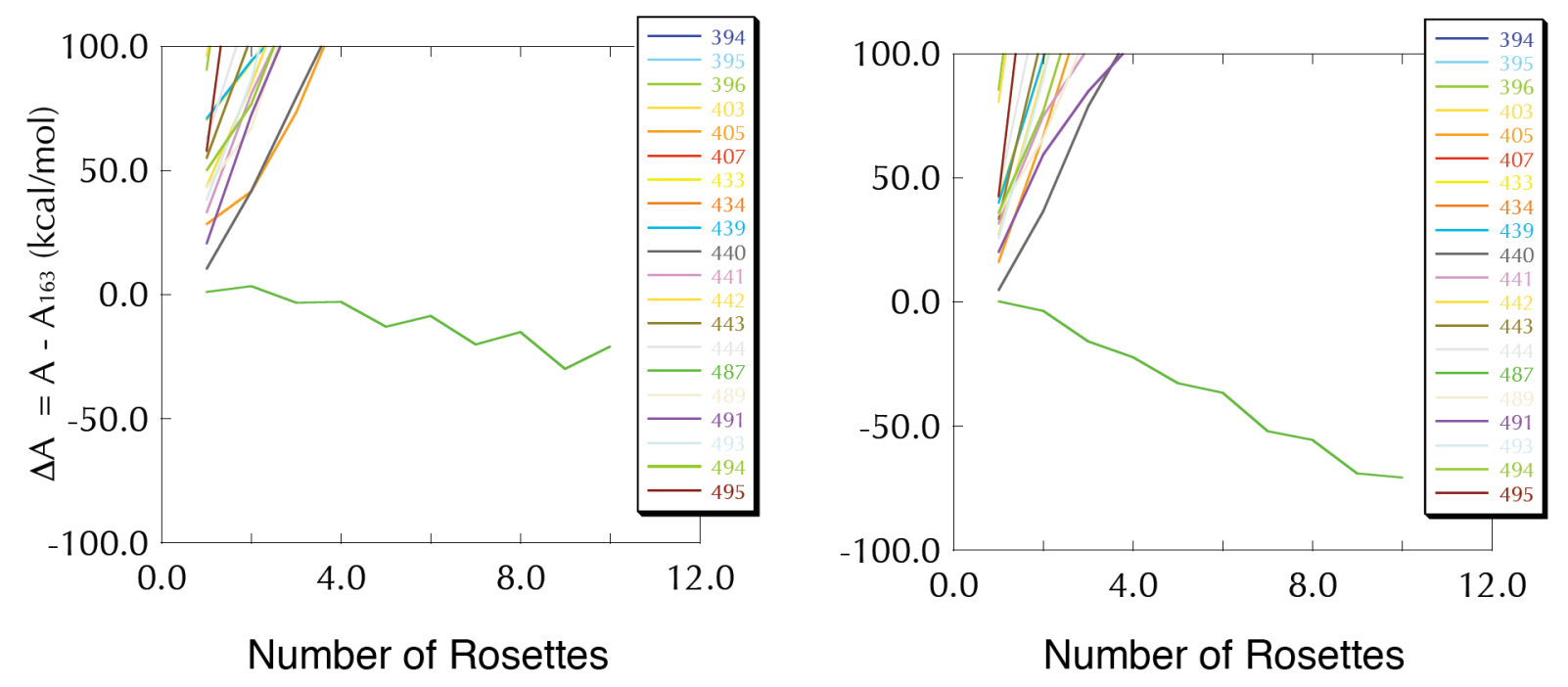

Figure S27. Free energy trajectories of RNTs 394-495 relative to RNT \#163 in water (left) and methanol (right).
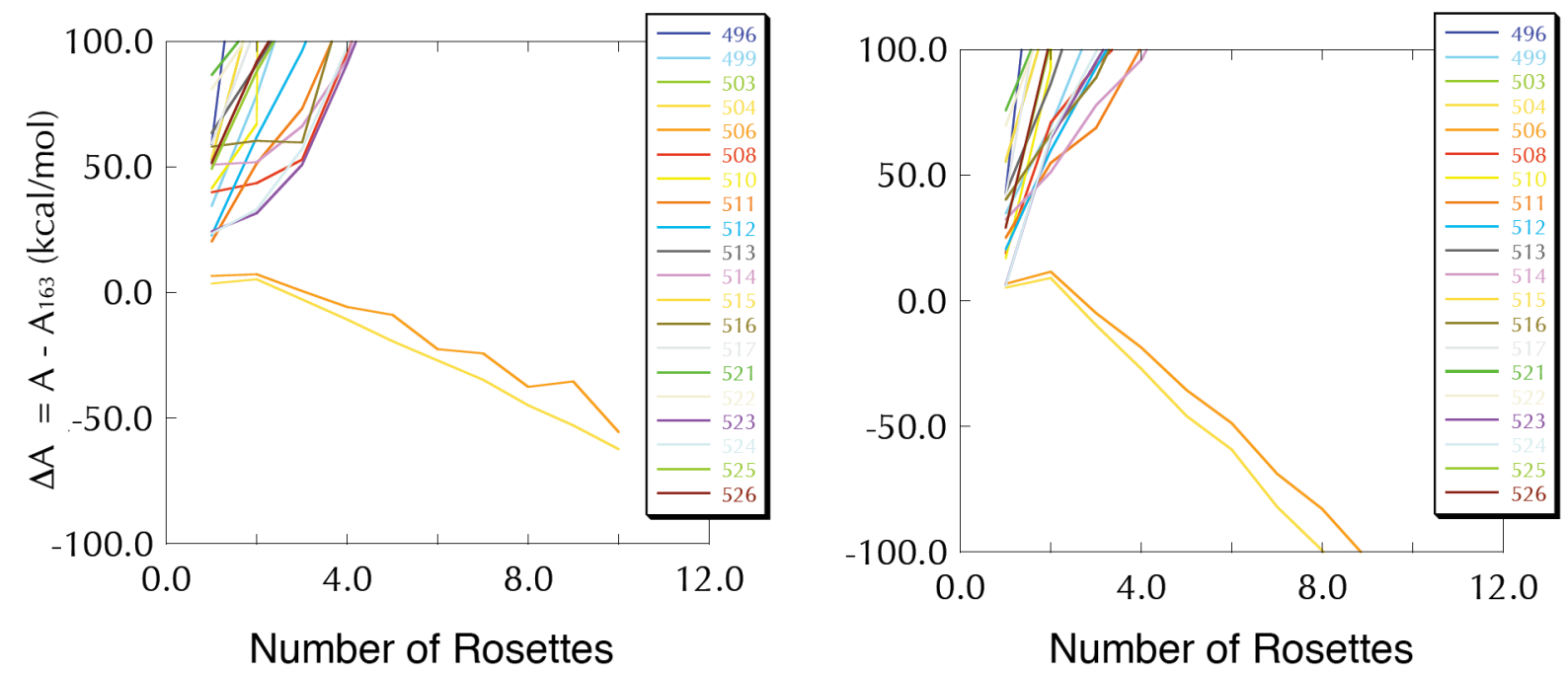

Figure S28. Free energy trajectories of RNTs 496-526 relative to RNT \#163 in water (left) and methanol (right). 

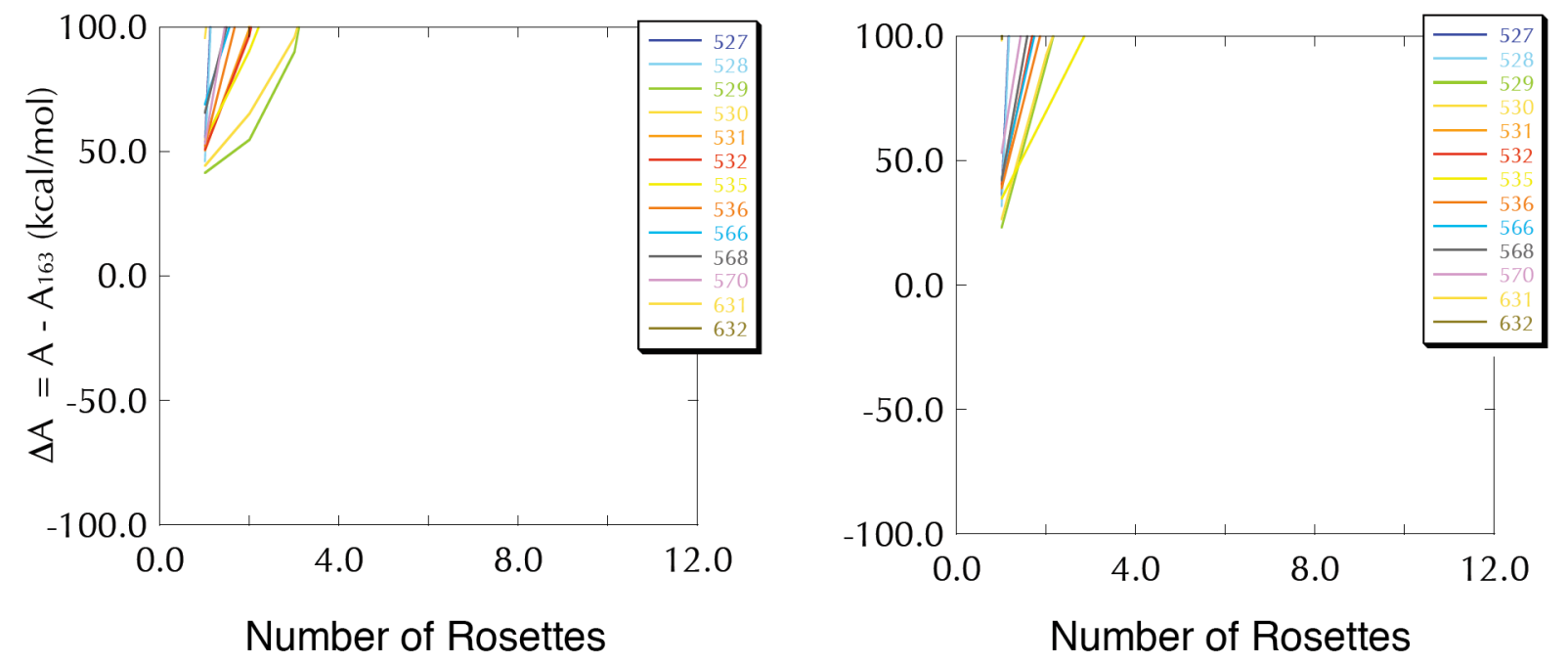

Figure S29. Free energy trajectories of RNTs 527-632 relative to RNT \#163 in water (left) and methanol (right).

W-Chiromer

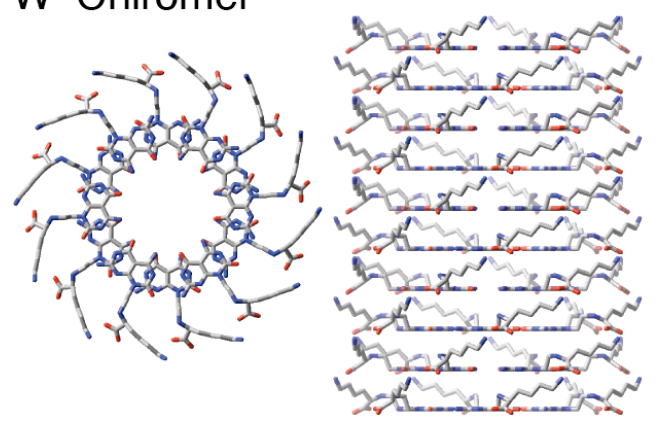

M-Chiromer

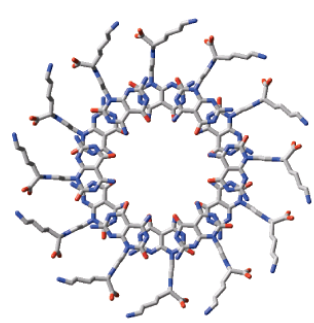

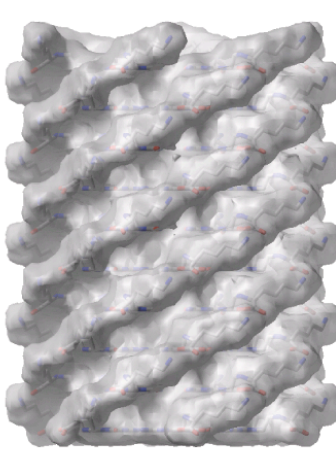

Figure S30. Top view (left), side view (middle) and molecular surface (right) of right-handed Wchiromer (RNT\#515) and lefthanded M-chiromer (RNT\#2), composed of 10 rosettes. 


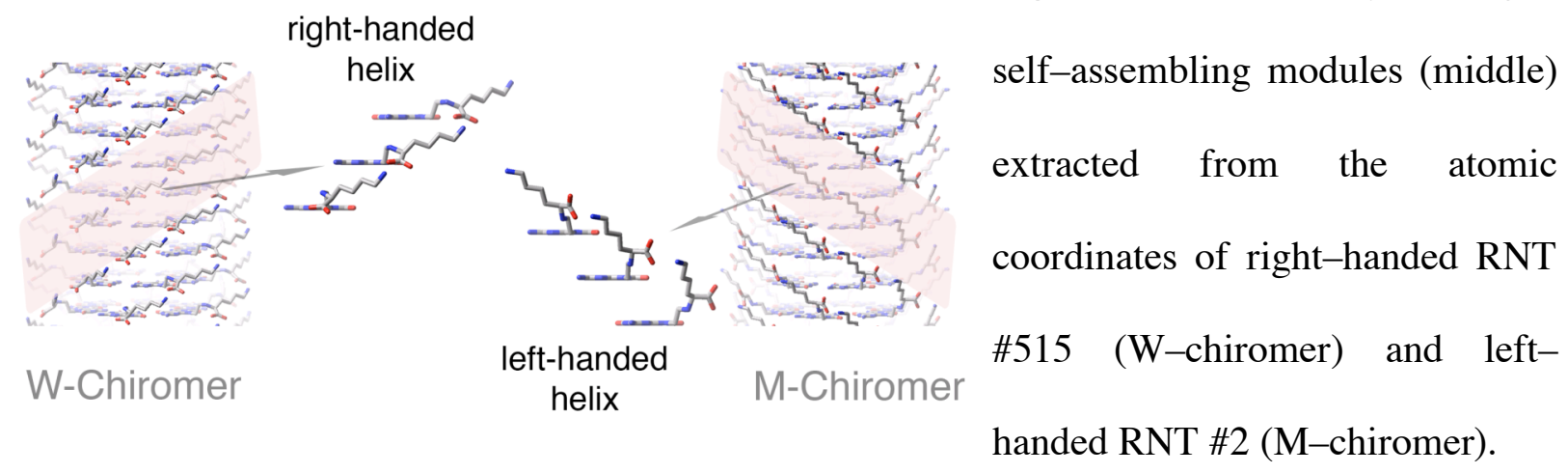

To further substantiate this hypothesis we have also carried out electronic structure calculations to obtain theoretical CD spectra for helically arranged motifs derived from stable RNT \#515 (W-chiromer) and \#2 (M-chiromer) as shown in Figure S31. DFT calculations were done using Gaussian03 at the B3LYP/6-31g(d,p) level of theory and PCM continuum solvent model. ${ }^{9}$ The lowest 10,30 , and 90 excited states were obtained for 1, 2, and 3 motifs, respectively. The rotational strengths for each exited states were obtained. The theoretical CD spectrum is obtained based on the relation

$$
R_{0 \lambda}=22.97 \int_{\text {band } \lambda} \frac{\Delta \varepsilon(E)}{E} d E
$$

where $\mathrm{R}_{0 \lambda}$ is the rotational strength associated with band $\lambda$ and $\Delta \varepsilon=\varepsilon_{L}-\varepsilon_{R}$ is the difference in the absorption coefficients for left-hand and right-hand circularly polarized light. Theoretical CD spectra were generated with the sum of normalized Gaussian functions centered at the excitation energies $\Delta E_{\lambda}$ with the band-width (full-width at half-maximum), $0.08\left(\Delta E_{\lambda}\right)^{-1 / 2}$, was employed. ${ }^{10}$ As shown in Figure S32, theoretical CD spectra show that as the number of motifs increases, the M- and W-chiromers assume opposite CD profiles, in agreement with experimental spectra. 

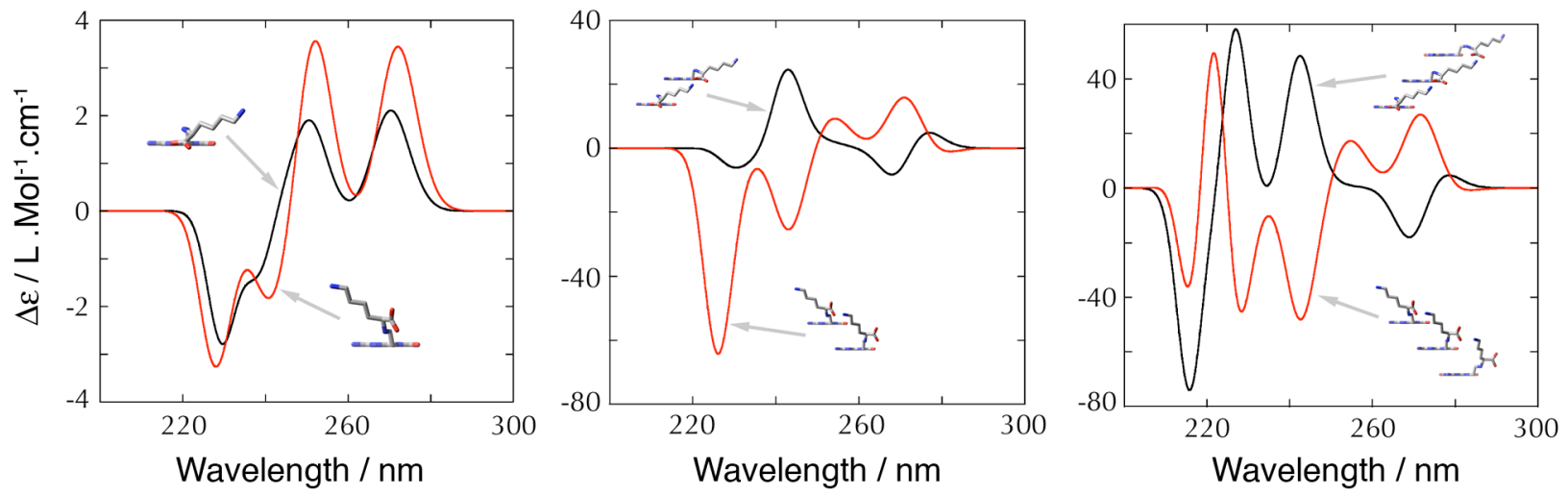

Figure S32. Calculated CD spectra of 1 (left), 2 (center), and 3 (right) motif(s) extracted from the atomic coordinates of RNT \#515 (W-chiromer, black traces) and RNT \#2 (M-chiromer, red traces). Based on these results, we anticipate that the similarity between experimental and theoretical spectra would increase with the number of helically arranged motifs.

Table S2. Supramolecular variation on Le Châtelier's targeted equilibrium shifting leading to the conversion of left-handed M-chiromer into right-handed W-chiromer.

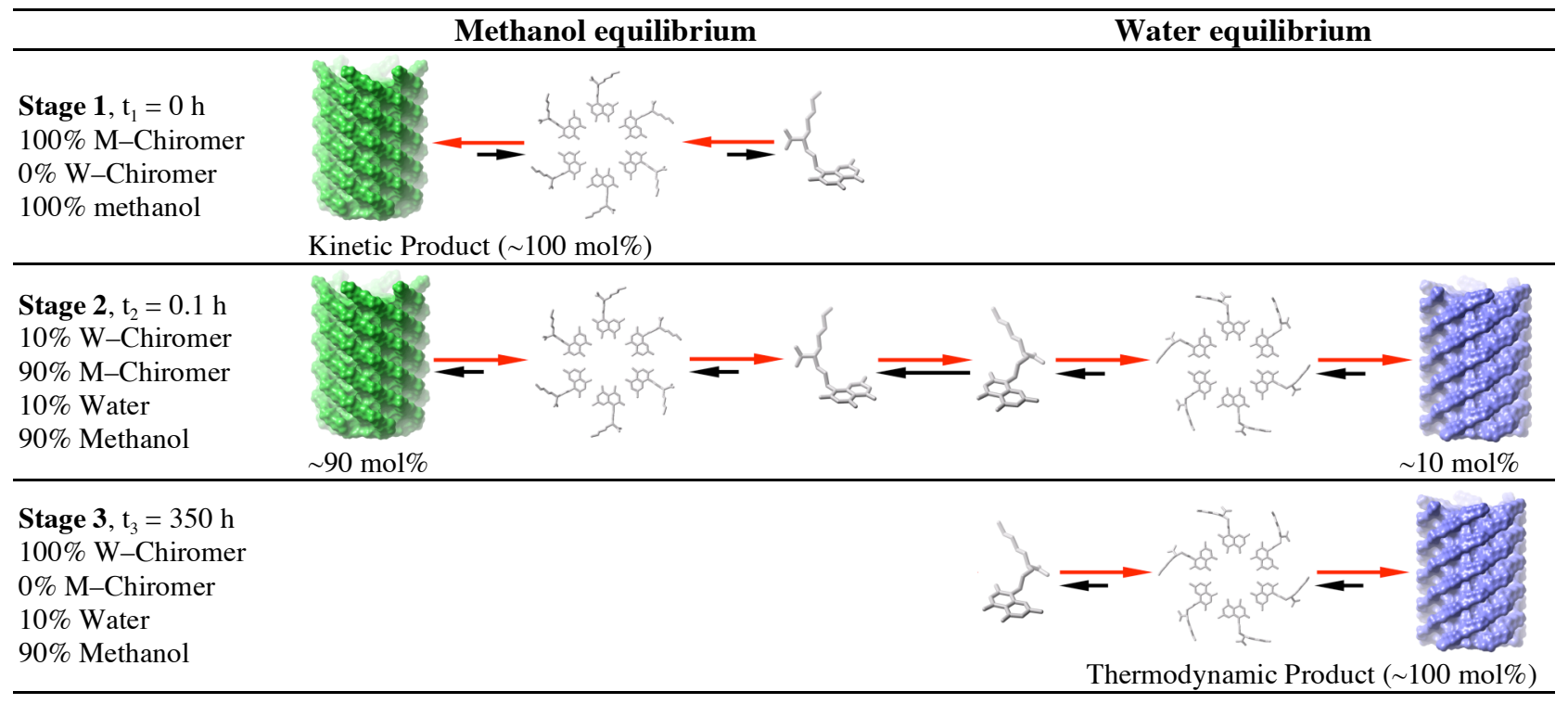




\section{N. Solvation models}

By solving the 3D-RISM-KH integral equations, the 3D distribution functions $g_{\alpha}(\mathbf{r})$ of interaction sites $\alpha$ of solvent molecules around the chiromers was obtained. To establish the role of these molecules in promoting the formation of each chiromer, solvation models with the most probable positions and orientations of solvent molecules associated to the nanotube were constructed as follows. The W-chiromer was chosen to illustrate this approach. First, positions of peak maxima of the 3D distribution functions $g_{\alpha}(\mathbf{r})$ of water oxygen within a range of $5 \AA$ of $\mathrm{NH}_{2}^{+}$(protonated lysine $\alpha$-amino group) were identified (Figure S33A). Water-solvated Wchiromer (RNT \#515) showed three high oxygen peaks $\left(g_{\mathrm{O}}(\mathbf{r})>9.0\right)$. The peak height can be correlated with the attractive potential between a solvent molecule and the nanotube in solution (potential of mean force, PMF). Thus, the hydrated nanotube attracts water molecules most strongly at these three positions (Figure S33B).
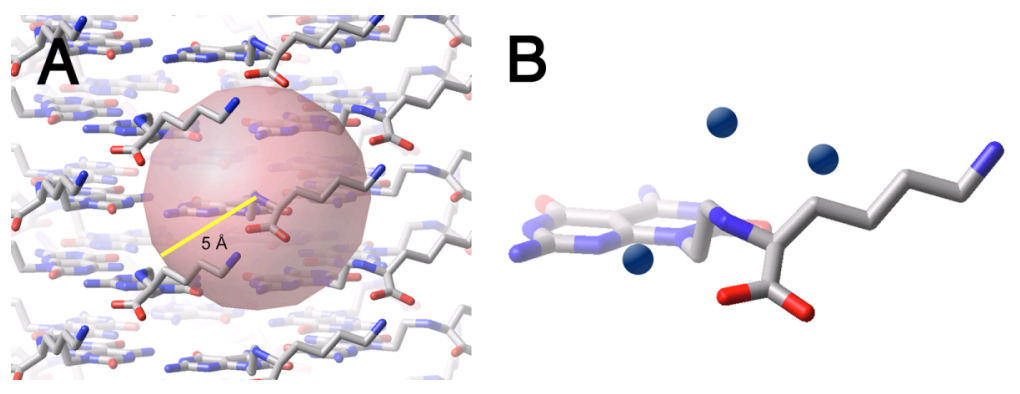

Figure S33. (A) A sphere of radius $5 \AA$ centered on the $\mathrm{NH}_{2}^{+}$site (protonated $\alpha$-amino group of lysine) of a motif in W-chiromer. This area is large enough to cover an entire motif. (B) Three positions of the water oxygen distribution peaks around a single motif in W-chiromer with $g_{\mathrm{O}}(\mathbf{r})>9.0$.

Although $g_{0}(\mathbf{r})$ peaks clearly point to sites with a high probability of finding solvent molecules, there is no trivial relationship between $g_{0}(\mathbf{r})$ peaks and the number of solvent molecules. To access this number, the 3D distribution function was averaged around each of the $g_{\mathrm{O}}(\mathbf{r})$ maxima, 
$g(r)=\frac{1}{\Omega} \int g(\mathbf{r}) d \Omega_{1}=\frac{1}{\Omega} \int g\left(r, \Omega_{1}\right) d \Omega_{1}$

where $g(\mathbf{r})=g\left(r, \Omega_{1}\right)$ is the $3 \mathrm{D}$ distribution function of separation $r$ from an orientation $\Omega_{1}$ around the peak maxima, and $\Omega$ is the normalization constant for angular integration. The resulting radial distribution function $g(r)$ was then integrated to obtain the running average number of molecules $n(r)$ in a sphere of radius $r$ around each maximum,

$n(r)=4 \pi \rho \int_{0}^{r} g\left(r^{\prime}\right) r^{\prime 2} d r^{\prime}$

where $\rho$ is the solvent number density.
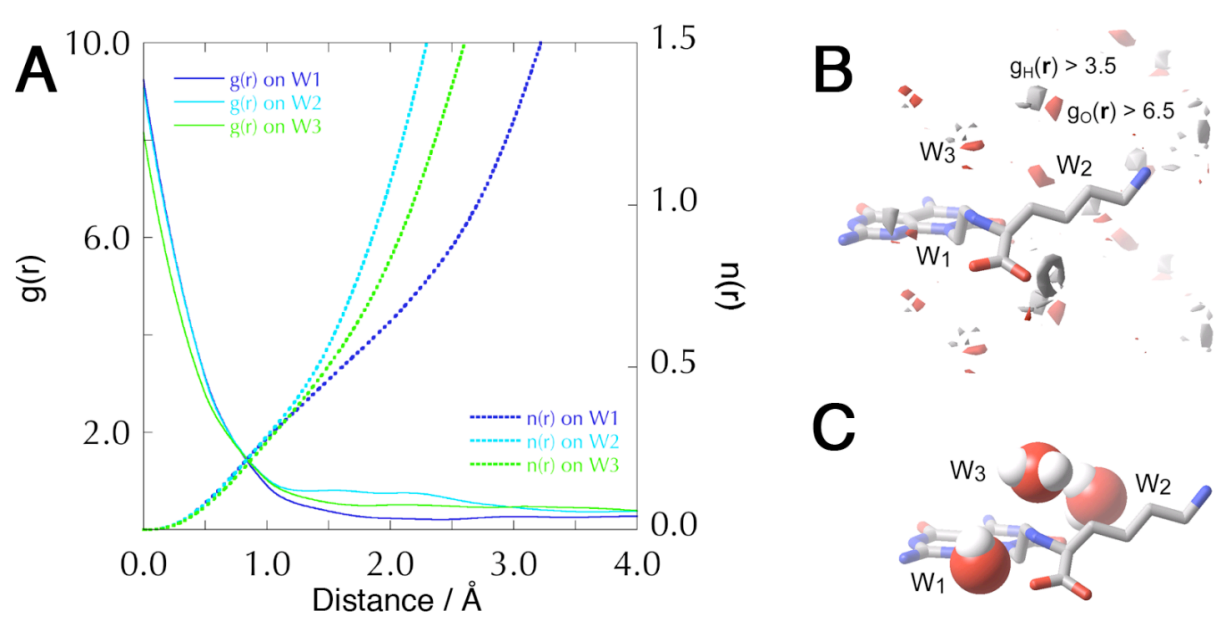

Figure S34. (A)

Radially averaged distribution functions $g(r)$ and the average number of water molecules $n(r)$ around the three

maximum positions of the 3D distribution of water around a single motif in $\mathrm{W}$-chiromer. (B) Isosurface representation of the 3D distribution functions for oxygen (red, $\left.g_{\mathrm{O}}(\mathbf{r})>6.5\right)$ and hydrogen (gray, $g_{\mathrm{H}}(\mathbf{r})>3.5$ ) atoms around one motif in $\mathrm{W}$-chiromer. (B) A highly probable hydration model constructed according to the 3D distribution functions of water around a single motif around $\mathrm{W}-$ chiromer.

For instance, Figure S34A shows the presence of a water molecule within a 2-3 A range from each of the three peak maxima identified in Figure S33B. Figure S34B,C shows the 
isosurface representation of the $3 \mathrm{D}$ distribution functions for the oxygen (red, $\left.g_{\mathrm{o}}(\mathbf{r})>6.5\right)$ and hydrogen (silver, $g_{\mathrm{H}}(\mathbf{r})>3.5$ ) atoms, and the corresponding hydration model. Applying the rosette nanotube symmetry to this hydrated motif resulted in the essential part of the first hydration shell structure for W-chiromer in water (Figure S39).

To further validate this solvation model, we applied Equations (6) and (7) to average the 3D distribution function around the nitrogen atoms of the $\mathrm{NH}_{2}^{+}$site and the exocyclic $\mathrm{NH}_{2}$ group. The radial distribution functions (RDFs) $g(r)$ and the running average number $n(r)$ of water molecules around $\mathrm{NH}_{2}^{+}$and $\mathrm{NH}_{2}$ for $\mathrm{W}$-chiromer are shown in Figures S35A and S36A, respectively. The first maximum of the $\mathrm{RDF}$ around the $\mathrm{NH}_{2}^{+}$site, at $r_{\max 1}=2.9 \AA$, corresponds to a running average number, $n\left(r_{\max 1}\right)$, of 0.6 water molecules (Figure S35A). By definition, the first maximum is centered on a water molecule of size $\sigma$ in proximity with the $\mathrm{NH}_{2}^{+}$site, and the entire water molecule is within a sphere of radius $\sim\left(r_{\max 1}+\sigma / 2\right)$. Therefore, $n\left(r_{\max 1}\right)$ corresponds to approximately half the number of water molecules in the first hydration shell. This gives an estimated average of $2 \times 0.6=1.2$ water molecules in the first hydration shell around the $\mathrm{NH}_{2}^{+}$site.

The first maximum of the $\mathrm{RDF}$ of water around $\mathrm{NH}_{2}$ nitrogen at $r_{\max 1}=2.9 \AA$ with $n\left(r_{\max 1}\right)=0.5$ leads to an estimated average of $2 \times 0.5=1$ water molecule in the first hydration shell around the $\mathrm{NH}_{2}$ group (Figure $\mathrm{S} 36 \mathrm{~A}$ ). Thus, we find one water molecule at separation $3 \AA$ from the $\mathrm{NH}_{2}^{+}$site and one water molecule at separation $3 \AA$ from the exocyclic $\mathrm{NH}_{2}$ group, in agreement with the solvation model shown in Figures S34C and S39. Similarly, we considered both W-chiromer and M-chiromer in water, in methanol, and in a 50/50 water-methanol mixture, and constructed the solvation models depicted in Figure S40. These models are in agreement with the RDFs $g(r)$ and the running average solvation numbers $n(r)$ of water and methanol around the $\mathrm{NH}_{2}^{+}$and $\mathrm{NH}_{2}$ nitrogen sites shown in Figures $\mathrm{S} 35-\mathrm{S} 38$. 

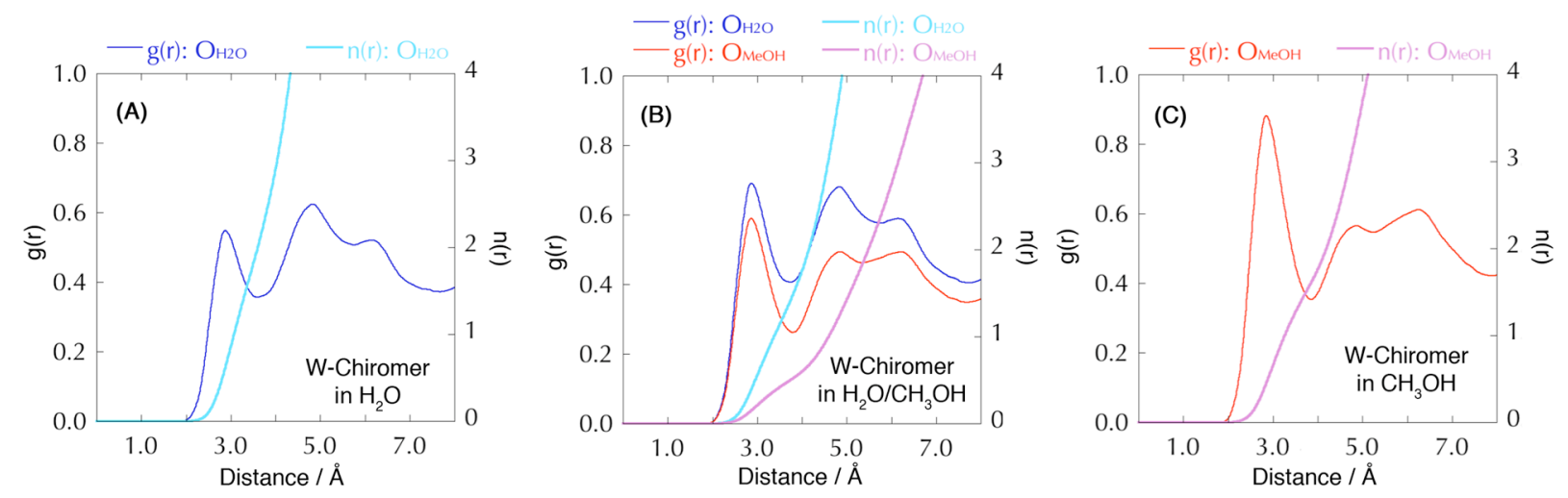

Figure S35. The radial distribution functions $g(r)$ and the running average solvation numbers $n(r)$ around the $\mathrm{NH}_{2}^{+}$site (protonated $\alpha$-amino group of lysine) of $\mathrm{W}$-chiromer solvated in water (A), in 50/50 water-methanol mixture (B) and in methanol (C). $g(r)$ and $n(r)$ of water oxygen (dark-blue and light-blue lines, respectively), and of methanol oxygen (orange and pink lines, respectively).
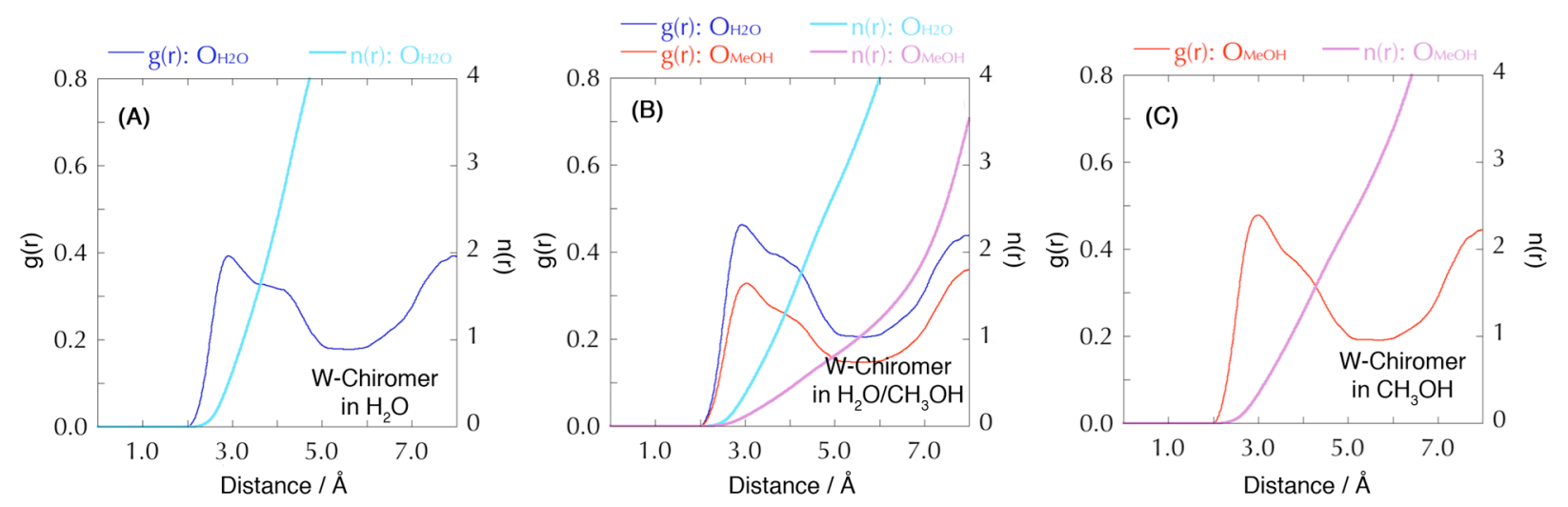

Figure S36. The radial distribution functions $\mathrm{g}(\mathrm{r})$ and the running average solvation numbers $n(r)$ around the $\mathrm{NH}_{2}$ site (exocyclic amino group) of $\mathrm{W}$-chiromer solvated in water (A), in 50/50 water-methanol mixture (B) and in methanol (C). $g(r)$ and $n(r)$ of water oxygen (dark-blue and light-blue lines, respectively), and of methanol oxygen (orange and pink lines, respectively). 

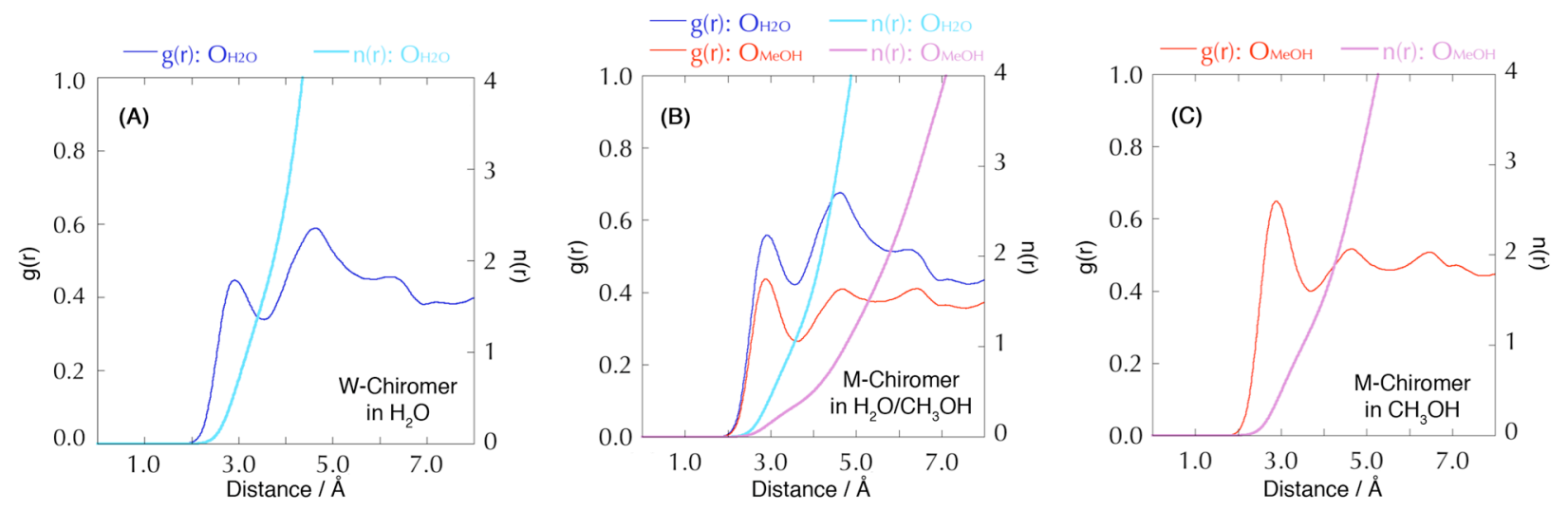

Figure S37. The radial distribution functions $g(r)$ and the running average solvation numbers $n(r)$ around the $\mathrm{NH}_{2}{ }^{+}$site (protonated $\alpha$-amino group of lysine) of $\mathrm{M}$-chiromer solvated in water (A), in 50/50 water-methanol mixture (B), and in methanol (C). $g(r)$ and $n(r)$ of water oxygen (dark-blue and light-blue lines, respectively), and of methanol oxygen (orange and pink lines, respectively).
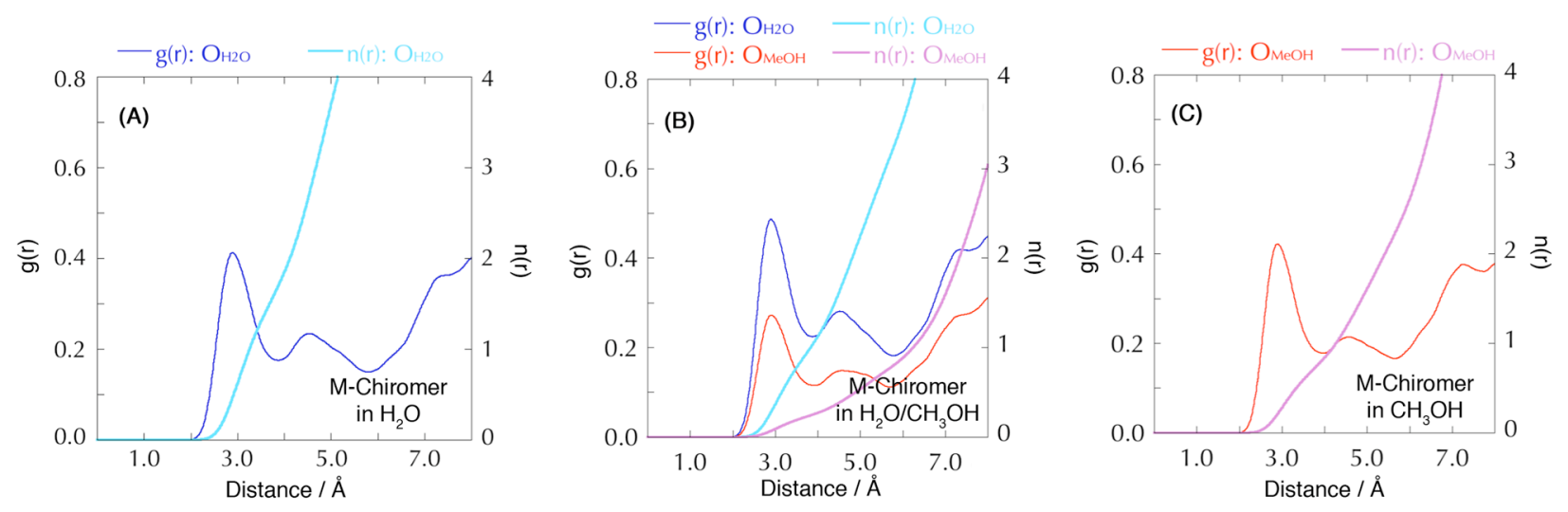

Figure S38. The radial distribution functions $\mathrm{g}(\mathrm{r})$ and the running average solvation numbers $\mathrm{n}(\mathrm{r})$ around the $\mathrm{NH}_{2}$ site (exocyclic amino group) of $\mathrm{M}$-chiromer solvated in water (A), in 50/50 water-methanol mixture (B), and in methanol (C). $g(r)$ and $n(r)$ of water oxygen (dark-blue and light-blue lines, respectively), and of methanol oxygen (orange and pink lines, respectively). 


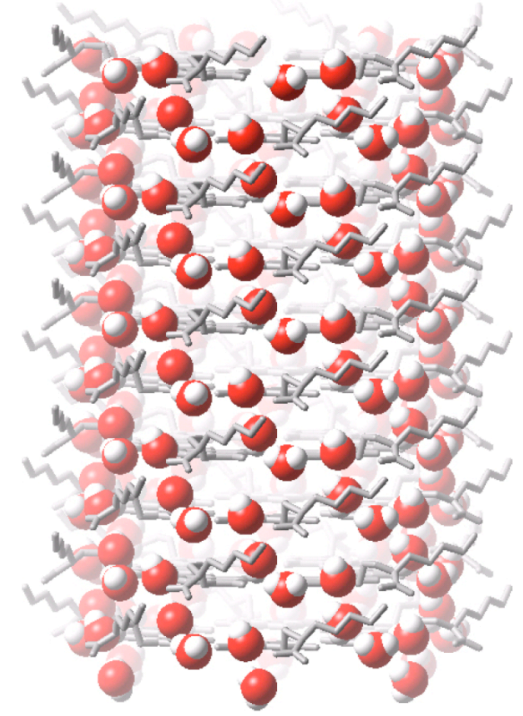

Figure S39. Hydration model for RNT \#515 (W-chiromer) with 10 rosette rings.

The 3D distribution function $g_{0}(\mathbf{r})$ peak height gives the attractive well depth of the PMF acting on the solvent molecules, or the free energy of their binding to the nanotubes in solution. To reduce numerical errors due to the $3 \mathrm{D}$ grid discreteness, we averaged the PMF well depth over the symmetric positions at each

of the motifs comprising 4 middle rosettes of a 10-rosette RNT. Table 1 (main text) shows the PMFs for the unique water and methanol solvent molecules identified in Figure S40.
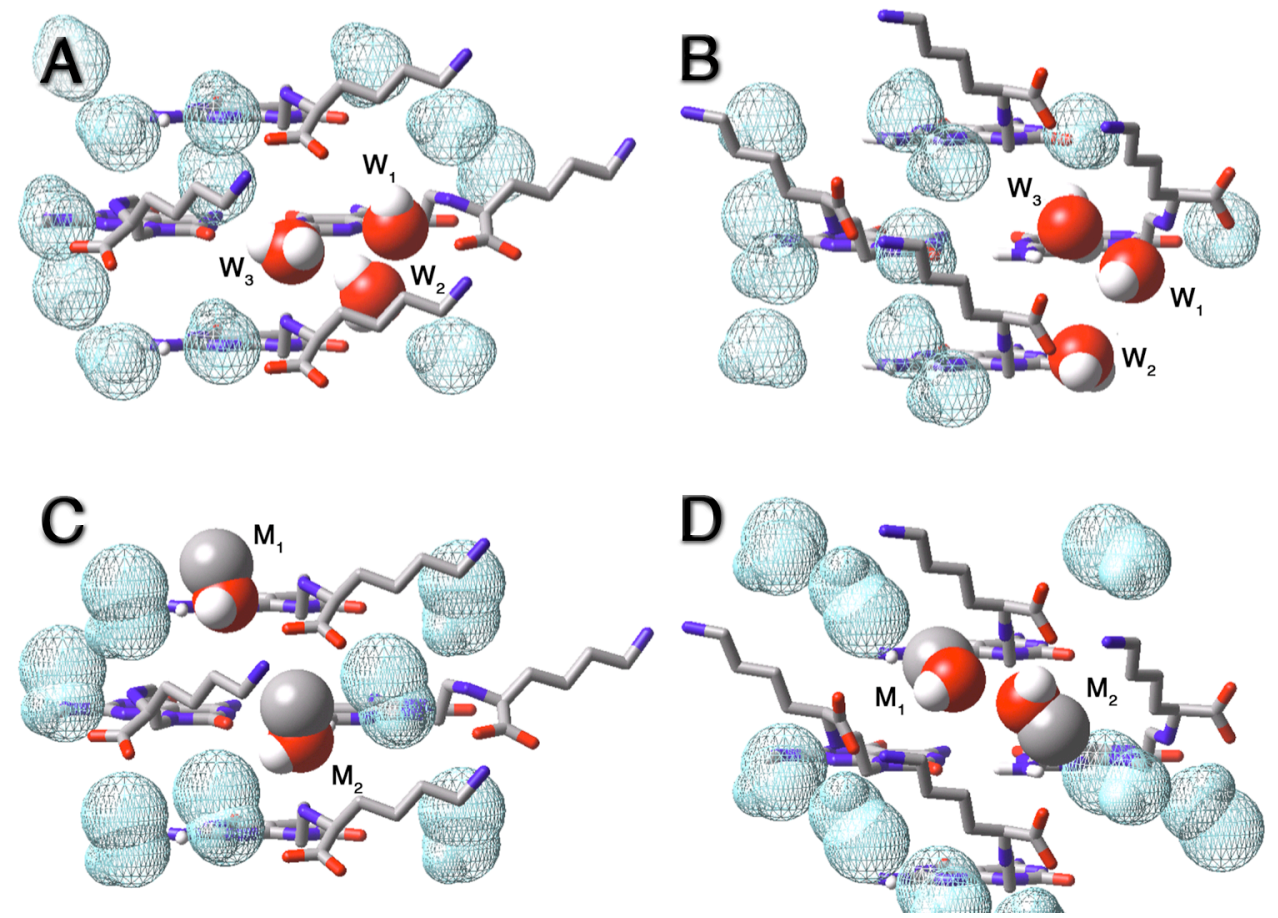

Figure S40. Sections of the solvation models for W-chiromer (A, C) and M-chiromer (B, D) in water (A, B) and methanol (C, D). For clarity, solvent molecules that are symmetrically equivalent are shown in wire frames. 


\section{REFERENCES}

(1) (a) Fenniri, H.; Mathivanan, P.; Vidale, K. L.; Sherman, D. M.; Hallenga, K.; Wood, K. V.; Stowell, J. G. J. Am. Chem. Soc. 2001, 123, 3854-3855. (b) Fenniri, H.; Deng, B.-L.; Ribbe, A. E.; Hallenga, K.; Jacob, J.; Thiyagarajan, P. Proc. Natl. Acad. Sci. USA 2002, 99, 6487-6492. (c) Fenniri, H.; Deng, B. L.; Ribbe, A. E. J. Am. Chem. Soc. 2002, 124, 11064-11072. (d) Haas, A.; Lieb, M. J. Heterocyclic Chem. 1986, 23, 1079-1084.

(2) (a) Piotto, M.; Saudek, V.; Sklenár, V. J. Biomol. NMR 1992, 2, 661-665. (b) Hwang, T.; Shaka, A. J. Magn. Reson. 1995, 112A, 275-279. (c) Price, W. S.; Hayamizu, K.; Arata, Y. J. Magn. Reson. 1997, 126, 256-265. (d) Liu, M.; Mao, X.; Ye, C.; Huang, H.; Nicholson, J.; Lindon, J. C. J. Magn. Reson. 1998, 132, 125-129.

(3) Wüthrich, K. NMR of Proteins and Nucleic Acids. John Wiley \& Sons: New York, 1986.

(4) Chin, D. N.; Simanek, E. E.; Li, X.; Wazeer, M. I. M.; Whitesides, G. M. J. Org. Chem. 1997, 62, 1891-1895.

(5) Jorgensen, W. L.; Maxwell, D. S.; Tirado-Rives, J. J. J. Am. Chem. Soc. 1996, 118, $11225-11235$.

(6) (a) Kovalenko, A. Three-dimensional RISM theory for molecular liquids and solidliquid interfaces, in: Molecular Theory of Solvation, Hirata, F. (ed.) Series: Understanding Chemical Reactivity, Vol.24, Mezey, P.G. (ed.) Kluwer Academic Publishers, Dordrecht, (2003), pp.169-275. (b) Kovalenko, A.; Hirata, F. J. Chem. Phys. 1999, 110, 10095-10112. (c) Kovalenko, A.; Hirata, F. J. Chem. Phys. 2000, 112, $10391-10417$.

(7) Moralez, J. G.; Raez, J.; Yamazaki, T.; Motkuri, R. K.; Kovalenko, A.; Fenniri, H. J. Am. Chem. Soc. 2005, 127, 8307-8309. 
(8) Perkyns, J.S.; Pettitt, B.M. J. Chem. Phys. 1992, 97, 7656-7666.

(9) Gaussian 03, Revision C.02, Frisch, M. J.; Trucks, G. W.; Schlegel, H. B.; Scuseria, G. E.; Robb, M. A.; Cheeseman, J. R.; Montgomery, Jr., J. A.; Vreven, T.; Kudin, K. N.; Burant, J. C.; Millam, J. M.; Iyengar, S. S.; Tomasi, J.; Barone, V.; Mennucci, B.; Cossi, M.; Scalmani, G.; Rega, N.; Petersson, G. A.; Nakatsuji, H.; Hada, M.; Ehara, M.; Toyota, K.; Fukuda, R.; Hasegawa, J.; Ishida, M.; Nakajima, T.; Honda, Y.; Kitao, O.; Nakai, H.; Klene, M.; Li, X.; Knox, J. E.; Hratchian, H. P.; Cross, J. B.; Bakken, V.; Adamo, C.; Jaramillo, J.; Gomperts, R.; Stratmann, R. E.; Yazyev, O.; Austin, A. J.; Cammi, R.; Pomelli, C.; Ochterski, J. W.; Ayala, P. Y.; Morokuma, K.; Voth, G. A.; Salvador, P.; Dannenberg, J. J.; Zakrzewski, V. G.; Dapprich, S.; Daniels, A. D.; Strain, M. C.; Farkas, O.; Malick, D. K.; Rabuck, A. D.; Raghavachari, K.; Foresman, J. B.; Ortiz, J. V.; Cui, Q.; Baboul, A. G.; Clifford, S.; Cioslowski, J.; Stefanov, B. B.; Liu, G.; Liashenko, A.; Piskorz, P.; Komaromi, I.; Martin, R. L.; Fox, D. J.; Keith, T.; Al-Laham, M. A.; Peng, C. Y.; Nanayakkara, A.; Challacombe, M.; Gill, P. M. W.; Johnson, B.; Chen, W.; Wong, M. W.; Gonzalez, C.; and Pople, J. A.; Gaussian, Inc., Wallingford CT, 2004.

(10) Autschbach, J.; Ziegler, T.; van Gisbergen, S. J. A. J. Chem. Phys. 2002, 116, 69306940. 